\title{
Parameterization of homogeneous ice nucleation for cloud and climate models based on classical nucleation theory
}

\author{
V. I. Khvorostyanov ${ }^{1}$ and J. A. Curry ${ }^{2}$ \\ ${ }^{1}$ Central Aerological Observatory, Dolgoprudny, Moscow Region, Russia \\ ${ }^{2}$ School of Earth and Atmospheric Sciences, Georgia Institute of Technology, Atlanta, Georgia, USA \\ Correspondence to: J. A. Curry (curryja@eas.gatech.edu) \\ Received: 6 February 2012 - Published in Atmos. Chem. Phys. Discuss.: 5 March 2012 \\ Revised: 3 September 2012 - Accepted: 19 September 2012 - Published: 11 October 2012
}

\begin{abstract}
A new analytical parameterization of homogeneous ice nucleation is developed based on extended classical nucleation theory including new equations for the critical radii of the ice germs, free energies and nucleation rates as simultaneous functions of temperature and water saturation ratio. By representing these quantities as separable products of the analytical functions of temperature and supersaturation, analytical solutions are found for the integral-differential supersaturation equation and concentration of nucleated crystals. Parcel model simulations are used to illustrate the general behavior of various nucleation properties under various conditions, for justifications of the further key analytical simplifications, and for verification of the resulting parameterization.

The final parameterization is based upon the values of the supersaturation that determines the current or maximum concentrations of the nucleated ice crystals. The crystal concentration is analytically expressed as a function of time and can be used for parameterization of homogeneous ice nucleation both in the models with small time steps and for substep parameterization in the models with large time steps. The crystal concentration is expressed analytically via the error functions or elementary functions and depends only on the fundamental atmospheric parameters and parameters of classical nucleation theory. The diffusion and kinetic limits of the new parameterization agree with previous semi-empirical parameterizations.
\end{abstract}

\section{Introduction}

Homogeneous freezing of haze particles and cloud droplets plays an important role in crystal formation in cirrus, orographic, deep convective clouds and other clouds under low temperatures. Development of parameterizations of homogeneous ice nucleation suitable for cloud and climate models has been underway for the past several decades. These parameterizations have been mostly semi-empirical, based on heuristic relations for various properties of ice nucleation: nucleation rates, critical humidities, nucleated crystal concentrations, etc. These parameterizations have been developed using parcel model simulations and either experimental data or some relations of classical nucleation theory or alternative nucleation theories.

These parameterizations can be separated into two general types. The first type provides equations for the instantaneous characteristics of the nucleation process at any given intermediate time of nucleation. The second type considers the entire nucleation process as a sub-step process (taking less than one time step in a model) and derives equations for the final characteristics of the nucleation process after the nucleation has ceased: crystal concentrations, radii, masses.

Parameterizations of the first type. One of the most important characteristics of freezing is the nucleation rate, $J_{\text {hom }}$, the number of ice embryos formed per unit volume per unit time. Heymsfield and Miloshevich (1993) used results from the statistical molecular model of Eadie (1971) and fitted $J_{\text {hom, } 0}$ for pure water with a power law expression.

$$
J_{\text {hom }, 0}(T)=10^{-X\left(T_{\mathrm{c}}\right)}, X(T)=\sum_{i=0}^{4} A_{\mathrm{i}, \mathrm{HM}} T_{\mathrm{c}}^{\mathrm{i}},
$$


with $J_{\mathrm{hom}, 0}$ in $\mathrm{cm}^{-3} \mathrm{~s}^{-1}, T_{\mathrm{c}}$ is temperature in degrees Celsius, and $A_{0, \mathrm{HM}}=606.3952, A_{1, \mathrm{HM}}=52.6611, A_{2, \mathrm{HM}}=$ $1.7439, A_{3, \mathrm{HM}}=0.0265, A_{4, \mathrm{HM}}=1.536 \times 10^{-4}$. Experimental data show that the freezing rates of haze particles are smaller than given by this equation, since they are depressed by the presence of solute. Sassen and Dodd (1988, 1989) suggested describing this depression of the nucleation rate by introducing an effective freezing temperature

$T^{*}=T+\lambda_{\mathrm{SD}} \Delta T_{\mathrm{m}}$, or $\Delta T_{\mathrm{f}}=T_{\mathrm{f}}^{*}-T=\lambda_{\mathrm{SD}} \Delta T_{\mathrm{m}}$,

where $T$ is temperature in degrees Kelvin, $\Delta T_{\mathrm{m}}$ and $\Delta T_{\mathrm{f}}$ are the depressions of the melting and freezing temperatures respectively. Then the nucleation freezing rate $J_{\mathrm{f}, \text { hom }}$ of the haze particles could be calculated with Eq. (1) but with $T^{*}$ instead of $T$. The value $\lambda_{\mathrm{SD}}=1.7$ was chosen in Sassen and Dodd (1988) as an average over the experimental data by Rasmussen (1982) on the relationship between depressions of the nucleation and melting temperatures for a number of salts. It was clarified later that the coefficient 1.7 is not universal, and can vary over the range 1.4-2.4 and may reach 3-5 for some organic substances, depending on the chemical composition and concentration of a solute (Martin, 2000; Chen et al., 2000; Lin et al., 2002; DeMott, 2002; Koop and Zobrist, 2009).

DeMott et al. (1994) suggested a parameterization of $\Delta T_{\mathrm{m}}$ for ammonium sulfate as a function of molality $\hat{M}$. Molality was evaluated in terms of the equilibrium particle diameter, which was calculated using Köhler's (1936) equation and the freezing point depression was calculated with Eq. (2a). DeMott et al. (1994) used Eqs. (1), (2a) and their parameterization of $\hat{M}$ to calculate the frozen fraction $F_{\mathrm{hf}}$ of the haze particles at various $T$ and water saturation ratios $S_{\mathrm{w}}$. Having calculated $F_{\mathrm{hf}}$ at various $T$ and $S_{\mathrm{w}}$ and assuming an exponential size spectrum of haze particles, DeMott et al. (1994) suggested a fit for the concentration of nucleated crystals as an integral of $F_{\text {hf }}$ over the haze size spectrum. This scheme reproduced the experimental data on ice nucleation of haze particles and was suitable for use in cloud models.

An important characteristic of homogeneous ice nucleation is the critical humidity or the critical water saturation ratio $S_{\mathrm{w}, \mathrm{cr}}^{\text {hom }}$. Sassen and Dodd $(1988,1989)$ and Heymsfield and Miloshevich (1995) parameterized $S_{\mathrm{w}, \mathrm{cr}}^{\text {hom }}$ as polynomial fits by the temperature. Sassen and Benson (2000) generalized these equations to account for wind shear. Koop et al. (1998) and Bertram et al. (2000), based on their measurements of the freezing temperatures $T_{\mathrm{f}}$ of aqueous solutions droplets of sulfuric acid and ammonium sulfate, parameterized $T_{\mathrm{f}}$ as polynomial functions of the solution concentration. Using these data and thermodynamic model of Clegg et al. (1998), these authors developed parameterizations of the critical humidities, water activity and freezing point depression as the polynomial functions of the water vapor pressure.

Koop et al. (2000) suggested a parameterization of $J_{\text {hom,f }}$ similar to Heymsfield and Miloshevich (1993) for pure water, but accounted for solute effects parameterized with polynomial fits of $\Delta a_{\mathrm{w}}=a_{\mathrm{w}}-a_{\mathrm{w}}^{\mathrm{i}}$, where $a_{\mathrm{w}}$ is the water activity in the liquid solution and $a_{\mathrm{w}}^{\mathrm{i}}$ is the activity of water in solution in equilibrium with ice. Koop et al. (2000) assumed that in equilibrium $a_{\mathrm{w}}$ is equal to the environmental water saturation ratio $S_{\mathrm{w}}$, and $a_{\mathrm{w}}^{\mathrm{i}}$ was parameterized as an exponential function of the chemical potentials of water in pure ice and pure liquid water, respectively.

Many of these empirically based dependencies can be described with classical nucleation theory (CNT) for homogeneous and heterogeneous ice nucleation (Frenkel, 1946; Dufour and Defay, 1963; Defay et al., 1966; Pruppacher and Klett, 1997, hereafter PK97; Seinfeld, and Pandis, 1998; Kashchiev, 2000). CNT was extended further in a number of works as reviewed in Laaksonen et al. (1995), Mishima and Stanley (1998), Ice Physics (1999), Slezov and Schmelzer (1999). Subsequent extensions of CNT were performed by Khvorostyanov and Sassen (1998a, 2002, hereafter KS98a, KS02), by Khvorostyanov and Curry (2000, 2004a, b, 2005, 2009a, hereafter KC00, KC04a,b, KC05, KC09a) and Curry and Khvorostyanov (2012, hereafter CK12). Analytical expressions for the critical radii $r_{\mathrm{cr}}$ of ice germs, critical energies $\Delta F_{\mathrm{cr}}$, and nucleation rates $J_{\text {nuc }}$ derived in these works describe the dependence of these quantities not only on the temperature $T$ as in CNT, but also the dependencies on water saturation ratio $S_{\mathrm{w}}$, finite radius of freezing particles, external pressure and some other factors. In particular, KS98a showed that the concentrations of nucleated crystals calculated with this extended CNT were very close to those in the semi-empirical scheme by DeMott et al. (1994). The expressions for $r_{\mathrm{cr}}, \Delta F_{\mathrm{cr}}, J_{\text {nuc }}$ for solution particles in KS98a and $\mathrm{KCOO}$ depended on water saturation ratio $S_{\mathrm{w}}$, but dependence on chemical composition vanished in the derivation. Thus, these expressions predicted that nucleation characteristics are a colligative property that do not depend on chemical nature of solute substance. This was confirmed by Koop et al. (2000) from an analysis of experimental data on freezing temperatures of various substances. It was shown in $\mathrm{KCO} 4 \mathrm{a}, \mathrm{b}$ that the relation between the freezing and melting point depressions analyzed in Sassen and Dodd $(1988,1989)$ can be derived from the extended CNT.

Furthermore, the equivalence of the solution and pressure effects discussed in Kanno and Angell (1977) and in Koop et al. (2000) based on the experimental data was derived in Khvorostyanov and Curry (2004a) from the extended CNT in a simple quantitative form

$\Delta p=-Q_{\mathrm{p}} \ln S_{\mathrm{w}} \approx-Q_{\mathrm{p}} \ln a_{\mathrm{w}}, Q_{\mathrm{p}}(T, p)=\frac{R T \rho_{\mathrm{i}} \rho_{\mathrm{w}}}{M_{\mathrm{w}}\left(\rho_{\mathrm{w}}-\rho_{\mathrm{i}}\right)}$,

where $\Delta p$ is the external pressure, $R$ is the universal gas constant, $\rho_{\mathrm{i}}$ and $\rho_{\mathrm{W}}$ are the densities of ice and water, $M_{\mathrm{W}}$ is the molecular weight of water. This equation relates $S_{\mathrm{W}}$ (or equivalent molality) and $\Delta p$, and shows that a decrease in $S_{\mathrm{W}}$ (increase in solution molality) is equivalent to an increase in $\Delta p$, with proportionality determined by the function $Q_{\mathrm{p}}$ 
that depends on the densities and temperature. The proportionality is $\Delta p \sim-T \ln S_{\mathrm{w}}$ with constant densities, although they in turn depend on $p, T$. The value of $Q_{\mathrm{p}}$ in Eq. (2b) calculated in KC04a is very large, $Q_{\mathrm{p}} \sim 10^{4} \mathrm{~atm}$ at $T \sim 273 \mathrm{~K}$ and increases with decreasing $T$, so that a saturation ratio $S_{\mathrm{w}}=0.9\left(\ln S_{\mathrm{w}} \approx-0.1\right)$ at $T \sim 273 \mathrm{~K}$ is equivalent to a high external pressure of $\sim 10^{3} \mathrm{~atm}$. It was shown in $\mathrm{KC} 04$ that Eq. (2b) allows a simple quantitative description of the solution-pressure equivalence in the depression of the melting and freezing points experimentally derived in Kanno and Angell (1977) and is in a good agreement with the laboratory measurements at high pressures. These comparisons show that many empirical functional dependencies of nucleation and parameterizations can be derived from CNT.

The densities of ice and water, $\rho_{\mathrm{i}}$ and $\rho_{\mathrm{w}}$, and other thermodynamic parameters of water and ice at low temperatures and high pressures can be calculated from the equations of state for_water and ice or can be obtained from standard tables recommendable from the new International Thermodynamic Equation Of Seawater 2010 (TEOS-10) (e.g., Jeffery and Austin, 1997; Feistel and Wagner, 2006; IOC, SCOR, and IAPSO, 2010; McDougall et al., 2010; Holten et al., 2011, 2012; Feistel, 2012; IAPWS, 2012). Reviews of the recently refined equations of state for water and ice, the recent developments of the nucleation theory and their applications for ice nucleation and deliquescence-efflorescence phenomena are given in Hellmuth et al., 2012a, b).

Parameterizations of homogeneous freezing of the second type as a sub-step process in the models include more intermediate steps and assumptions. Such parameterizations are also semi-empirical, and as examples we describe the parameterizations developed by Kärcher and Lohmann (2002a, b) and Ren and MacKenzie (2005). The methods used in these parameterizations are similar to the method developed by Twomey (1959) for drop activation. The basis of these parameterizations is the equation for ice saturation ratio $S_{\mathrm{i}}$. The sink term in this equation, the deposition rate in an ensemble of the crystals, is defined as the time integral of the number density of aerosol particles $\mathrm{d} n_{\mathrm{c}}\left(t_{0}\right) / \mathrm{d} t_{0}$ that freeze within the time interval between $t_{0}$ and $t_{0}+\mathrm{d} t_{0}$, with monodisperse or polydisperse model of the haze particles. To solve this nonlinear system of equations, the authors introduce several additional hypotheses. Following Ford (1998a, b), a hypothesis on the exponential time behavior of the nucleation rate $R_{\mathrm{f}, \text { hom }}=\mathrm{d} n_{\mathrm{c}} / \mathrm{d} t_{0}$ was introduced

$\frac{\mathrm{d} n_{\mathrm{c}}}{\mathrm{d} t_{0}}=R_{\mathrm{f}, \text { hom }}\left(t_{0}\right)=R_{\mathrm{f}, \text { hom }}(t) \exp \left(-\frac{t-t_{0}}{\tau_{\mathrm{nuc}}}\right)$,

where $\tau_{\text {nuc }}$ is a characteristic time scale of the nucleation event, unknown for now, which has to be determined. Integration of Eq. (3) by $t$ yields

$$
N_{\mathrm{c}}=\int_{-\infty}^{t} \mathrm{~d} t_{0} R_{\mathrm{f}, \text { hom }}\left(t_{0}\right)=R_{\mathrm{f}, \text { hom }}(t) \tau_{\text {nuc }} .
$$

An additional heuristic hypothesis was introduced for the timescale of the nucleation event $\tau_{\text {nuc }}$ by Kärcher and Lohmann $(2002 a, b)$ relating it to the temperature change rate $\mathrm{d} T / \mathrm{d} t$,

$\tau_{\text {nuc }}^{-1}=c_{\tau}\left(\left|\frac{\partial \ln J_{\text {hom }}}{\partial T}\right|\right)_{S_{\mathrm{i}}=S_{\mathrm{i}, \text { cr }}} \frac{\mathrm{d} T}{\mathrm{~d} t}$.

The unknown parameter $c_{\tau}$ was parameterized in Kärcher and Lohmann (2002a) as a function of temperature, and was replaced with a constant value $c_{\tau}=50$ in Kärcher and Lohmann (2002b). Ren and MacKenzie (2005) arrived at a simpler expression, $\tau_{\text {nuc }}^{-1} \approx c_{\tau}(T)(\mathrm{d} T / \mathrm{d} t)$, where $c_{\tau}$ was approximated by the temperature polynomial. A further hypothesis was that the ice saturation ratio $S_{\mathrm{i}}$ changes only slightly around its critical value $S_{\mathrm{i}, \text { cr }}$ during the nucleation event, and it can be assumed that $S_{\mathrm{i}}(t) \approx S_{\mathrm{i}, \mathrm{cr}}(T)$. An additional assumption is that diffusional growth of the nucleated crystals is described by the equations for the diffusion growth regime with kinetic corrections. And finally, they assume that homogeneous ice nucleation stops when $S_{\mathrm{i}}$ reaches a maximum, $\mathrm{d} S_{\mathrm{i}} / \mathrm{d} t=0$ at $S_{\mathrm{i}, \mathrm{cr}}$.

With these assumptions, Kärcher and Lohmann (2002b) and Ren and MacKenzie (2005) found analytical solutions for $R_{\mathrm{f}, \mathrm{hom}}\left(t_{0}\right)$ and the concentrations of the nucleated crystals $N_{\mathrm{c}}$, and studied several limiting cases. In particular, they found for the diffusion growth regime, $N_{\mathrm{c}} \sim w^{3 / 2}$, and

$N_{\mathrm{c}} \sim \rho_{\text {is }}^{-1 / 2}$, where $w$ is the vertical velocity and $\rho_{\text {is }}$ is the saturated vapor density over ice. For the kinetic crystal growth, Ren and MacKenzie (2005) found that $N_{\mathrm{c}} \sim w$ for the large particles, and $N_{\mathrm{c}} \sim w^{2}, N_{\mathrm{c}} \sim \rho_{\text {is }}^{-2}$ for small particles.

Barahona and Nenes (2008) developed a similar substep parameterization of homogeneous ice nucleation, using Twomey's (1959) upper limit approximation for ice supersaturation, and a representation for the nucleation rate similar to that from Khvorostyanov and Curry (2004b)

$\ln \frac{J_{\mathrm{hom}}\left(S_{\mathrm{i}}\right)}{J_{\mathrm{hom}}\left(S_{\mathrm{i}, \mathrm{cr}}\right)}=b_{\tau}(T)\left(S_{\mathrm{i}}-S_{\mathrm{i}, \mathrm{cr}}\right)$.

They used the temperature dependence for $b_{\tau}(T)$ from Koop et al. (2000), made several auxiliary simplifications and arrived at a parameterization that required an iterative numerical solution. All the parameterizations described above used parcel models for tuning the parameters of the final paramaterization equations.

In the studies reviewed above, it was assumed that stable hexagonal ice Ih nucleates in supercooled water or solution droplets. The thermodynamic parameters associated with ice Ih were therefore used when interpreting the data. Evidence 
was provided recently that metastable cubic ice Ic may form first in some cases at low temperatures, especially at $T<200$ $\mathrm{K}$, with subsequent relaxation to the stable ice Ih (e.g., Murray et al., 2005, 2010; Murray and Bertram, 2006; Malkin et al., 2012). However, uncertainty remains in the general conceptual picture of this sequence of the processes, and a wide spread in the current data on the thermodynamic parameters for Ic, so that the nucleation rates for Ic estimated with CNT may vary by many orders of magnitude (e.g., Murray et al., 2010). We therefore assume in this work, as in most of the others, that hexagonal ice Ih nucleates in droplets and use the corresponding parameters for Ih. Calculations for Ic or any other type of ice can be done using the same equations derived in this work with corresponding changes of the thermodynamic parameters: the surface tension, melting heat, saturated vapor pressure, etc.

We have shown above that many (or most) parameterizations of ice nucleation of the first type can be derived from CNT. A question arises as to whether the more complicated parameterizations of the second type (integral) can be also derived from the CNT. This paper addresses homogeneous freezing of deliquescent haze particles and water drops. The new analytical parameterization developed here is based directly on extended classical nucleation theory with minimum auxiliary hypotheses and simplifications. Parcel model simulations are used in Sect. 2 to illustrate the general behavior of various nucleation properties under various conditions, for justification of key analytical simplifications, and for their verification. The new analytical solutions are derived in Sect. 3, and the diffusion and kinetic limits are determined. It is shown that the new analytical dependencies agree with the previous parameterizations and can be expressed in terms of the primary parameters of modified classical theory.

\section{Kinetics of homogeneous ice nucleation simulated with a parcel model}

\subsection{Parcel model}

The parcel model used here was described in Khvorostyanov and Curry (2005, hereafter KC05). The parcel model is a zero-dimensional or Lagrangian model of an adiabatic rising air parcel that cools, causing nucleation and growth of the drops and crystals. All variables depend only on time $t$. The dynamics in this parcel model is parameterized by prescription of a vertical velocity $w$ constant in time. The primary thermodynamic equations are the prognostic equations for supersaturation and temperature. This system of equations includes terms that describe the phase transitions and is closed using the two kinetic equations for the drop and ice crystal size distribution functions that account for nucleation, condensation and deposition, and two equations for the droplets and crystals growth rates. Similar to the methodology adopted for the Cirrus Parcel Model Comparison Project
(CPMCP, Lin et al., 2002), we exclude from consideration coagulation among the droplets and aggregation between the droplets and crystals, sedimentation, entrainment, turbulent exchange, etc. to isolate the effects directly related to nucleation processes. The system of equations comprising the parcel model is described below.

The heat balance is calculated using the equation for the temperature $T$ in a wet adiabatic process:

$$
\frac{\mathrm{d} T}{\mathrm{~d} t}=-\gamma_{\mathrm{a}} w+\frac{L_{\mathrm{e}}}{c_{\mathrm{p}} \rho_{\mathrm{a}}} I_{\text {con }}+\frac{L_{\mathrm{s}}}{c_{\mathrm{p}} \rho_{\mathrm{a}}} I_{\mathrm{dep}}+\frac{L_{\mathrm{m}}}{c_{\mathrm{p}} \rho_{\mathrm{a}}} I_{\mathrm{fr}},
$$

where $\gamma_{\mathrm{a}}$ is the dry adiabatic lapse rate, $L_{\mathrm{e}}, L_{\mathrm{s}}$ and $L_{\mathrm{m}}$ are the latent heats of condensation, deposition and melting (cal $\left.\mathrm{g}^{-1}\right), c_{\mathrm{p}}$ is the specific heat capacity, $\rho_{\mathrm{a}}$ is the air density, $I_{\text {con }}, I_{\mathrm{dep}}$ and $I_{\mathrm{fr}}$ are the rates of condensation, deposition, and freezing $\left(\mathrm{g} \mathrm{cm}^{-3} \mathrm{~s}^{-1}\right)$.

Both water and ice supersaturation govern ice nucleation kinetics: water supersaturation determines the nucleation process, and growth of ice particles is determined by ice supersaturation. We consider the equations for fractional water and ice supersaturations, $s_{\mathrm{w}}=\left(\rho_{\mathrm{v}}-\rho_{\mathrm{ws}}\right) / \rho_{\mathrm{ws}}$, and $s_{\mathrm{i}}=$ $\left(\rho_{\mathrm{v}}-\rho_{\mathrm{is}}\right) / \rho_{\mathrm{is}}$, where $\rho_{\mathrm{v}}$ is the environmental water vapor density, $\rho_{\mathrm{ws}}$ and $\rho_{\mathrm{is}}$ are the densities of vapor saturated over water and ice, respectively. In a rising air parcel, supersaturation is governed by two competing processes: supersaturation generation by cooling in an updraft and supersaturation absorption by the crystals in the vapor deposition process.

This process can be described by the supersaturation equations that account for homogeneous ice nucleation (KC05, Sect. 2a therein):

$\frac{1}{\left(1+s_{\mathrm{w}}\right)} \frac{\mathrm{d} s_{\mathrm{w}}}{\mathrm{d} t}=c_{1 \mathrm{w}} w-\frac{\Gamma_{12}}{\rho_{\mathrm{v}}} I_{\mathrm{dep}}$,

$\frac{1}{\left(1+s_{\mathrm{i}}\right)} \frac{\mathrm{d} s_{\mathrm{i}}}{\mathrm{d} t}=c_{1 \mathrm{i}} w-\frac{\Gamma_{2}}{\rho_{\mathrm{v}}} I_{\mathrm{dep}}$.

Here $\Gamma_{12}$ and $\Gamma_{2}$ are the psychrometric corrections associated with the latent heat release at condensation derived in $\mathrm{KC} 05$,

$\Gamma_{2}=1+\frac{L_{\mathrm{s}}^{2}}{c_{\mathrm{p}} R_{\mathrm{v}} T^{2}} \frac{\rho_{\mathrm{is}}}{\rho_{\mathrm{a}}}, \Gamma_{12}=1+\frac{L_{\mathrm{e}} L_{\mathrm{s}}}{c_{\mathrm{p}} R_{\mathrm{v}} T^{2}} \frac{\rho_{\mathrm{ws}}}{\rho_{\mathrm{a}}}$,

$I_{\mathrm{dep}}$ is the deposition integral that describes the vapor flux onto the crystals, and

$$
\begin{aligned}
& c_{1 \mathrm{w}}(T)=\left(\frac{L_{\mathrm{e}}}{c_{\mathrm{p}} T} \frac{M_{\mathrm{w}}}{M_{\mathrm{a}}}-1\right) \frac{g}{R_{\mathrm{a}} T}, \\
& c_{1 \mathrm{i}}(T)=\left(\frac{L_{\mathrm{s}}}{c_{\mathrm{p}} T} \frac{M_{\mathrm{w}}}{M_{\mathrm{a}}}-1\right) \frac{g}{R_{\mathrm{a}} T},
\end{aligned}
$$

where $M_{\mathrm{w}}$ and $M_{\mathrm{a}}$ are the molecular weights of water and air, $R_{\mathrm{a}}$ is the gas constant of air. The vapor flux $I_{\text {dep }}$ to the crystals is the integral of the mass growth rate over the crystal 
size spectrum. We consider ice nucleation in haze particles at water subsaturation, formation of water drops is not considered in this work and the term $I_{\text {con }}$ is absent in Eqs. (8a, b). However, both $s_{\mathrm{w}}$ and $s_{\mathrm{i}}$ are required for further consideration since ice nucleation is governed by $s_{\mathrm{w}}$, and crystal growth is governed by $s_{\mathrm{i}}$. We assume that crystal size can be characterized by an effective radius $r_{\mathrm{c}}$, then $I_{\mathrm{dep}}$ is expressed via crystal growth rate $\left(\mathrm{d} r_{\mathrm{c}} / \mathrm{d} t\right)$

$I_{\mathrm{dep}}(t)=4 \pi \rho_{\mathrm{i}} \int_{0}^{\infty} \frac{\mathrm{d} r_{\mathrm{c}}\left(t, t_{0}\right)}{\mathrm{d} t} r_{\mathrm{c}}^{2}\left(t, t_{0}\right) f\left(r_{\mathrm{c}}, t_{0}\right) \mathrm{d} r_{\mathrm{c}}$,

where $f_{\mathrm{c}}\left(r_{\mathrm{c}}, t_{0}\right)$ is the size distribution function of the crystals nucleated at a time $t_{0}$, and $r_{\mathrm{c}}\left(t, t_{0}\right)$ denotes the radius at time $t$ of a crystal nucleated at time $t_{0}$. We use $\left(\mathrm{d} r_{\mathrm{c}} / \mathrm{d} t\right)$ in the form similar to Fuchs (1959) and Sedunov (1974)

$\frac{\mathrm{d} r_{\mathrm{c}}}{\mathrm{d} t}=\frac{c_{3 \mathrm{i}} s_{\mathrm{i}}}{r_{\mathrm{c}}+\xi_{\mathrm{dep}}}, \quad c_{3 \mathrm{i}}=\frac{D_{\mathrm{v}} \rho_{\mathrm{is}}}{\rho_{\mathrm{i}} \Gamma_{2}}$,

$\xi_{\text {dep }}=\frac{4 D_{\mathrm{v}}}{\alpha_{\mathrm{d}} V_{\mathrm{w}}}, \quad V_{\mathrm{w}}=\left(\frac{8 R T}{\pi M_{\mathrm{w}}}\right)^{1 / 2}$,

where $D_{\mathrm{v}}$ is the water vapor diffusion coefficient, $\xi_{\text {dep }}$ is the kinetic correction to the radius growth rate, $V_{\mathrm{w}}$ is the thermal speed of water vapor molecules, $R$ is the universal gas constant, and $\alpha_{\mathrm{d}}$ is the deposition coefficient. This equation for $\mathrm{d} r_{\mathrm{c}} / \mathrm{d} t$ accounts for the kinetic correction $\xi_{\text {dep }}$.

Substitution of Eq. (12) into Eq. (11) yields

$$
I_{\text {dep }}(t)=s_{\mathrm{i}}(t) \frac{4 \pi D_{\mathrm{v}} \rho_{\mathrm{is}}}{\Gamma_{2}} \int_{0}^{\infty} \frac{r_{\mathrm{c}}^{2}\left(t, t_{0}\right)}{r_{\mathrm{c}}\left(t, t_{0}\right)+\xi_{\text {dep }}} f_{\mathrm{c}}\left(r_{\mathrm{c}}, t\right) \mathrm{d} r_{\mathrm{c}} .
$$

The radius $r_{\mathrm{c}}\left(t, t_{0}\right)$ at time $t$ of a crystal nucleated at time $t_{0}$ is evaluated by integrating Eq. (12) with constant $\rho_{\mathrm{i}}, \rho_{\text {is }}$ during the relatively short time of integration,

$r_{\mathrm{c}}\left(t, t_{0}\right)=\left\{\left(r_{\mathrm{c} 0}+\xi_{\text {dep }}\right)^{2}+2 c_{3 \mathrm{i}}\left[y_{\mathrm{i}}(t)-y_{\mathrm{i}}\left(t_{0}\right)\right]\right\}^{1 / 2}-\xi_{\text {dep }}$,

where $r_{\mathrm{c} 0}=r_{\mathrm{i}}\left(t_{0}\right)$ is the initial crystal radius at the activation time $t_{0}$, and $y_{\mathrm{i}}(t)$ is the integral ice supersaturation defined as

$$
y_{\mathrm{i}}(t)=\int_{0}^{t} s_{\mathrm{i}}\left(t^{\prime}\right) \mathrm{d} t^{\prime}
$$

Ice nucleation via haze freezing depends simultaneously on $T$ and $s_{\mathrm{W}}$, and we can consider the integrand in Eq. (14) for $I_{\text {dep }}$ using a kinetic equation for the crystal size spectrum and introducing two activity spectra, by supersaturation $\phi_{\mathrm{s}}\left(T, s_{\mathrm{w}}\right)$ and by temperature $\phi_{T}\left(T, s_{\mathrm{W}}\right)$

$$
\begin{aligned}
\frac{\partial f_{\mathrm{c}}\left(r_{\mathrm{c}}\right)}{\partial t} & +\frac{\partial}{\partial r}\left(\frac{\mathrm{d} r_{\mathrm{c}}}{\mathrm{d} t} f_{\mathrm{c}}\right)=\left[\phi_{\mathrm{s}}\left(T, s_{\mathrm{W}}\right) \frac{\mathrm{d} s_{\mathrm{W}}}{\mathrm{d} t}\right. \\
& \left.+\phi_{T}\left(T, s_{\mathrm{w}}\right) \frac{\mathrm{d} T}{\mathrm{~d} t}\right] \delta\left(r_{\mathrm{c}}-r_{\mathrm{c}}\left(t_{0}\right)\right) \equiv \psi_{\mathrm{fc}},
\end{aligned}
$$

where the Dirac delta function $\delta\left(r_{\mathrm{c}}-r_{\mathrm{c}}\left(t_{0}\right)\right)$ describes nucleation of a crystal with radius $r_{\mathrm{c}}\left(t_{0}\right)$ and $\psi_{\mathrm{fc}}$ denotes the righthand side that will be specified in the finite difference approximation as described below. Equation (17) can be viewed as a generalization of the known relation for the drop activation on the $\mathrm{CCN}$, where usually only the supersaturation activity spectrum is accounted for (e.g., Twomey, 1959; Sedunov, 1974; Khvorostyanov and Curry, 2008, 2009b; Ghan et al., 2011; Tao et al., 2012). We could consider each of these spectra in Eq. (17) separately, and this will be done in Sect. 3.3, Eqs. (52b, c), but a simpler and faster way is to use an equivalent equation for concentration conservation

$$
\begin{aligned}
\mathrm{d} N_{\mathrm{fr}}\left(t_{0}\right) & =f_{\mathrm{c}}\left(r_{\mathrm{c}}\right) \mathrm{d} r_{\mathrm{c}}=\phi_{\mathrm{s}}\left(T, s_{\mathrm{w}}\right) \mathrm{d} s_{\mathrm{w}}+\phi_{T}\left(T, s_{\mathrm{w}}\right) \mathrm{d} T \\
& =R_{\mathrm{f}, \text { hom }}\left(t_{0}\right) \mathrm{d} t_{0},
\end{aligned}
$$

where $R_{\mathrm{f}, \text { hom }}=\mathrm{d} N_{\mathrm{c}}(t) / \mathrm{d} t\left(\mathrm{~cm}^{-3} \mathrm{~s}^{-1}\right)$ is the polydisperse homogeneous freezing nucleation rate describing effects of both $T$ and $s_{\mathrm{w}}$ on freezing defined below.

The probability of freezing of a haze particle or a drop with radius $r_{\mathrm{a}}$ and volume $v\left(r_{\mathrm{a}}\right)$ during the time interval from $t_{0}$ to $t$ is

$$
P_{\mathrm{f}, \text { hom }}\left(r_{\mathrm{a}}, t\right)=1-\exp \left(-\int_{t_{0}}^{t} J_{\mathrm{f}, \text { hom }}\left(t^{\prime}\right) v\left(r_{\mathrm{a}}\right) \mathrm{d} t^{\prime}\right),
$$

where $J_{\mathrm{f}, \text { hom }}$ is the homogeneous nucleation rate $\left(\mathrm{cm}^{-3} \mathrm{~s}^{-1}\right)$ considered in Sect. 3.2, Eq. (36). The crystal concentration $N_{\mathrm{c}}$ in a polydisperse aerosol with uniform size and surface properties can be calculated by integrating the probability of freezing $P_{\mathrm{f}, \text { hom }}$ of an individual haze or cloud droplet over the size spectrum $f\left(r_{\mathrm{a}}\right)$ of aerosol or droplets normalized to the aerosol or drop concentration $N_{\mathrm{a}}$ :

$$
\begin{aligned}
& N_{\mathrm{c}, \text { hom }}(t)=\int_{r_{\min }}^{r_{\max }} P_{\mathrm{f}, \text { hom }}\left(r_{\mathrm{a}}, t\right) f_{\mathrm{a}}\left(r_{\mathrm{a}}\right) \mathrm{d} r_{\mathrm{a}} \\
& =\int_{r_{\min }}^{r_{\max }}\left[1-\exp \left(-\int_{0}^{t} J_{\mathrm{f}, \text { hom }}\left(t^{\prime}\right) v\left(r_{\mathrm{a}}\right) \mathrm{d} t^{\prime}\right)\right] f_{\mathrm{a}}\left(r_{\mathrm{a}}\right) \mathrm{d} r_{\mathrm{a}} .
\end{aligned}
$$

The polydisperse nucleation rate $R_{\mathrm{f}, \text { hom }}$ can be calculated as (PK97, KC04a,b)

$$
\begin{aligned}
& R_{\mathrm{f}, \text { hom }}\left(t_{0}\right)=\frac{\mathrm{d} N_{\mathrm{c}, \text { hom }}}{\mathrm{d} t}=\int_{r_{\text {min }}}^{r_{\text {max }}} \mathrm{d} r_{\mathrm{a}} f_{\mathrm{a}}\left(r_{\mathrm{a}}\right) v\left(r_{\mathrm{a}}\right) \\
& \quad \times J_{\mathrm{f}, \text { hom }}\left(t_{0}\right) \exp \left(-\int_{0}^{t} J_{\mathrm{f}, \text { hom }}\left(t^{\prime}\right) v\left(r_{\mathrm{a}}\right) \mathrm{d} t^{\prime}\right),
\end{aligned}
$$

where $v\left(r_{\mathrm{a}}\right)$ is the volume of a freezing particle with radius $r_{\mathrm{a}}, J_{\mathrm{f}, \text { hom }}$ is the homogeneous nucleation rate that is calculated from the extension of the classical nucleation theory (CNT) as developed by the authors and employed here (see 
Sect. 3.2). It is expressed via the activation and critical energies of an ice germ freezing that depend simultaneously on the temperature and water saturation ratio. Substituting the conservation law for the nucleated crystals $f_{\mathrm{c}}\left(r_{\mathrm{c}}\right) \mathrm{d} r_{\mathrm{c}}=$ $R_{\mathrm{f}, \text { hom }}\left(t_{0}\right) \mathrm{d} t_{0}$ from Eq. (18a) into Eq. (14) for $I_{\text {dep }}$ and using Eq. (15) we obtain

$I_{\mathrm{dep}}=s_{\mathrm{i}} \frac{4 \pi D_{\mathrm{v}} \rho_{\mathrm{is}}}{\Gamma_{2}} \int_{0}^{t} r_{\mathrm{c}, \mathrm{ef}}\left(t, t_{0}\right) R_{\mathrm{f}, \mathrm{hom}}\left(t_{0}\right) \mathrm{d} t_{0}$,

where we introduced the effective radius $r_{\mathrm{c}, \mathrm{ef}}\left(t, t_{0}\right)$, which is the first multiplier in the integrand in Eq. (14)

$$
\begin{aligned}
& r_{\mathrm{c}, \text { ef }}\left(t, t_{0}\right)=\frac{r_{\mathrm{c}}^{2}\left(t, t_{0}\right)}{r_{\mathrm{c}}\left(t, t_{0}\right)+\xi_{\mathrm{dep}}} \\
& =\frac{\left\{\left[\left(r_{\mathrm{c} 0}+\xi_{\mathrm{dep}}\right)^{2}+2 c_{3 \mathrm{i}}\left(y_{\mathrm{i}}(t)-y_{\mathrm{i}}\left(t_{0}\right)\right)\right]^{1 / 2}-\xi_{\mathrm{dep}}\right\}^{2}}{\left[\left(r_{\mathrm{c} 0}+\xi_{\mathrm{dep}}\right)^{2}+2 c_{3 \mathrm{i}}\left(y_{\mathrm{i}}(t)-y_{\mathrm{i}}\left(t_{0}\right)\right)\right]^{1 / 2}} .
\end{aligned}
$$

Substituting Eq. (19) into Eq. (8b) and using Eq. (16) for $y_{\mathrm{i}}(t)$, we obtain an equation for integral ice supersaturation

$$
\frac{1}{\left(1+y_{\mathrm{i}}^{\prime}\right)} \frac{\mathrm{d} y_{\mathrm{i}}^{\prime}}{\mathrm{d} t}=c_{1 \mathrm{i}} w-\frac{\Gamma_{2}}{\rho_{\mathrm{v}}} I_{\mathrm{dep}}
$$

where

$$
I_{\text {dep }}=y_{\mathrm{i}}^{\prime} \frac{4 \pi D_{\mathrm{v}} \rho_{\mathrm{is}}}{\Gamma_{2}} \int_{0}^{t} r_{\mathrm{c}, \mathrm{ef}}\left(t, t_{0}\right) R_{\mathrm{f}, \mathrm{hom}}\left(t_{0}\right) \mathrm{d} t_{0} .
$$

Substitution of $R_{\mathrm{f}, \text { hom }}$ from Eq. (18d) into Eq. (22) yields

$$
\begin{aligned}
I_{\text {dep }} & =y_{\mathrm{i}}^{\prime} \frac{4 \pi D_{\mathrm{v}} \rho_{\mathrm{is}}}{\Gamma_{2}}\left[\int_{0}^{t} r_{\mathrm{c}, \mathrm{ef}}\left(t, t_{0}\right) \int_{r_{\text {min }}}^{r_{\text {max }}} f_{\mathrm{a}}\left(r_{\mathrm{a}}\right) v\left(r_{\mathrm{a}}\right)\right. \\
& \left.\times J_{\mathrm{f}, \text { hom }}\left(t_{0}\right) \exp \left(-\int_{0}^{t} J_{\mathrm{f}, \text { hom }}\left(t^{\prime}\right) v\left(r_{\mathrm{a}}\right) \mathrm{d} t^{\prime}\right) \mathrm{d} r_{\mathrm{a}} \mathrm{d} t_{0}\right]
\end{aligned}
$$

Substitution of Eq. (23) into Eq. (21) and using the relation $\rho_{\mathrm{v}}=\left(1+y_{\mathrm{i}}^{\prime}\right) \rho_{\text {is }}$ yields

$$
\begin{aligned}
& \frac{1}{\left(1+y_{\mathrm{i}}^{\prime}\right)} \frac{\mathrm{d} y_{\mathrm{i}}^{\prime}}{\mathrm{d} t}=c_{\mathrm{i}} w-\frac{y_{\mathrm{i}}^{\prime}}{\left(1+y_{\mathrm{i}}^{\prime}\right)}\left(4 \pi D_{\mathrm{v}}\right)\left[\int_{0}^{t} r_{\mathrm{c}, \mathrm{ef}}\left(t, t_{0}\right)\right. \\
& \left.\times \int_{r_{\min }}^{r_{\max }} f_{\mathrm{a}}\left(r_{\mathrm{a}}\right) v\left(r_{\mathrm{a}}\right) J_{\mathrm{f}, \mathrm{hom}}\left(t_{0}\right) \exp \left(-\int_{0}^{t} J_{\mathrm{f}, \mathrm{hom}}\left(t^{\prime}\right) v\left(r_{\mathrm{a}}\right) \mathrm{d} t^{\prime}\right) \mathrm{d} r_{\mathrm{a}} \mathrm{d} t_{0}\right]
\end{aligned}
$$

This equation describes evolution of integral ice supersaturation. It is analogous to Twomey's (1959) and Sedunov's (1974) supersaturation equations for the drop activation, but includes a more complicated description of crystal nucleation. The first term on the RHS describes supersaturation generation by cooling action of updrafts, and the second term accounts for its depletion by the newly nucleated and growing crystals.

We consider in this section homogeneous ice nucleation at cold temperatures and not very vigorous updrafts when the haze solution particles freeze at water subsaturation, so that drops do not form. The crystal nucleation term in Eq. (17) can be calculated in the finite difference scheme as

$\psi_{\mathrm{fc}}=\Delta N_{\mathrm{c}, \mathrm{fr}}(\Delta t) / \Delta r_{\mathrm{c}} / \Delta t$,

where $\Delta N_{\mathrm{c}, \mathrm{fr}}$ is the number concentration of the crystals nucleated via homogeneous freezing in a time step $\Delta t$ and calculated with Eq. (18c) using equations for the nucleation rate $J_{\text {f,hom }}\left(\right.$ Eq. 36 here) and $\Delta r_{\mathrm{c}}$ denotes the first size step by the crystal radii $(0.1-0.2 \mu \mathrm{m})$. The crystal size spectrum includes 30 radius intervals: 10 steps by $0.1-1 \mu \mathrm{m}$ and the next 20 steps increasing logarithmically to $100-350 \mu \mathrm{m}$. This division allows coverage of both small and large size ranges without loosing accuracy.

\subsection{Simulation results}

The design of the simulations generally follows the protocol of the Cirrus Parcel Model Comparison Project (CPMCP; Lin et al., 2002). To simulate the ice crystal nucleation process, the parcel model was run for $1 \mathrm{~h}$ with most initial data specified following the CPMCP and varying some parameters to estimate the sensitivity of the results. We describe the results for three values of the vertical velocity, $w=4,20$, and $100 \mathrm{~cm} \mathrm{~s}^{-1}$, two values of the initial temperature, $T_{0}=$ $-40^{\circ} \mathrm{C}$ and $-60^{\circ} \mathrm{C}$, and two values of the aerosol concentration, $N_{\mathrm{a}}=200 \mathrm{~cm}^{-3}$, and with increased $N_{\mathrm{a}}=500 \mathrm{~cm}^{-3}$. The initial humidities were chosen as $\mathrm{RHW}_{0}=90 \%$ for $T_{0}=-40^{\circ} \mathrm{C}$ and $\mathrm{RHW}_{0}=78 \%$ for $T_{0}=-60^{\circ} \mathrm{C}$. The initial pressure $p_{0}$ was specified to be $340 \mathrm{hPa}$. The parcel model includes the option of isolating specific ice crystal nucleation modes. Here we consider only the homogeneous freezing of deliquescent haze particles, excluding the other modes (heterogeneous freezing, deposition, contact, immersion). Integration over the haze size spectrum was performed using a lognormal size spectrum of soluble haze particles with the mean radius of $0.02 \mu \mathrm{m}$ and dispersion $\sigma_{\mathrm{s}}=2.5$. The time steps were $0.01-0.2 \mathrm{~s}$ in the main program, but the time step can be divided further, if necessary, in the nucleation or condensation subroutines to meet stability conditions. The accuracy of the calculations was controlled by comparing the total number of crystals nucleated with those obtained by integration over the size spectrum of the grown crystals at the end of a parcel run. If the error exceeded $5 \%$ (especially at low temperatures), the time and radius steps were varied and several additional runs were performed until the error became less than $5 \%$.

Figures 1 and 2 illustrate the effect of the vertical velocity $\left(w=4\right.$ and $\left.20 \mathrm{~cm} \mathrm{~s}^{-1}\right)$ on the kinetics of homogeneous freezing at $T_{0}=-40^{\circ} \mathrm{C}$ and $N_{\mathrm{a}}=200 \mathrm{~cm}^{-3}$. It is seen that the nucleation process has two branches with increasing and 

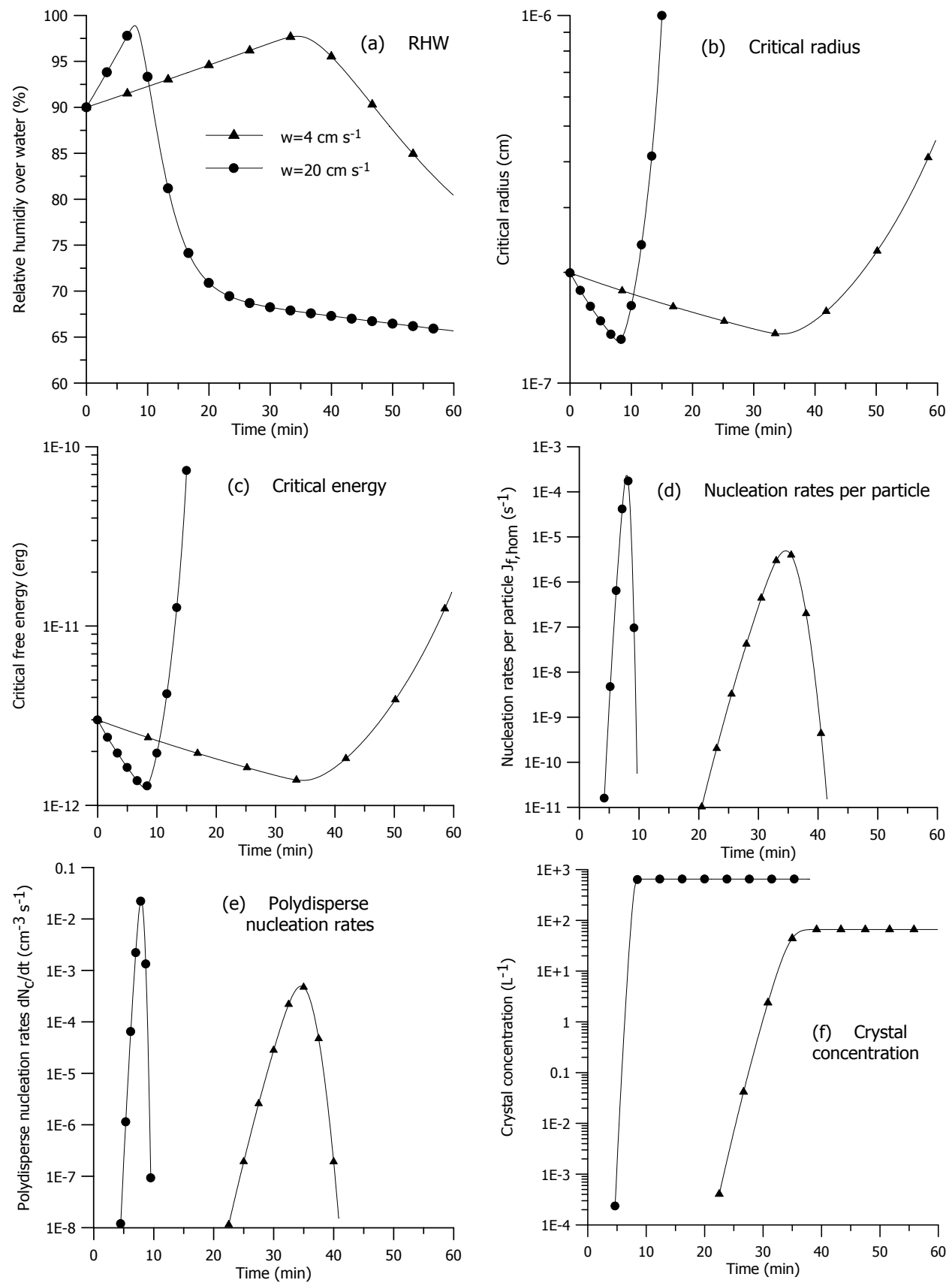

Fig. 1. Kinetics of homogeneous nucleation at $T_{0 \mathrm{c}}=-40^{\circ} \mathrm{C}, \mathrm{RHW}=90 \%, p_{0}=340 \mathrm{hPa}, N_{\mathrm{a}}=200 \mathrm{~cm}^{-3}$ and two vertical velocities, $w=4 \mathrm{~cm} \mathrm{~s}^{-1}$, and $w=20 \mathrm{~cm} \mathrm{~s}^{-1}$. (a) Relative humidity over water RHW, defined as $100 \cdot S_{\mathrm{W}, \text { th }}$; (b) critical radius $r_{\mathrm{cr}}$; (c) critical free energy $\Delta F_{\mathrm{cr}}$; (d) homogeneous $J_{\mathrm{f}, \text { hom }} r_{\mathrm{a}}^{3}$ nucleation rates for a particle with radius of $0.11 \mu \mathrm{m} ;(\mathbf{e})$ polydisperse nucleation rates, $R_{\mathrm{f}, \text { hom }}=\mathrm{d} N_{\mathrm{fr}} / \mathrm{d} t$, defined by Eq. (18d); (f) crystal concentration.

decreasing supersaturations. At the ascending branch, the first term on the right-hand side of Eq. (21) or Eq. (24) with supersaturation generation dominates; therefore the relative humidity and supersaturation increase from the initial values to the maximum values reached at the time $t_{\max }$. At the descending branch, RHW, $s_{\mathrm{W}}$, and $s_{\mathrm{i}}$ decrease due to domination of the second term on the RHS of Eq. (21) or Eq. (24) with supersaturation depletion. Due to cooling in the parcel, RHW increases in the ascending branch and reaches at $w=4 \mathrm{~cm} \mathrm{~s}^{-1}$ a maximum of $97.7 \%$ at $t \sim 35 \mathrm{~min}$, then begins to decrease (Fig. 1a).

The critical or threshold water and ice supersaturations $s_{\mathrm{w}, \text { cr }}$ and $s_{\mathrm{i}, \mathrm{cr}}$ can be defined as the points where the nucleation rates become significant and the crystal concentrations 

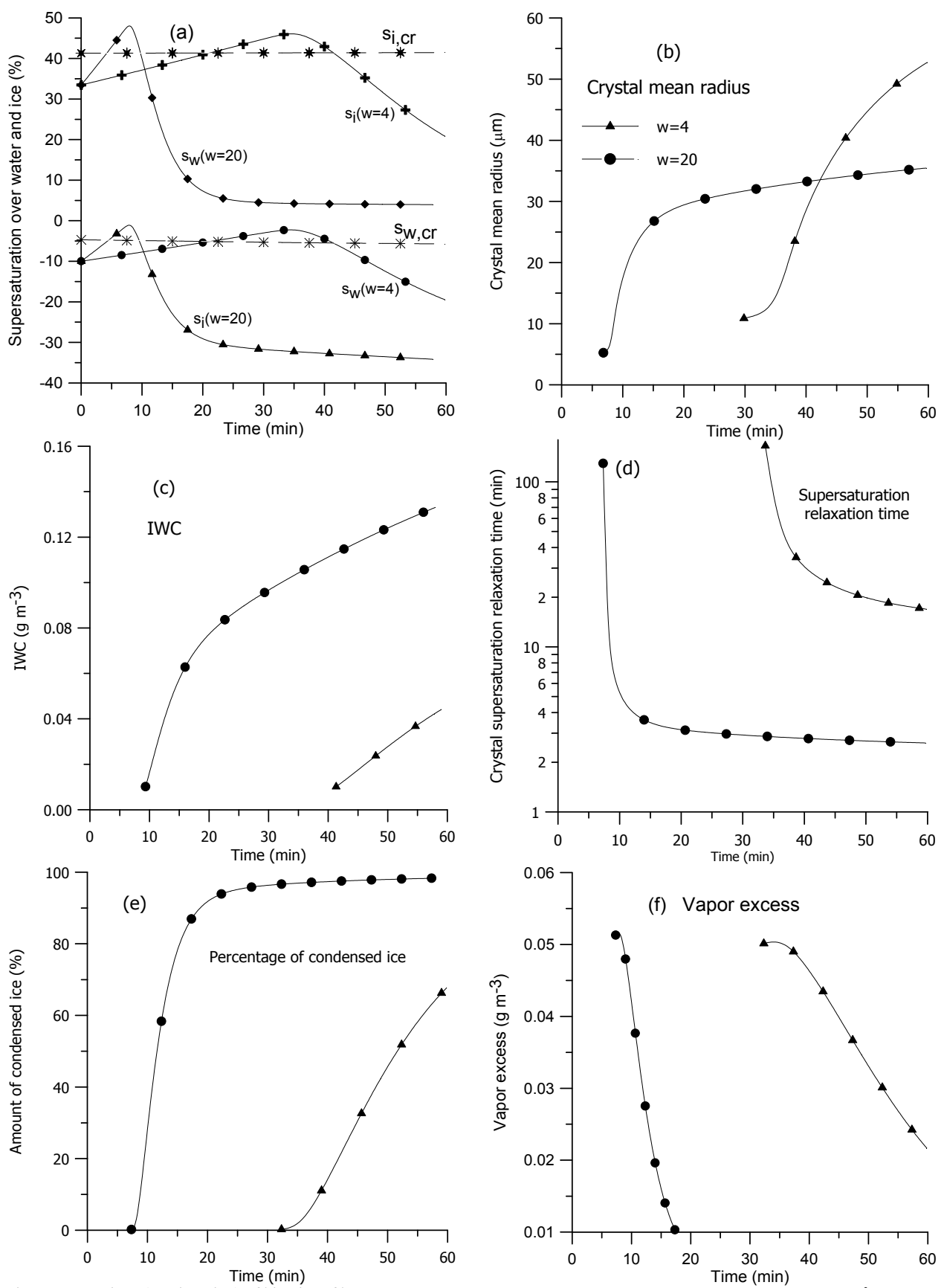

Fig. 2. Comparison (continuation) of kinetics of homogeneous ice nucleation at $w=4 \mathrm{~cm} \mathrm{~s}^{-1}$ (solid circles) and $w=20 \mathrm{~cm} \mathrm{~s}-1$ (triangles) at $-40^{\circ} \mathrm{C}$ and the other parameters as in Fig. 1. (a) Supersaturations over water, $s_{\mathrm{W}}$, and ice, $s_{\mathrm{i}}, \%$ and corresponding critical supersaturations. (b) Crystal mean radius, $\mu \mathrm{m}$; (c) ice water content, $\mathrm{g} \mathrm{m}^{-3}$; (d) crystal supersaturation relaxation time, min; (e) relative amount of condensed ice, $\%$; (f) vapor excess, $\mathrm{g} \mathrm{m}^{-3}$.

reach some threshold values, e.g., $N_{\mathrm{c}} \sim 10^{-3} 1^{-1}$ (a more rigorous quantitative description is given in Khvorostyanov and Curry, 2009a). The water and ice supersaturation pass in the ascending branch the first critical values of $s_{\mathrm{w}, \mathrm{cr} 1}=-4.2 \%$ and $s_{\mathrm{i}, \mathrm{cr} 1}=42 \%$ at about $t \approx 22 \mathrm{~min}$, reach maxima of $-2.45 \%$ and $46 \%$ respectively at $t=33.67 \mathrm{~min}$, then de- crease in the descending branch to the second critical values reached at about $t=40 \mathrm{~min}$ (Fig. 2a). Note that the change in ice supersaturation $\Delta s_{\mathrm{i}}=s_{\mathrm{i}, \max }-s_{\mathrm{i}, \mathrm{cr} 1} \approx 4 \%$, or $\Delta s_{\mathrm{i}} / s_{\mathrm{i}, \max }$ is less than $10 \%$. Thus it can be assumed that nucleation occurs at almost constant ice supersaturation. 
Noticeable ice nucleation with $w=4 \mathrm{~cm} \mathrm{~s}^{-1}$ begins after the first critical point $s_{\mathrm{w}, \mathrm{cr} 1}$ at $t \approx 22 \mathrm{~min}$ (Fig. 1d, e, f). At the time of maximum RHW and $s_{\mathrm{W}}$, the crystal critical radius and energy reach minima of $1.36 \times 10^{-7} \mathrm{~cm}$ and $1.38 \times 10^{-12}$ erg respectively (Fig. 1b, c), while the nucleation rate per particle $\left(J_{\mathrm{f}, \text { hom }} r_{\mathrm{h}}^{3}\right.$, with $\left.r_{\mathrm{h}}=0.11 \mu \mathrm{m}\right)$ and the polydisperse nucleation rate $R_{\mathrm{f}, \text { hom }}$ reach maxima of $4.90 \times 10^{-6} \mathrm{~s}^{-1}$ and $4.93 \times 10^{-4} \mathrm{~cm}^{-3} \mathrm{~s}^{-1}$ (Fig. 1d, e). The values of $r_{\mathrm{cr}}$ and $\Delta F_{\mathrm{cr}}$ are substantially greater, while $J_{\mathrm{f}, \text { hom }} r_{\mathrm{h}}^{3}$ and $R_{\mathrm{f}}$, hom are smaller at the later times, although the temperature continues to decrease. This illustrates an important key role of humidity in ice nucleation.

In contrast to drop activation, the ice nucleation process continues after $t_{\mathrm{m}}$ along the descending branch until the point when the second critical values $s_{\mathrm{w}, \mathrm{cr}}$ and $s_{\mathrm{i}, \mathrm{cr}}$ are reached (this process has been mostly disregarded in previous parameterizations of ice nucleation.) The entire nucleation process takes 15-20 min with $w=4 \mathrm{~cm} \mathrm{~s}^{-1}$, and the final crystal concentration is $661^{-1}$ (Fig. 1f). The crystal mean radius grows to $43 \mu \mathrm{m}$ by $t=1 \mathrm{~h}$, the ice water content (IWC) increases to $0.044 \mathrm{~g} \mathrm{~m}^{-3}$ and the supersaturation relaxation time $\tau_{\mathrm{fc}}$ decreases from more than $3 \mathrm{~h}$ at the beginning of nucleation to $17 \mathrm{~min}$ by the end of simulation. This indicates that deposition of the vapor is not instantaneous but a significant amount of vapor is deposited over a period of hours.

For quantitative illustration, it is convenient to introduce the two quantities, vapor excess, $\Delta M_{\mathrm{v}}$, and the relative amount, or percentage of condensed ice, $\mathrm{Fr}_{\mathrm{con}}$,

$\Delta M_{\mathrm{v}}=\rho_{\mathrm{v}} s_{\mathrm{i}}, \mathrm{Fr}_{\text {con }}=\mathrm{IWC} /\left(\mathrm{IWC}+\Delta M_{\mathrm{v}}\right) \times 100$.

These quantities characterize the mass of uncondensed ice and the fraction of condensed ice. In a bulk model with instantaneous condensation and deposition, $\Delta M_{\mathrm{v}}=0$, and $\mathrm{Fr}_{\text {con }}=100 \%$, but it is not so in this microphysical model with explicit calculation of supersaturation. Fig. $2 \mathrm{f}$ shows that the vapor excess is greater or comparable to IWC and the fraction of condensed ice is less than $50 \%$ during $30 \mathrm{~min}$. This means that optical thickness and emissivity of cirrus clouds at the initial stages of their formation are significantly smaller than predicted in a bulk model.

The corresponding curves for the case with $w=20 \mathrm{~cm} \mathrm{~s}^{-1}$ (solid circles in Figs. 1 and 2) show much faster nucleation, about $5 \mathrm{~min}$. The other features of the nucleation process are qualitatively similar, with some quantitative differences. The minimum critical radius and energy are somewhat smaller, the nucleation rates increase by almost two orders of magnitude, and the final crystal concentration increases to $6491^{-1}$, almost 10 times greater than with $w=4 \mathrm{~cm} \mathrm{~s}^{-1}$. Because of more numerous crystals and their competition for vapor, the mean crystal radius is smaller than with $w=4 \mathrm{~cm} \mathrm{~s}^{-1}$, but the relaxation time $\tau_{\mathrm{fc}}$ is also smaller with a minimum of 2.6 $\min$. The deposition is faster with $w=20 \mathrm{~cm} \mathrm{~s}^{-1}$, but the vapor excess and fraction of condensed ice are still smaller for 15-20 min that would be in a bulk model with instantaneous deposition (Fig. 2e, f).
A comparison of the results with $N_{\mathrm{a}}=200 \mathrm{~cm}^{-3}$ and $500 \mathrm{~cm}^{-3}$ at $T_{0}=-40^{\circ} \mathrm{C}, w=4 \mathrm{~cm} \mathrm{~s}^{-1}$ is shown in Figs. 3 and 4; all other parameters are as before. This comparison shows that a significant increase in $N_{\mathrm{a}}$ causes very weak effect on nucleation kinetics and all the resulting quantities. Nucleation with higher $N_{\mathrm{a}}$ begins and ceases a little earlier, and the resulting crystal concentration is $68.61^{-1}$ vs. $661^{-1}$ with $N_{\mathrm{a}}=200 \mathrm{~cm}^{-3}$; that is, an increase 2.5 times in $N_{\mathrm{a}}$ causes and increase of only $4 \%$ in $N_{\mathrm{c}}$. This remarkable insensitivity to the initial concentration of deliquescent freezing aerosol indicates a kind of "saturation" with respect to $N_{\mathrm{a}}$ at values of $N_{\mathrm{a}}$ much smaller than these values typical for the upper troposphere.

The fraction of nucleated haze particles (the ratio $N_{\mathrm{c}} / N_{\mathrm{a}}$ ), is tiny $\left(661^{-1}\right) /\left(2000001^{-1}\right)=3.3 \times 10^{-4}$, which is much smaller than the typical fraction of $\mathrm{CCN}$ activated into the drops, $\sim 0.3-0.7$. This very small fraction of freezing solution particles is explained by the following factors: (a) very strong negative feedback by the water supersaturation: even a small decrease in $s_{\mathrm{W}}$ causes a significant decrease in the nucleation rate $J_{\mathrm{f}, \mathrm{hom}}$; ; and (b) much faster crystal growth at high ice supersaturation than drop growth at small water supersaturation.

The effect of temperature is illustrated in Figs. 5 and 6 , where a comparison is made for the cases $-40^{\circ} \mathrm{C}$ and $-60^{\circ} \mathrm{C}$, at $w=4 \mathrm{~cm} \mathrm{~s}^{-1}$, and all other parameters as before. The critical and maximum water supersaturations (negative) decrease and ice supersaturations increase with decreasing temperature. Minimum critical radius and energy are comparable at both temperatures, while the nucleation rates grow 4-7 times at lower $T$. The crystal concentration increases almost 4 times to $2421^{-1}$ at lower $T$ (Fig. 5f), but crystal growth is slower; therefore the mean radius is about 4 times smaller and the fraction of condensed ice is lower by the end of simulation at $t=1 \mathrm{~h}$, and the supersaturation relaxation times are close, $\sim 15-17 \mathrm{~min}$, since increase in crystal concentration is balanced by decrease in the mean radius (Fig. 6). Thus, the amount of condensed ice is again smaller than would be in a bulk model.

Some properties of the nucleation rates allow simplification of the nucleation equations. The nucleation rates are very small at all stages of the process, $J_{\mathrm{f}, \mathrm{hom}} r_{\mathrm{h}}^{3}<10^{-5}-10^{-4} \mathrm{~s}^{-1}$ and $R_{\mathrm{f}, \mathrm{hom}}<10^{-3}-10^{-1} \mathrm{~cm}^{-3} \mathrm{~s}^{-1}$ even at their maxima; see Figs. 1d, e, 3d, e, 5d, e. Therefore Eqs. (18b-d) for homogeneous nucleation rate can be substantially simplified since

$\exp \left(-\int_{0}^{t} J_{\mathrm{f}, \mathrm{hom}}\left(t^{\prime}\right) v\left(r_{\mathrm{a}}\right) \mathrm{d} t^{\prime}\right) \approx 1-\int_{0}^{t} J_{\mathrm{f}, \mathrm{hom}}\left(t^{\prime}\right) v\left(r_{\mathrm{a}}\right) \mathrm{d} t^{\prime}$.

The probability $P_{\mathrm{f}, \text { hom }}\left(r_{\mathrm{a}}, t\right)$ (Eq. $18 \mathrm{~b}$ ) of homogeneous freezing of a haze particle or a drop with radius $r_{\mathrm{a}}$ and volume $v\left(r_{\mathrm{a}}\right)$ during the time interval from $t_{0}$ to $t$ can be simplified as 

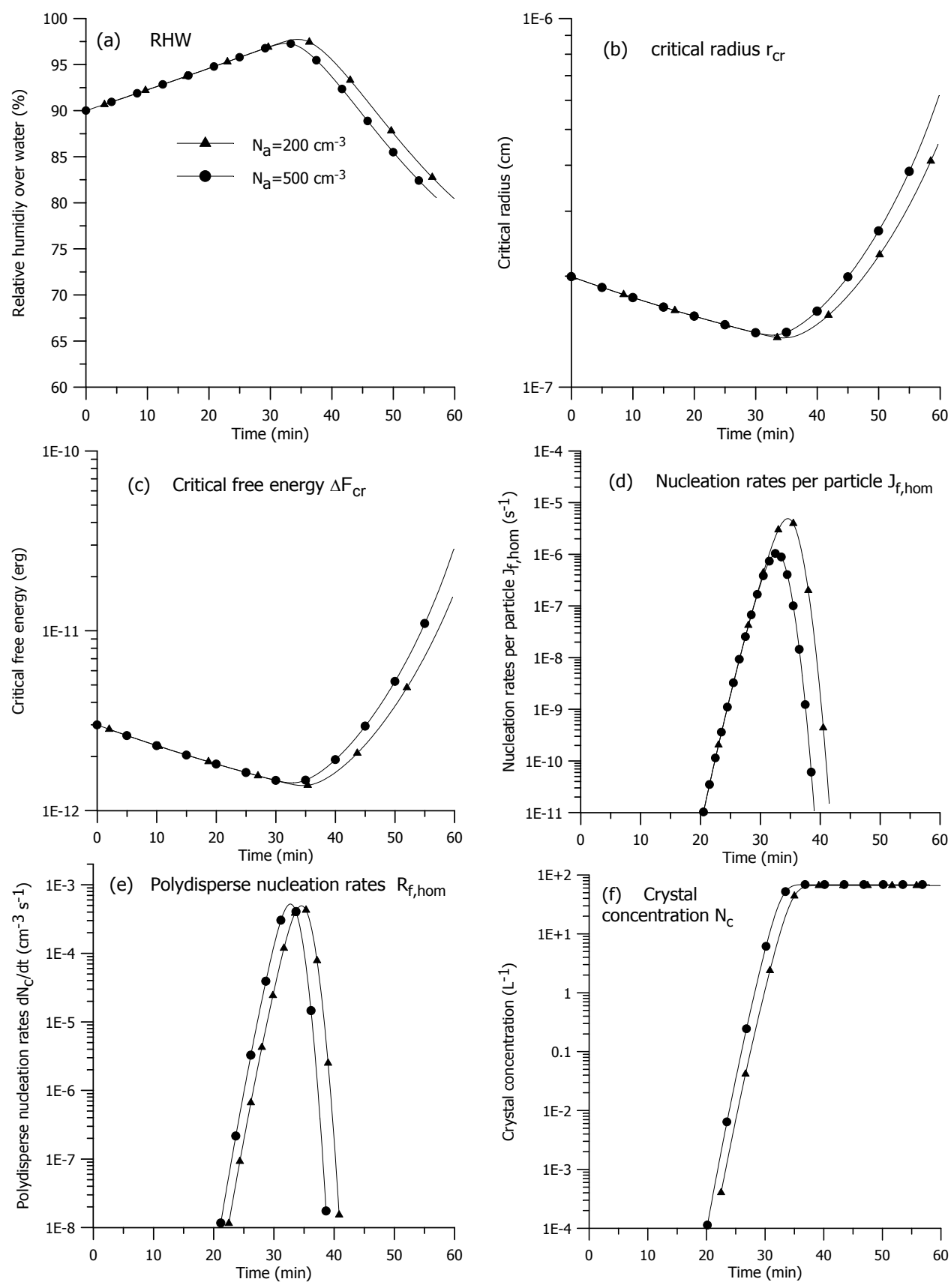

Fig. 3. Comparison of homogeneous nucleation kinetics at $N_{\mathrm{a}}=200 \mathrm{~cm}^{-3}$ and $500 \mathrm{~cm}^{-3}$. The other parameters are: $T_{0 \mathrm{c}}=-40^{\circ} \mathrm{C}$, $\mathrm{RHW}_{0}=90 \%, p_{0}=340 \mathrm{hPa}, w=4 \mathrm{~cm} \mathrm{~s}^{-1}$. (a) Relative humidity over water RHW, defined as $100 \cdot S_{\mathrm{W}, \text { th }}$; (b) critical radius $r_{\mathrm{cr}}$; (c) critical free energy $\Delta F_{\mathrm{cr}} ;(\mathbf{d})$ homogeneous $J_{\mathrm{f}, \text { hom }} r_{\mathrm{a}}^{3}$ nucleation rates for a particle with radius of $0.11 \mu$ m; (e) polydisperse nucleation rates, $R_{\mathrm{f}, \text { hom }}=\mathrm{d} N_{\mathrm{fr}} / \mathrm{d} t$, defined by Eq. (18d); (f) crystal concentration.

$$
\begin{gathered}
P_{\mathrm{f}, \text { hom }}\left(r_{\mathrm{a}}, t\right)=1-\exp \left(-\int_{t_{0}}^{t} J_{\mathrm{f}, \mathrm{hom}}\left(t^{\prime}\right) v\left(r_{\mathrm{a}}\right) \mathrm{d} t^{\prime}\right) \\
\approx \int_{t_{0}}^{t} J_{\mathrm{f}, \text { hom }}\left(t^{\prime}\right) v\left(r_{\mathrm{a}}\right) \mathrm{d} t^{\prime} .
\end{gathered}
$$

Equation (18c) for the crystal concentration $N_{\mathrm{c}, \text { hom }}$ in a polydisperse aerosol can be simplified as

$$
\begin{gathered}
N_{\mathrm{c}, \text { hom }}(t)=\int_{r_{\text {min }}}^{r_{\text {max }}} P_{\mathrm{f}, \text { hom }}\left(r_{\mathrm{a}}, t\right) f_{\mathrm{a}}\left(r_{\mathrm{a}}\right) \mathrm{d} r_{\mathrm{a}}, \\
\approx \int_{r_{\min }}^{r_{\text {max }}} \int_{t_{0}}^{t} J_{\mathrm{f}, \text { hom }}\left(t^{\prime}\right) v\left(r_{\mathrm{a}}\right) f_{\mathrm{a}}\left(r_{\mathrm{a}}\right) d t^{\prime} \mathrm{d} r_{\mathrm{a}} .
\end{gathered}
$$



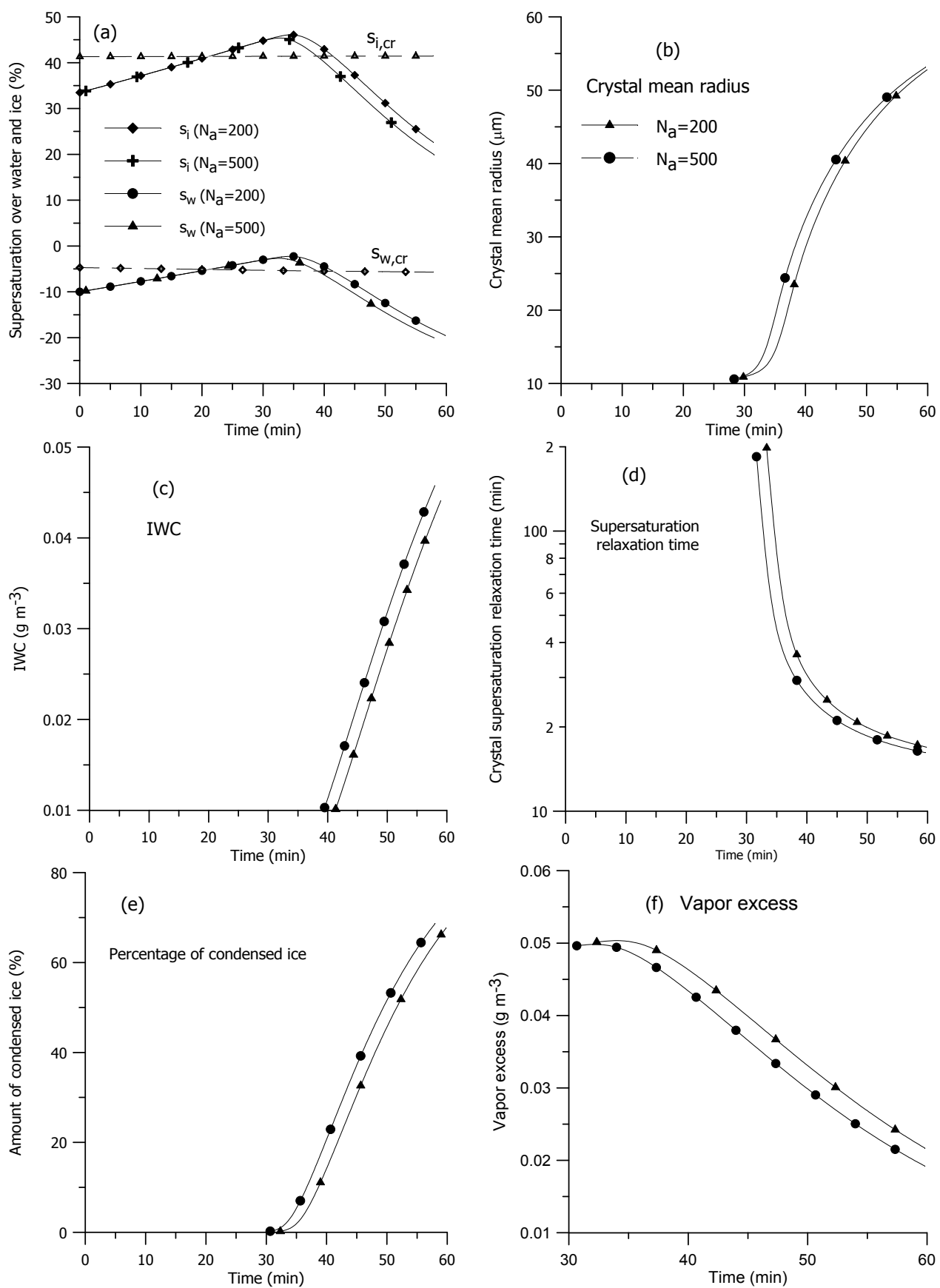

Fig. 4. Comparison (continuation) of homogeneous ice nucleation kinetics at $N_{\mathrm{a}}=200 \mathrm{~cm}^{-3}$ (solid circles) and $500 \mathrm{~cm}^{-3}$ (triangles), at $-40{ }^{\circ} \mathrm{C}$ and the other parameters as in Fig. 3. (a) Supersaturations over water, $s_{\mathrm{W}}$, and ice, $s_{\mathrm{i}}$, and critical supersaturations, $s_{\mathrm{W}, \mathrm{cr}}$, and ice, $s_{\mathrm{i}, \mathrm{cr}}, \%$; (b) crystal mean radius, $\mu \mathrm{m}$; (c) ice water content, $\mathrm{g} \mathrm{m}^{-3}$; (d) crystal supersaturation relaxation time, min; (e) relative amount of condensed ice, $\%$; (f) vapor excess, $\mathrm{g} \mathrm{m}^{-3}$.

The crystal nucleation rate $R_{\mathrm{f} \text {,hom }}$ (Eq. 18d) in a polydisperse aerosol can be simplified and is obtained by differentiating of Eq. (29) by $t$ :

$R_{\mathrm{f}, \mathrm{hom}}(t)=\frac{\mathrm{d} N_{\mathrm{c}, \mathrm{hom}}}{\mathrm{d} t} \approx \int_{r_{\min }}^{r_{\text {max }}} f_{\mathrm{a}}\left(r_{\mathrm{a}}\right) v\left(r_{\mathrm{a}}\right) J_{\mathrm{f}, \text { hom }}(t) \mathrm{d} r_{\mathrm{a}}$.

\section{Parameterization of homogeneous ice nucleation kinetics}

In this section, a new parameterization of homogeneous ice nucleation kinetics is derived, based on extended classical nucleation theory and analytical solutions of the supersaturation equation. 

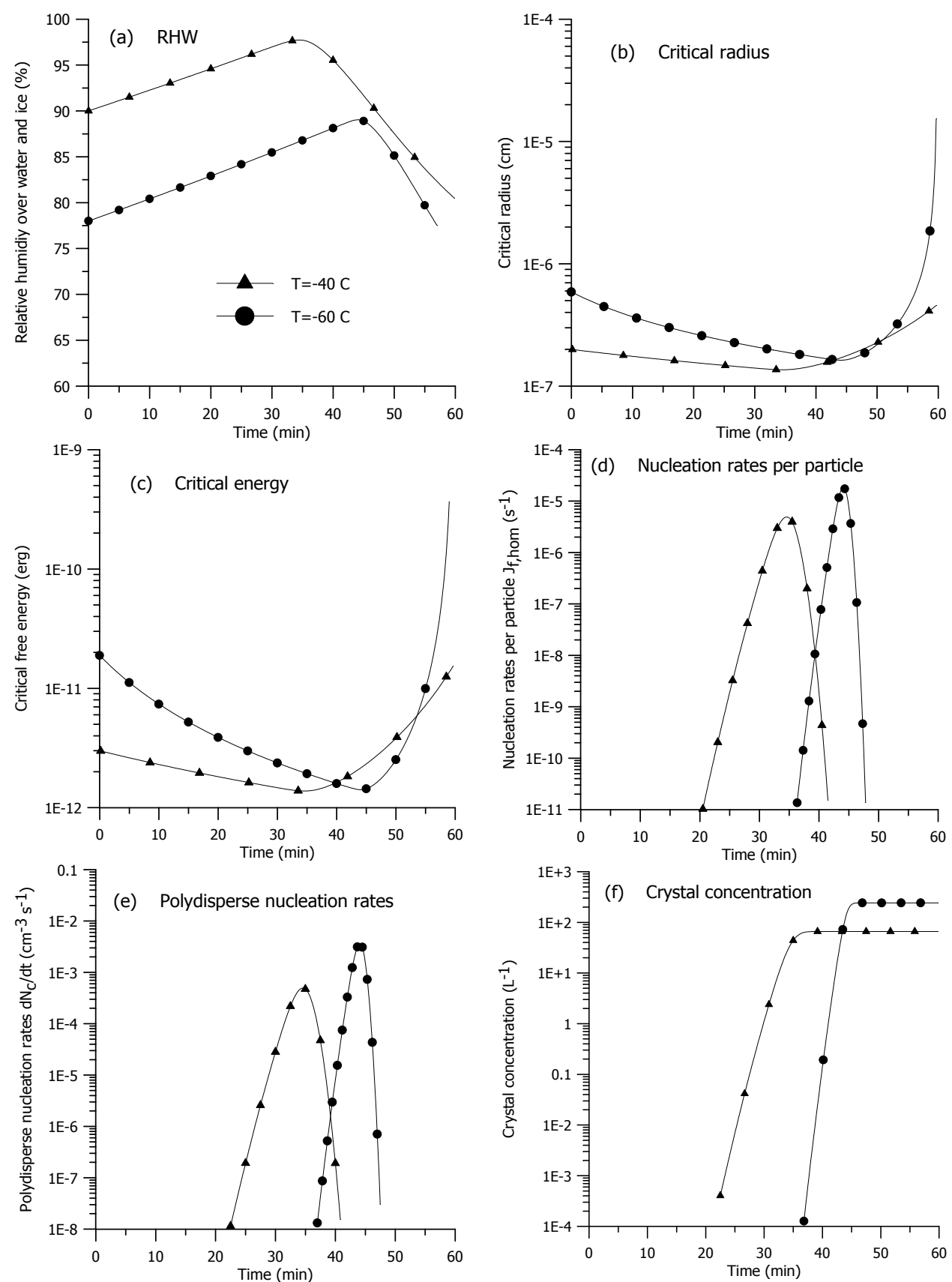

Fig. 5. Comparison of homogeneous nucleation kinetics at $T=-40{ }^{\circ} \mathrm{C}$ and $-60^{\circ} \mathrm{C}$. The other parameters are: $\mathrm{RHW}_{0}\left(-40{ }^{\circ} \mathrm{C}\right)=90 \%$ and $\mathrm{RHW}_{0}\left(-60^{\circ} \mathrm{C}\right)=78 \%, p_{0}=340 \mathrm{hPa}, w=4 \mathrm{~cm} \mathrm{~s}^{-1}$. (a) Relative humidity over water RHW; (b) critical radius $r_{\mathrm{cr}}$; (c) critical free energy $\Delta F_{\mathrm{cr}}$; (d) homogeneous $J_{\mathrm{f}, \text { hom }} r_{\mathrm{a}}^{3}$ nucleation rates for a particle with radius of $0.11 \mu \mathrm{m} ;(\mathbf{e})$ polydisperse nucleation rates, $R_{\mathrm{f}, \text { hom }}=\mathrm{d} N_{\mathrm{fr}} / \mathrm{d} t$, defined by Eq. (18d); (f) crystal concentration.

\subsection{General properties of nucleation and freezing rate}

\subsubsection{General features of homogeneous ice nucleation kinetics}

The general features of homogeneous ice nucleation kinetics are illustrated in more detail in Fig. 7. The symbols $t_{\mathrm{cr}, 1}$ and $t_{\mathrm{cr}, 2}$ denote the 1 st and 2 nd times when the critical (threshold) ice supersaturations $s_{\mathrm{i}, \mathrm{cr} 1}$ and $s_{\mathrm{i}, \mathrm{cr} 2}$ are reached (marked with ellipses), that is, the start and end of nucleation; $t_{\max }$ is the time when maximum ice and water supersaturations, $s_{\mathrm{i}, \max }$ and $s_{\mathrm{W}, \max }$, are reached. Figure 7 shows that homogeneous ice nucleation has features that are both similar and different from drop nucleation. In both cases, supersaturation 
increases due to cooling by the updraft, but in contrast to drop activation, ice nucleation begins at water subsaturations of a few percent at time $t_{\mathrm{cr}, 1}$, when a critical ice supersaturation $s_{\mathrm{i}, \mathrm{cr}, 1}$ is reached.

The $s_{\mathrm{i}}(t)$ and $s_{\mathrm{W}}(t)$ curves consist of two branches with increasing and decreasing supersaturations. However, in contrast to the drop activation, nucleation does not cease at $t_{\max }$, when maximum $s_{\mathrm{i}, \max }$ and $s_{\mathrm{w}, \max }$ are reached. Only about half of the final crystal concentration has been nucleated by this time (the ellipse in Fig. 7b), and nucleation continues along the branch with decreasing supersaturation to the point $t_{\mathrm{cr}, 2}, s_{\mathrm{i}, \mathrm{cr} 2}$ when $s_{\mathrm{i}}(t)$ again intersects the line $s_{\mathrm{i}, \mathrm{cr}}(t)$. It is seen that an increase in both $s_{\mathrm{W}}$ and $s_{\mathrm{i}}$ is linear almost to the maximum, and both $s_{\mathrm{W}}$ and $s_{\mathrm{i}}$ can be well approximated with linear functions.

The basic equations describing kinetics of homogeneous ice nucleation include the integro-differential equations for water and ice supersaturations derived in Sect. 2, and the equation for crystal radius growth rate with account for kinetic effects. In addition, we need an equation for homogeneous nucleation rate of haze particles with account for solution effects, an equation for the critical supersaturation $s_{\mathrm{w}, \mathrm{cr}}$, and equations for the critical radius and energy of homogeneous nucleation.

\subsubsection{Freezing rate}

The equation for the critical water supersaturation $s_{\mathrm{w}}=S_{\mathrm{w}}-$ 1 was derived in Khvorostyanov and Curry (2009a, hereafter $\mathrm{KC} 09 \mathrm{a}$ ) based on the extension of classical nucleation theory $s_{\mathrm{w}, \mathrm{cr}}=S_{\mathrm{w}, \mathrm{cr}}^{\mathrm{hom}}-1=\left[\left(T / T_{0}\right) \exp \left(H_{\mathrm{v}, \mathrm{fr}}+H_{\mathrm{f}, \mathrm{hom}}\right)\right]^{1 / G_{n}}-1$

$\approx\left(T / T_{0}\right)\left[1-\left(H_{\mathrm{v}, \text { fr }}+H_{\mathrm{f}, \text { hom }}\right)\right]^{M_{\mathrm{w}} L_{\mathrm{m}}^{\text {ef }} / R T} \approx\left(T / T_{0}\right)^{M_{\mathrm{w}} L_{\mathrm{m}}^{\mathrm{Lef}} / R T}$,

where $G_{n}=\left(R T / M_{\mathrm{w}} L_{\mathrm{m}}^{\mathrm{ef}}\right)$ is a dimensionless parameter, $L_{\mathrm{m}}^{\mathrm{ef}}$ is the specific melting heat averaged over temperature, $R$ is the universal gas constant, $M_{\mathrm{w}}$ is the molecular weight of water, $H_{\mathrm{v}, \mathrm{fr}}$ and $H_{\mathrm{f}, \text { hom }}$ are functions of the melting heat, water and ice densities, external pressure and surface tension (KC09a). The last approximate equality in Eq. (31) is written neglecting effects of external pressure (small for this case), and for very slow nucleation rates (see KC09a). The corresponding ice saturation ratio $S_{\mathrm{i}}$ and supersaturation $s_{\mathrm{i}}$ can be obtained using standard relations between $s_{\mathrm{W}}$ and $s_{\mathrm{i}}$.

The polydisperse freezing rate $R_{\mathrm{f}, \text { hom }}=\mathrm{d} N_{\mathrm{c}}\left(t_{0}\right) / \mathrm{d} t_{0}$ can be calculated using classical nucleation theory as described by Eq. (18d). It was illustrated in Figs. 1 and 2 that at typical cooling rates $(w)$, the inner integral in the exponent of Eq. (18d) is close to 1. Therefore, Eq. (30) can be used as a good approximation for $R_{\mathrm{f} \text {,hom: }}$ :

$R_{\mathrm{f}, \text { hom }}\left(t_{0}\right)=\frac{\mathrm{d} N_{\mathrm{fr}}}{\mathrm{d} t}=\int_{r_{\text {min }}}^{r_{\text {max }}} \mathrm{d} r_{\mathrm{a}} f_{\mathrm{a}}\left(r_{\mathrm{a}}\right) v\left(r_{\mathrm{a}}\right) J_{\mathrm{f}, \mathrm{hom}}\left(t_{0}\right)$.

This expression can be further simplified if the depletion of $v\left(r_{\mathrm{a}}\right)$ and $f_{\mathrm{a}}\left(r_{\mathrm{a}}\right)$ are small during freezing, which is usually a good approximation with abundant concentrations of freezing particles

$R_{\mathrm{f}, \text { hom }}\left(t_{0}\right) \approx J_{\mathrm{f}, \text { hom }}\left(t_{0}\right) \int_{r_{\text {min }}}^{r_{\text {max }}} \mathrm{d} r_{\mathrm{a}} f_{\mathrm{a}}\left(r_{\mathrm{a}}\right) v\left(r_{\mathrm{a}}\right)=N_{\mathrm{a}} \bar{v}_{\mathrm{a}} J_{\mathrm{f}, \text { hom }}\left(t_{0}\right)$,

where $\bar{v}_{\mathrm{a}}$ is the mean aerosol volume averaged over the haze size spectrum

$\bar{v}_{\mathrm{a}}=\frac{4}{3} \pi \frac{1}{N_{\mathrm{a}}} \int_{r_{\min }}^{r_{\max }} r_{\mathrm{a}}^{3} f_{\mathrm{a}}\left(r_{\mathrm{a}}\right) \mathrm{d} r_{\mathrm{a}}$.

In general, $N_{\mathrm{a}}$ and $\bar{v}_{\mathrm{a}}$ vary with time; however, the fraction of haze particles nucleated into crystals is very small compared to the initial haze population. Therefore, $I_{\text {dep }}$ in Eq. (23) can be further simplified assuming $N_{\mathrm{a}} \approx$ const, $\bar{v}_{\mathrm{a}} \approx$ const.

$I_{\text {dep }}=y_{\mathrm{i}}^{\prime} \frac{4 \pi D_{\mathrm{v}} \rho_{\mathrm{is}}}{\Gamma_{2}} N_{\mathrm{a}} \bar{v}_{\mathrm{a}} \int_{0}^{t} r_{\mathrm{c}, \text { ef }}\left(t, t_{0}\right) J_{\mathrm{f}, \mathrm{hom}}\left(t_{0}\right) \mathrm{d} t_{0}$.

\subsection{Separation of the temperature and supersaturation dependencies}

The nucleation rate $J_{\mathrm{f}, \mathrm{hom}}\left(T, s_{\mathrm{W}}\right)$ can be calculated using classical nucleation theory (CNT) (PK97)

$J_{\text {f,hom }}=2 N_{\text {cont }}\left(\frac{\rho_{\mathrm{w}}}{\rho_{\mathrm{i}}} \frac{k T}{h}\right)\left(\frac{\sigma_{\mathrm{is}}}{k T}\right)^{1 / 2} \exp \left(-\frac{\Delta F_{\text {act }}+\Delta F_{\mathrm{cr}}}{k T}\right)$,

where $\rho_{\mathrm{w}}$ and $\rho_{\mathrm{i}}$ are the densities of water and ice, $\sigma_{\mathrm{is}}$ is the surface tension at the solution-ice interface, $\Delta F_{\text {act }}$ and $\Delta F_{\mathrm{cr}}$ are the activation and critical energies of an ice germ freezing, $N_{\text {cont }}$ is the number of molecules in contact with a unit area of ice surface, $k$ and $h$ are the Boltzmann's and Planck's constants. In CNT, the energy $\Delta F_{\text {act }}$ is a function of temperature; $\Delta F_{\mathrm{cr}}$ is a function of the critical germ radius $r_{\mathrm{cr}}$, which is also a function of $T$ (PK97). More general analytical expressions for $r_{\mathrm{cr}}\left(T, S_{\mathrm{w}}, r_{\mathrm{d}}, \Delta p\right)$ and $\Delta F_{\mathrm{cr}}\left(T, S_{\mathrm{w}}\right.$, $r_{\mathrm{d}}, \Delta p$ ) were derived in Khvorostyanov and Sassen (1998a), Khvorostyanov and Curry (2000, 2004a, b). Here we use a somewhat simpler expression from KS98a, KC00, KC04a,b with account for $T$ and $S_{\mathrm{w}}$,

$$
\begin{gathered}
r_{\mathrm{cr}}\left(T, S_{\mathrm{w}}\right)=\frac{2 \sigma_{\mathrm{is}}}{\rho_{\mathrm{i}} L_{\mathrm{m}}^{\mathrm{ef}}(T)\left[\ln \left(\frac{T_{0}}{T} S_{\mathrm{w}}^{G_{n}}\right)\right]}, \\
G_{n}=\frac{R T}{M_{\mathrm{w}} L_{\mathrm{m}}^{\mathrm{ef}}} ; \quad \Delta F_{\mathrm{cr}}\left(T, S_{\mathrm{w}}\right)=\frac{4}{3} \pi \sigma_{\mathrm{is}} r_{\mathrm{cr}}^{2} \\
=\frac{(16 \pi / 3) \sigma_{\mathrm{is}}^{3}}{\left[\rho_{\mathrm{i}} L_{\mathrm{m}}^{\mathrm{ef}}(T) \ln \left(\frac{T_{0}}{T} S_{\mathrm{w}}^{G_{n}}\right)\right]^{2}},
\end{gathered}
$$

where $G_{n} \sim 0.4-0.6$ with relatively weak $T$-dependence (KC09a). Analytical solution of the supersaturation equation requires some simplifications; in particular, it is desirable to 

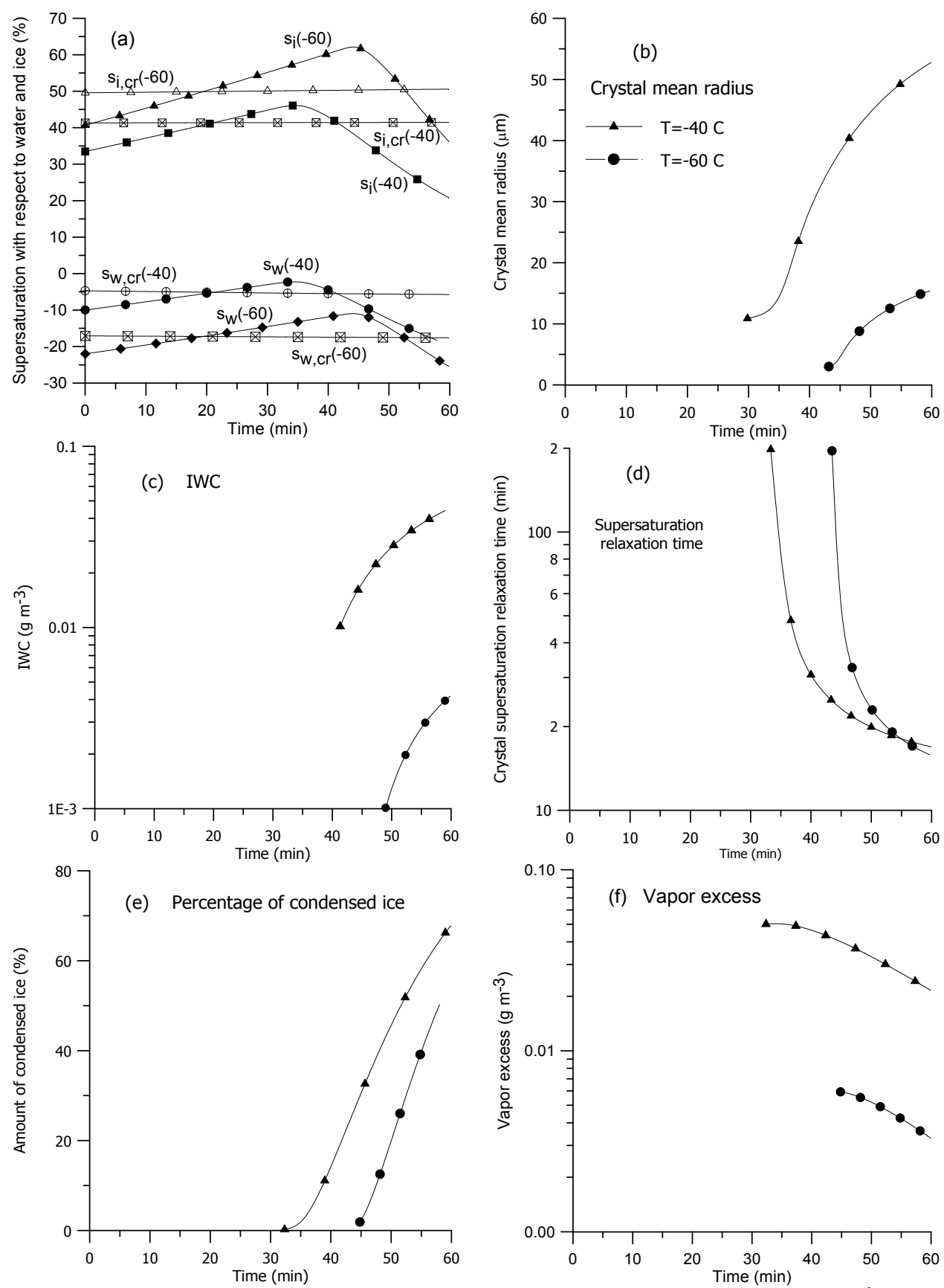

Fig. 6. Comparison of homogeneous nucleation kinetics at $T=-40^{\circ} \mathrm{C}$ and $-60^{\circ} \mathrm{C}$ (continuation). The other parameters are: $\mathrm{RHW}_{0}\left(-40^{\circ} \mathrm{C}\right)=90 \%$ and $\mathrm{RHW}_{0}\left(-60^{\circ} \mathrm{C}\right)=78 \%, p_{0}=340 \mathrm{hPa}, w=4 \mathrm{~cm} \mathrm{~s}^{-1}$. (a) Supersaturations over water, $s_{\mathrm{W}}$, and ice, $s_{\mathrm{i}}, \%$; (b) crystal mean radius, $\mu \mathrm{m}$; (c) ice water content, $\mathrm{g} \mathrm{m}^{-3}$; (d) crystal supersaturation relaxation time, min; (e) relative amount of condensed ice, \%; (f) vapor excess, $\mathrm{g} \mathrm{m}^{-3}$.

find a representation of $J_{\mathrm{f}, \text { hom }}$ with separated $T$ - and $S_{\mathrm{w}}$ or $s_{\mathrm{W}}$-dependencies. Here, we express $\Delta F_{\mathrm{cr}}$ via water supersaturation $s_{\mathrm{w}}$ using Eq. (37a) and the relation $S_{\mathrm{w}}=1+s_{\mathrm{w}}$, then

$\Delta F_{\mathrm{cr}}=\frac{(16 \pi / 3) \sigma_{\mathrm{is}}^{3}}{\left\{\rho_{\mathrm{i}} L_{\mathrm{m}}^{\mathrm{ef}}(T) \ln \left[\frac{T_{0}}{T}\left(1+s_{\mathrm{W}}\right)^{G_{n}}\right]\right\}^{2}}$.

This equation for $\Delta F_{\mathrm{cr}}$ can be transformed so that the dependencies of $T$ and $s_{\mathrm{W}}$ are separated, following KC04b. It 

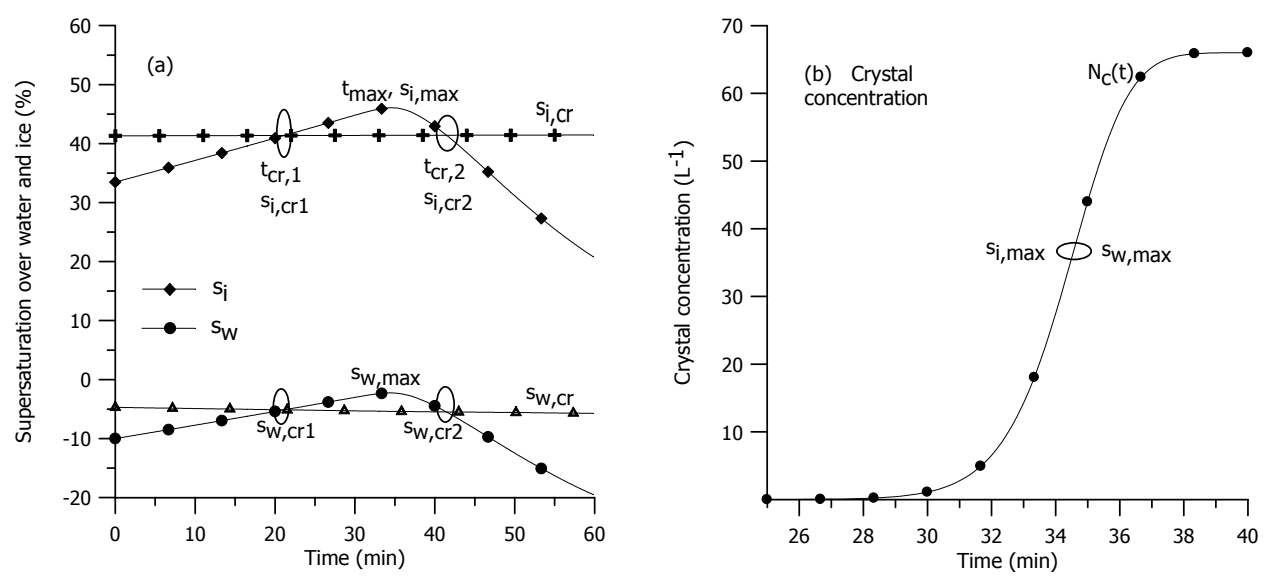

Fig. 7. General features of homogeneous ice nucleation kinetics (evolution of water and ice supersaturations and crystal concentration) illustrated with a parcel model run with the parameters: initial temperature $T_{\mathrm{c}}=-40{ }^{\circ} \mathrm{C}, s_{\mathrm{W}}(t=0)=-0.1(-10 \%)$, lognormal size spectrum of haze particles with mean geometric radius of $0.02 \mu \mathrm{m}$ and concentration $N_{\mathrm{a}}=200 \mathrm{~cm}^{-3}$. The symbols $t_{\mathrm{cr}, 1}$ and $t_{\mathrm{cr}, 2}$ (marked with ellipses) denote the 1 st and 2nd times when critical (threshold) ice supersaturations $s_{\mathrm{i}, \mathrm{cr} 1}$ and $s_{\mathrm{i}, \mathrm{cr} 2}$ are reached, that is, the start and end of nucleation; $t_{\max }$ is the time when maximum ice and water supersaturations $s_{\mathrm{i}, \max }, s_{\mathrm{W}, \max }$ are reached; $s_{\mathrm{W}, \mathrm{cr}}$ denote the curves of critical (threshold) water and ice supersaturations.

was found from observations and model simulations that homogeneous freezing of haze droplets in cirrus clouds usually occurs at small water subsaturations of $-2 \%$ to $-10 \%$, i.e., $s_{\mathrm{W}}=-2 \times 10^{-2}$ to $-10 \times 10^{-2}$, so that $\left|s_{\mathrm{w}}\right| \ll 1$ (see e.g., Figs. 1-7 here; Sassen and Dodd, 1989; Lin et al., 2002). Since $\left|s_{\mathrm{w}}\right| \ll 1$, we can expand the denominator in Eq. (37b) into a power series in $s_{\mathrm{W}}$. The logarithmic term can be transformed as

$$
\begin{gathered}
\ln \left[\frac{T_{0}}{T}\left(1+s_{\mathrm{W}}\right)^{G_{n}}\right] \approx \ln \left[\frac{T_{0}}{T}\left(1+G_{n} s_{\mathrm{W}}\right)\right] \approx \ln \left(\frac{T_{0}}{T}\right) \\
+G_{n} s_{\mathrm{W}}=\ln \left(\frac{T_{0}}{T}\right)\left(1+\frac{G_{n} s_{\mathrm{W}}}{\ln \left(T_{0} / T\right)}\right),
\end{gathered}
$$

where we used a relation $\ln \left(1+G_{n} s_{\mathrm{W}}\right) \approx G_{n} s_{\mathrm{W}}$ for $\left|s_{\mathrm{W}}\right| \ll 1$ and $G_{n} \sim 0.4-0.6$. Substituting this expansion into Eq. (37b), we obtain

$$
\Delta F_{\mathrm{cr}}\left(T, s_{\mathrm{W}}\right) \approx \Delta F_{\mathrm{cr}, 0}(T)\left[1-\kappa_{\mathrm{s}} s_{\mathrm{w}}\right],
$$

where

$\kappa_{\mathrm{S}}=\frac{2 G_{n}}{\ln \left(T_{0} / T\right)}=\frac{2 R T}{M_{\mathrm{w}} L_{\mathrm{m}}^{\mathrm{ef}} \ln \left(T_{0} / T\right)}$,

$\Delta F_{\mathrm{cr}, 0}=\frac{(16 \pi / 3) \sigma_{\mathrm{is}}^{3}}{\left[\rho_{\mathrm{i}} L_{\mathrm{m}}^{\mathrm{ef}}(T) \ln \left(T_{0} / T\right)\right]^{2}}$.

That is, $\Delta F_{\mathrm{cr}, 0}$ is the critical energy for pure water defined by Eq. (37b) but at $S_{\mathrm{w}}=1$ or $s_{\mathrm{w}}=0$, i.e., it depends only on temperature but does not depend on supersaturation. For $T \sim-50{ }^{\circ} \mathrm{C}, G_{n} \sim 0.5$, and $\kappa_{\mathrm{s}} \sim 5$, then with $s_{\mathrm{W}}=$ $-3 \times 10^{-2}(-3 \%)$, the term $\kappa_{\mathrm{s}} s_{\mathrm{W}} \sim-0.15 \ll 1$. The second order term in expansion by $\kappa_{\mathrm{S}} s_{\mathrm{W}}$ in Eq. (39) contributes $\sim 3.5 \%$; therefore, retaining only the first term in Eq. (39) is justified. Substitution of Eq. (39) into Eq. (36) yields

$$
J_{\mathrm{f}, \operatorname{hom}}\left(T, s_{\mathrm{W}}\right)=J_{\text {f,hom }}^{(0)}(T) \exp \left[u_{\mathrm{s}}(T) s_{\mathrm{W}}(t)\right],
$$

$$
J_{\mathrm{f}, \operatorname{hom}}\left(T, s_{\mathrm{W}}\right)=J_{\mathrm{f}, \mathrm{hom}}^{(0)}(T)\left[b_{\mathrm{hom}}(T)\right]^{s_{\mathrm{w}}(t)},
$$

so that $J_{\mathrm{f}, \text { hom }}$ can be written such that the $s_{\mathrm{W}}$-dependence is presented in the exponential or power law forms, similar to those derived in $\mathrm{KC} 04 \mathrm{~b}$ for heterogeneous nucleation. The parameters $u_{\mathrm{s}}$ and $b_{\text {hom }}$ are

$$
\begin{aligned}
u_{\mathrm{s}}(T) & =\frac{\Delta F_{\mathrm{cr}, 0}}{k T} \frac{2 G_{n}}{\ln \left(T_{0} / T\right)}=\frac{2 R}{k M_{\mathrm{w}} L_{\mathrm{m}}^{\mathrm{ef}}} \frac{\Delta F_{\mathrm{cr}, 0}}{\ln \left(T_{0} / T\right)} \\
& =\frac{2 N_{\mathrm{Av}}}{M_{\mathrm{w}} L_{\mathrm{m}}^{\mathrm{ef}}} \frac{\Delta F_{\mathrm{cr}, 0}}{\ln \left(T_{0} / T\right)},
\end{aligned}
$$

$b_{\text {hom }}(T)=\exp \left(u_{\mathrm{s}}\right)$,

where $k$ is the Boltzmann constant, $N_{\mathrm{Av}}$ is the Avogadro number, and $J_{\text {f,hom }}^{(0)}$ is defined by Eq. (36) with $\Delta F_{\mathrm{cr}, 0}(T)$ from Eq. (40b), i.e., at $s_{\mathrm{w}}=0$. Thus, $J_{\mathrm{f}, \text { hom }}\left(T, s_{\mathrm{W}}\right)$ is presented in a separable form as a product of the two factors: $J_{\mathrm{f}, \text { hom }}^{(0)}\left(T, s_{\mathrm{W}}=0\right)$ depends on $T$ but does not depend on $s_{\mathrm{w}}$, and the dependence on $s_{\mathrm{W}}$ is separated into the exponent in Eqs. (41a), (42a). An estimate shows that at cirrus conditions $u_{\mathrm{S}} \sim(2-4) \times 10^{2} \gg 1$. Since $s_{\mathrm{W}}<0$ in the nucleation process, the value of $u_{\mathrm{S}} s_{\mathrm{W}}$ is negative. If $s_{\mathrm{W}} \sim-(4$ to 10$) \times 10^{-2}$, at typical nucleation conditions, the value of $\left|u_{\mathrm{S}} s_{\mathrm{W}}\right| \geq 10$, and we have an inequality $\exp \left(u_{\mathrm{S}} s_{\mathrm{W}}\right) \ll 1$. 


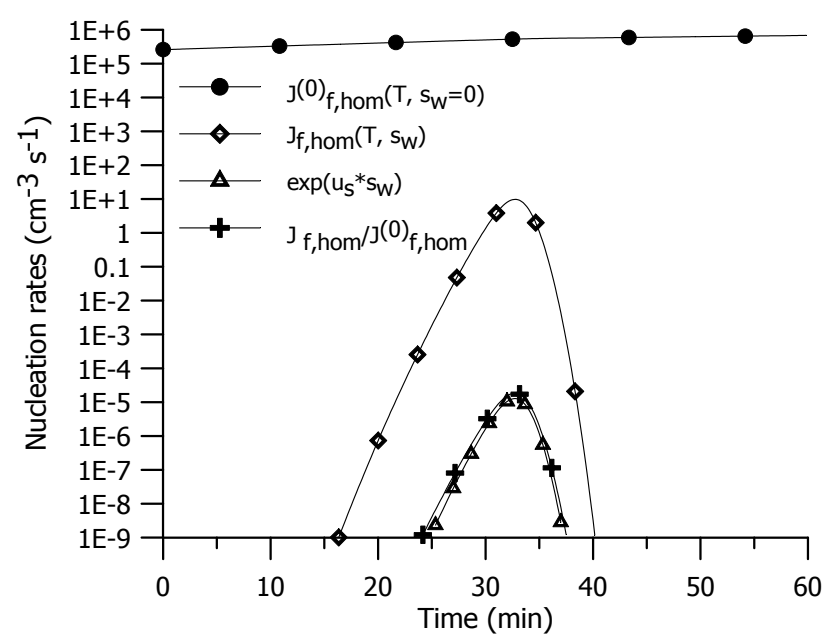

Fig. 8. Homogeneous nucleation rates $J_{\mathrm{f}, \mathrm{hom}}\left(T, s_{\mathrm{W}}\right)$, $J_{\mathrm{f}, \mathrm{hom}}^{(0)}\left(T, s_{\mathrm{W}}=0\right)$, their ratio $J_{\mathrm{f}, \mathrm{hom}}\left(T, s_{\mathrm{W}}\right) / J_{\mathrm{f}, \mathrm{hom}}^{(0)}\left(T, s_{\mathrm{W}}=0\right)$, and $\exp \left(u_{\mathrm{s}} s_{\mathrm{W}}\right)$ that determines this ratio. Calculations for the same

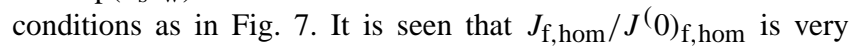
close to $\exp \left(u s_{\mathrm{W}}\right)$, which is a good approximation to this ratio.

Numerical simulation with the parcel model shows that changes in $J_{\mathrm{f}, \text { hom }}^{(0)}$ in Eq. (41a) are several orders of magnitude smaller than variations in $\exp \left(u_{\mathrm{s}} s_{\mathrm{W}}\right)$. This is illustrated in Fig. 8, which shows that $J_{\mathrm{f}, \mathrm{hom}}^{(0)}\left(T, s_{\mathrm{W}}=0\right) \sim(4-$ 5) $\times 10^{5} \mathrm{~cm}^{-3} \mathrm{~s}^{-1}$ and only varies slightly during the nucleation event, while $J_{\mathrm{f}, \mathrm{hom}}\left(T, s_{\mathrm{w}}\right)$ varies (decreases from maximum) by 10 orders of magnitude during nucleation. This is caused by the effect of $\exp \left(u_{\mathrm{S}} s_{\mathrm{W}}\right)$, which reaches a maximum $\sim 10^{-5}$ at $t=34.5 \mathrm{~min}$, the time of maximum of $s_{\mathrm{W}}$. Figure 8 shows that the ratio $J_{\mathrm{f}, \text { hom }}\left(T, s_{\mathrm{w}}\right) / J_{\mathrm{f}, \text { hom }}^{(0)}\left(T, s_{\mathrm{w}}=0\right)$ is very close to $\exp \left(u_{\mathrm{S}} s_{\mathrm{W}}\right)$, confirming the validity of the analytical separability of $T$ and $s_{\mathrm{w}}$ in Eqs. (41a, b). Further, the primary variations in $J_{\mathrm{f}, \mathrm{hom}}\left(T, s_{\mathrm{W}}\right)$ occur due to variations in $s_{\mathrm{W}}$, while changes due to the temperature are several orders smaller. Therefore, the deposition integral $I_{\text {dep }}$ in Eq. (35) can be presented in a form that substantially simplifies calculations

$I_{\mathrm{dep}}=y_{\mathrm{i}}^{\prime} \frac{4 \pi D_{\mathrm{v}} \rho_{\mathrm{is}}}{\Gamma_{2}} N_{\mathrm{a}} \bar{v}_{\mathrm{a}} J_{\mathrm{f}, \text { hom }}^{(0)} \int_{0}^{t} r_{\mathrm{c}, \mathrm{ef}}\left(t, t_{0}\right) \exp \left[u_{\mathrm{s}} s_{\mathrm{w}}\left(t_{0}\right)\right] \mathrm{d} t_{0}$,

or introducing the integral $J_{0 \mathrm{i}}$ as

$\begin{aligned} I_{\mathrm{dep}} & =y_{\mathrm{i}}^{\prime} \frac{4 \pi D_{\mathrm{v}} \rho_{\mathrm{is}}}{\Gamma_{2}} N_{\mathrm{a}} \bar{v}_{\mathrm{a}} J_{\mathrm{f}, \text { hom }}^{(0)} J_{0 \mathrm{i}}, \\ J_{0 \mathrm{i}} & =\int_{0}^{t} r_{\mathrm{c}, \mathrm{ef}}\left(t, t_{0}\right) \exp \left[u_{\mathrm{s}} s_{\mathrm{W}}\left(t_{0}\right)\right] \mathrm{d} t_{0} .\end{aligned}$

\subsection{Evaluation of nucleation rate and crystal concentration}

We seek a solution to the supersaturation equation, similar to that used in the parameterizations of drop activation (e.g., Twomey, 1959; Sedunov, 1974; Khvorostyanov and Curry, 2008, 2009b; Ghan et al., 2012; Tao et al., 2012), as a linear approximation but with the initial critical (threshold) values. The initial values are zero for drop activation but are equal to some nonzero critical values $s_{\mathrm{w}, \mathrm{cr}}, s_{\mathrm{i}, \mathrm{cr}}$ with account for the specifics of ice nucleation as illustrated in the previous figures

$s_{\mathrm{i}}(t)=y_{\mathrm{i}}^{\prime}(t)=s_{\mathrm{i}, \mathrm{cr}}+a_{1 \mathrm{i}} t, \quad y_{\mathrm{i}}(t)=s_{\mathrm{i}, \mathrm{cr}} t+\left(a_{1 \mathrm{i}} / 2\right) t^{2}$,
$s_{\mathrm{W}}(t)=y_{\mathrm{W}}^{\prime}(t)=s_{\mathrm{W}, \mathrm{cr}}+a_{1 \mathrm{w}} t, \quad y_{\mathrm{W}}(t)=s_{\mathrm{W}, \mathrm{cr}} t+\left(a_{1 \mathrm{w}} / 2\right) t^{2}$.

The integral supersaturations $y_{\mathrm{w}}$ and $y_{\mathrm{i}}$ are written assuming for simplicity that the time is counted from the moment $t_{0}=t_{\mathrm{cr}}$ when $s_{\mathrm{w}, \mathrm{cr}}$ and $s_{\mathrm{i}, \mathrm{cr}}$ are reached, then according to Eq. (16) the initial time $t_{0}=t_{\mathrm{cr}}=0$. The parameters $a_{1 \mathrm{w}}$ and $a_{1 \mathrm{i}}$ can be specified in various ways, which yield the lower and upper limits of the solution similar to drop activation. An approximation that gives a lower bound of the solution can be obtained with $a_{1 \mathrm{w}}=c_{1 \mathrm{w}} w$. The difference between the limits is on the order of $10-15 \%$ or smaller, and we for simplicity will consider the approximations $a_{1 \mathrm{w}}=c_{1 \mathrm{w}} w$, and $a_{1 \mathrm{i}}=c_{1 \mathrm{i}} w$, as prompted by the Eqs. (8a), (8b), (24), and (44), (45). Figures 2 and 7 show that the increase $\Delta s_{\mathrm{i}}=$ $c_{1 \mathrm{i}} w\left(t_{\max }-t_{0}\right) \sim 0.04(4 \%)$ during ice nucleation from $t_{0}$ to $t_{\max }$ is much smaller than the initial critical $s_{\mathrm{i}, \text { cr }} \sim 0.42$ (42\%) or maximum $s_{\mathrm{i}, \max } \sim 0.46(46 \%)$. Since $\Delta s_{\mathrm{i}} \ll s_{\mathrm{i}, \mathrm{cr}}$, we can neglect the increase $\Delta s_{\mathrm{i}}$ of $s_{\mathrm{i}}$ in Eq. (44) during a nucleation event, which was also neglected by Kärcher and Lohmann (2002a, b), and Ren and MacKenzie (2005). We also assume that $s_{\mathrm{i}}(t) \approx$ const $\approx s_{\mathrm{i}, \mathrm{cr}}$. In contrast, we cannot neglect the term $\Delta s_{\mathrm{w}}=c_{1 \mathrm{w}} w\left(t_{\max }-t_{0}\right)$ because water supersaturation varies substantially and determines variations in $J_{\mathrm{f}, \text { hom }}$ (Fig. 7). Thus, assuming again $t_{0}=t_{\mathrm{cr}}=0$,

$s_{\mathrm{i}}(t)=y_{\mathrm{i}}^{\prime}(t)=s_{\mathrm{i}, \mathrm{cr}}, \quad y_{\mathrm{i}}(t)=s_{\mathrm{i}, \mathrm{cr}} t$,

$s_{\mathrm{W}}(t)=y_{\mathrm{w}}^{\prime}(t)=s_{\mathrm{w}, \mathrm{cr}}+c_{1 \mathrm{w}} w t, \quad y_{\mathrm{w}}(t)=s_{\mathrm{w}, \mathrm{cr}} t+\left(c_{1 \mathrm{w}} w / 2\right) t^{2}$.

Substitution of $s_{\mathrm{W}}(t)$ into the separable nucleation rate in Eq. (41a) yields $J_{\mathrm{f}, \mathrm{hom}}\left(T, s_{\mathrm{w}}\right)$ as a function of time in the form

$J_{\mathrm{f}, \mathrm{hom}}\left[T, s_{\mathrm{W}}(t)\right]=J_{\mathrm{f}, \mathrm{hom}}^{(0)}\left(T_{\mathrm{cr}}\right) \exp \left(u_{\mathrm{S}} s_{\mathrm{w}, \mathrm{cr}}\right) \exp \left(u_{\mathrm{s}} c_{1 \mathrm{w}} w t\right)$,

where $u_{\mathrm{s}}$ is defined in (42a). We assume here, based on Fig. 8, that the major time dependence is determined by $s_{\mathrm{w}}$, and the temperature dependence is determined near $T_{\mathrm{cr}}$. Dividing $J_{\mathrm{f}, \mathrm{hom}}(t)$ by $J_{\mathrm{f} \text {,hom }}\left(t_{0}\right)$ at some initial $t_{0}$, we obtain the time dependence $J_{\mathrm{f} \text {,hom }}(t)$ of the form

$J_{\mathrm{f}, \text { hom }}(t)=J_{\mathrm{f}, \text { hom }}\left(t_{0}\right) \exp \left[u_{\mathrm{s}} c_{1 \mathrm{w}} w\left(t-t_{0}\right)\right]$. 
For $t_{0}=t_{\mathrm{cr}}$, Eq. (47b) can be rewritten with Eq. (46b) as

$\ln \frac{J_{\mathrm{f}, \mathrm{hom}}\left[s_{\mathrm{W}}(t)\right]}{J_{\mathrm{f}, \mathrm{hom}}\left[s_{\mathrm{w}, \mathrm{cr}}\left(t_{\mathrm{cr}}\right)\right]}=u_{\mathrm{s}} c_{1 \mathrm{w}} w\left(t-t_{\mathrm{cr}}\right)=u_{\mathrm{s}}(T)\left[s_{\mathrm{W}}(t)-s_{\mathrm{w}, \mathrm{cr}}\right]$.

Using the relation following from the Clausius-Clapeyron equation

$s_{\mathrm{W}}+1=c_{\mathrm{iw}}\left(s_{\mathrm{i}}+1\right), c_{\mathrm{iw}}=\exp \left[-L_{\mathrm{m}}\left(T_{0}-T\right) / R_{\mathrm{v}} T_{0} T\right]$,

where $R_{\mathrm{v}}$ is the vapor gas constant and $T_{0}=273.15$, we express $s_{\mathrm{W}}$ in Eq. (47c) via the ice saturation ratio $S_{\mathrm{i}}=s_{\mathrm{i}}+1$ and obtain

$\ln \frac{J_{\mathrm{f}, \mathrm{hom}}\left[s_{\mathrm{W}}(t)\right]}{J_{\mathrm{f}, \mathrm{hom}}\left[s_{\mathrm{W}, \mathrm{cr}}\left(t_{\mathrm{cr}}\right)\right]}=u_{\mathrm{s}}(T) c_{\mathrm{iw}}(T)\left[S_{\mathrm{i}}(t)-S_{\mathrm{i}, \mathrm{cr}}\right]$.

This expression has the same form as Eq. (6) hypothesized by Barahona and Nenes (2008), and their coefficient $b_{\tau}$ fitted with empirical data is expressed now from the extended classical nucleation theory as $b_{\tau}(T)=u_{\mathrm{s}}(T) c_{\mathrm{iw}}(T)$. Equation $(47 \mathrm{~b})$ can be also rewritten as

$J_{\text {f,hom }}(t)=J_{\mathrm{f}, \mathrm{hom}}\left(t_{0}\right) \exp \left[\left(t-t_{0}\right) / \tau_{\mathrm{nuc}}\right]$,

where we introduced the characteristic "nucleation time" $\tau_{\text {nuc }}$

$\tau_{\mathrm{nuc}}=\left(c_{1 \mathrm{w}} w u_{\mathrm{s}}\right)^{-1}=\left[c_{1 \mathrm{w}} w \frac{\Delta F_{\mathrm{cr}, 0}}{k T} \frac{2 G_{n}}{\ln \left(T_{0} / T\right)}\right]^{-1}$

$=\left(c_{1 \mathrm{w}} w\right)^{-1} \frac{k L_{\mathrm{m}}^{\mathrm{ef}} \ln \left(T_{0} / T\right)}{2 R_{\mathrm{v}} \Delta F_{\mathrm{cr}, 0}}=\left(c_{1 \mathrm{w}} w\right)^{-1} \frac{M_{\mathrm{w}} L_{\mathrm{m}}^{\mathrm{ef}} \ln \left(T_{0} / T\right)}{2 N_{\mathrm{Av}} \Delta F_{\mathrm{cr}, 0}}$,

where $k$ is the Boltzmann constant and $N_{\mathrm{Av}}$ is the Avogadro number. The temporal dependence of $J_{\mathrm{f}, \mathrm{hom}}(t)$ as in Eq. (48) was hypothesized by Ford (1998a, b), Kärcher and Lohmann (2002a, b) and Ren and MacKenzie (2005) and the time $\tau_{\text {nuc }}$ was found by fitting to some auxiliary relations Eqs. (3), (5) above. Here, the time dependence of $J_{\mathrm{f}, \mathrm{hom}}(t)$ and the time $\tau_{\text {nuc }}$ are derived in terms of the extended classical nucleation theory with the dependence on $S_{\mathrm{w}}$. Equation (49) shows that $\tau_{\text {nuc }}^{-1} \sim c_{1 \mathrm{w}} w$, that is, according to Eq. (5), is proportional to $(\mathrm{d} T / \mathrm{d} t)$, in agreement with Eq. (5), the other factors in Eq. (49) determine $\partial \ln J_{\mathrm{hom}} / \partial T$ and the empirical coefficient $c_{\tau}$ in Eq. (5). Thus, the approach based on extended CNT confirms the functional forms hypothesized in the previous parameterizations by Ford (1998a, b), Kärcher and Lohmann (2002a, b), Ren and MacKenzie (2005), Barahona and Nenes (2008), and allows to express them via the fundamental thermodynamic parameters reducing the number of hypothesized relations and quantities.

The linear approximation Eq. (46b) for $s_{\mathrm{W}}(t)$ allows description of the time evolution of the nucleation rate $R_{\mathrm{f}, \text { hom }}(t)$ and crystal concentration $N_{\mathrm{c}}(t)$. Substitution of Eq. (47a) into Eq. (33) yields

$$
\begin{aligned}
R_{\mathrm{f}, \operatorname{hom}}\left(t_{0}\right) & \approx N_{\mathrm{a}} \bar{v}_{\mathrm{a}} J_{\mathrm{f}, \text { hom }}^{(0)}\left(T_{\mathrm{cr}}\right) \exp \left(u_{\mathrm{s}} s_{\mathrm{w}, \mathrm{cr}}\right) \exp (\beta t), \\
& \approx N_{\mathrm{a}} \bar{v}_{\mathrm{a}} J_{\mathrm{f}, \text { hom }}^{(0)}\left(T_{\mathrm{cr}}\right) \exp \left[u_{\mathrm{s}} s_{\mathrm{w}}(t)\right]
\end{aligned}
$$

$\beta=u_{\mathrm{s}} c_{1 \mathrm{w}} w=\tau_{\text {nuc }}^{-1}$.

Integration over time assuming $t_{0}=t_{\mathrm{cr}}=0$ gives $N_{\mathrm{c}}(t)$

$$
\begin{aligned}
& N_{\mathrm{c}}(t)=\int_{0}^{t} R_{\mathrm{f}, \text { hom }}(t) \mathrm{d} t \\
& \approx N_{\mathrm{a}} \bar{v}_{\mathrm{a}} J_{\mathrm{f}, \mathrm{hom}}^{(0)}\left(T_{\mathrm{cr}}\right) \beta^{-1} \exp \left(u_{\mathrm{s}} s_{\mathrm{w}, \mathrm{cr}}\right)[\exp (\beta t)-1] . \\
& \approx N_{\mathrm{a}} \bar{v}_{\mathrm{a}} J_{\mathrm{f}, \mathrm{hom}}^{(0)}\left(T_{\mathrm{cr}}\right) \beta^{-1}\left\{\exp \left[u_{\mathrm{s}} s_{\mathrm{w}}(t)\right]-\exp \left(u_{\mathrm{s}} s_{\mathrm{w}, \mathrm{cr}}\right)\right\} .
\end{aligned}
$$

This is the parameterization for $N_{\mathrm{c}}(t)$ that we searched for. The dependencies of $N_{\mathrm{c}}$ on $s_{\mathrm{W}}$ and $T$ are separated in Eq. (52a), this allows to introduce the activity spectra $\varphi_{\mathrm{s}}(T$, $\left.s_{\mathrm{W}}\right)$ and $\varphi_{T}\left(T, s_{\mathrm{W}}\right)$ by $s_{\mathrm{W}}$ and $T$ defined in Eqs. (17), (18a). Differentiation of Eq. (52a) by $s_{\mathrm{W}}$ and $T$ yields

$$
\begin{aligned}
& \varphi_{\mathrm{s}}\left(T, s_{\mathrm{W}}\right) \\
& =\frac{\partial N_{\mathrm{c}}}{\partial s_{\mathrm{W}}} \approx N_{\mathrm{a}} \bar{v}_{\mathrm{a}} J_{\mathrm{f}, \mathrm{hom}}^{(0)}\left(T_{\mathrm{cr}}\right)\left(c_{1 \mathrm{w}} w\right)^{-1} \exp \left(u_{\mathrm{s}} s_{\mathrm{w}, \mathrm{cr}}\right) \exp (\beta t),
\end{aligned}
$$

$\varphi_{T}\left(T, s_{\mathrm{w}}\right)=$

$\frac{\partial N_{\mathrm{c}}}{\partial T} \approx N_{\mathrm{a}} \bar{v}_{\mathrm{a}} J_{\mathrm{f}, \text { hom }}^{(0)}\left(T_{\mathrm{cr}}\right) \frac{\partial}{\partial T}\left\{\beta^{-1} \exp \left(u_{\mathrm{s}} s_{\mathrm{w}, \mathrm{cr}}\right)[\exp (\beta t)-1]\right\}$.

The activity spectrum $\varphi_{\mathrm{S}}\left(T, s_{\mathrm{W}}\right)$ characterizes the rate of ice nucleation with increasing humidity and constant temperature, (similar to considered for drop activation), the spectrum $\varphi_{T}\left(T, s_{\mathrm{w}}\right)$, vice versa, characterizes the rate of ice nucleation with decreasing temperature and constant humidity. Such processes may occur under natural conditions of cirrus clouds formation with advection of humid air and weak variations of $T$, or with advection of cold air and weak changes of humidity. Using Eqs. (52b, c), the relative role of variations of the temperature and humidity can be estimated, or these processes can be studied in isolation in a cloud chamber.

The relation between $\beta$ and $t$ in Eq. (52a) determines the regime of growth of $N_{\mathrm{c}}$ with time. For example, at $T=-40^{\circ} \mathrm{C}$ with $u_{\mathrm{s}} \sim 250, c_{1 \mathrm{w}} \sim 10^{-5} \mathrm{~cm}^{-1}$, and $w \sim 10 \mathrm{~cm} \mathrm{~s}^{-1}$, an estimate gives $\beta \sim 2.5 \times 10^{-2} \mathrm{~s}^{-1}$ and $\tau_{\text {nuc }}=\beta^{-1} \sim 40 \mathrm{~s}$. Thus, for small times, $t \ll \beta^{-1} \sim 40 \mathrm{~s}$, yielding a linear growth of $N_{\mathrm{c}}(t)$ with time

$N_{\mathrm{c}}(t)=t N_{\mathrm{a}} \bar{v}_{\mathrm{a}} J_{\mathrm{f}, \text { hom }}^{(0)}\left(T_{\mathrm{cr}}\right) \exp \left(u_{\mathrm{s}} s_{\mathrm{w}, \mathrm{cr}}\right)$.

For large times, $t \gg \beta^{-1}=40 \mathrm{~s}$, we obtain from Eq. (52a) an exponential time dependence

$N_{\mathrm{c}}(t)=N_{\mathrm{a}} \bar{v}_{\mathrm{a}} J_{\mathrm{f}, \mathrm{hom}}^{(0)}\left(T_{\mathrm{cr}}\right) \tau_{\mathrm{nuc}} \exp \left(u_{\mathrm{S}} s_{\mathrm{W}, \mathrm{cr}}+\beta t\right) \sim \exp \left[u_{\mathrm{S}} s_{\mathrm{W}}(t)\right]$.

In this regime, $\ln \left[N_{\mathrm{c}}(t)\right] \sim t$, and explains the linear dependence of $\ln \left[N_{\mathrm{c}}(t)\right]$ with time in Figs. 1-7.

It is interesting to note that Eq. (54) for homogeneous nucleation can be presented in the form similar to the empirical 
parameterization suggested in Meyers et al. (1992) for heterogeneous freezing. We can write $N_{\mathrm{c}}(t)$ in Eq. (54) as

$N_{\mathrm{c}}\left(s_{\mathrm{W}}\right)=\exp \left(\ln A_{\mathrm{M}}+u_{\mathrm{s}} s_{\mathrm{W}}\right), \quad A_{\mathrm{M}}=N_{\mathrm{a}} \bar{v}_{\mathrm{a}} J_{\mathrm{f}, \text { hom }}^{(0)}\left(T_{\mathrm{cr}}\right) \tau_{\mathrm{nuc}}$.

Using Eq. (47d), we replace $s_{\mathrm{W}}$ with $s_{\mathrm{i}}$ and obtain

$$
N_{\mathrm{c}}\left(s_{\mathrm{i}}\right)=\exp \left(a_{\mathrm{M}}+b_{\mathrm{M}} s_{\mathrm{i}}\right)
$$

$$
\begin{aligned}
a_{\mathrm{M}}= & \ln A_{\mathrm{M}}+u_{\mathrm{s}}\left(c_{\mathrm{iw}}-1\right)=\ln \left[N_{\mathrm{a}} \bar{v}_{\mathrm{a}} J_{\mathrm{f}, \mathrm{hom}}^{(0)}\left(T_{\mathrm{cr}}\right) \tau_{\mathrm{nuc}}\right] \\
& +u_{\mathrm{s}}\left(c_{\mathrm{iw}}-1\right), \quad b_{\mathrm{M}}=u_{\mathrm{s}} c_{\mathrm{iw}} .
\end{aligned}
$$

Equation (56a) can be also presented as a power law by ice supersaturation

$$
N_{\mathrm{c}}\left(s_{\mathrm{i}}\right)=b_{\mathrm{H}}\left(c_{\mathrm{H}}\right)^{s_{\mathrm{i}}}, \quad b_{\mathrm{H}}=\exp \left(a_{\mathrm{M}}\right), c_{\mathrm{H}}=\exp \left(b_{\mathrm{M}}\right) .
$$

The aerosol concentration $N_{\mathrm{a}}$ is included in $A_{\mathrm{M}}$ in Eq. (55) but can be placed also in front of the exponent. These parameters are expressed via the primary atmospheric and aerosol quantities and substantially vary with temperature and cooling rate via $w$ in $u_{\mathrm{s}}$. Thus, the empirical parameterizations of the type of Meyers et al. (1992) can be derived from extended CNT.

If we consider the nucleation process at longer times and near the point of the maximum supersaturations in Figs. 1-7, the vapor depletion becomes substantial and finally exceeds supersaturation production. Then a more accurate consideration should include evaluation of the deposition integral $I_{\mathrm{dep}}$ and supersaturation equation, which is done in the following subsections.

\subsection{Evaluation of the deposition integral $I_{\text {dep }}$}

Evaluation of $I_{\mathrm{dep}}$ is analogous to that developed in Khvorostyanov and Curry (2008, 2009b) for drop nucleation; however integration for ice nucleation is more complicated due to the exponential activity spectrum. Substitution of $y_{\mathrm{i}}(t)$ from Eq. (46a) into Eq. (20) for $r_{\mathrm{c}, \text { ef }}\left(t, t_{0}\right)$ yields

$r_{\mathrm{c}, \mathrm{ef}}\left(t, t_{0}\right)=\frac{\left\{\left[\left(r_{\mathrm{c} 0}+\xi_{\mathrm{dep}}\right)^{2}+B_{\mathrm{i}}\left(t-t_{0}\right)\right]^{1 / 2}-\xi_{\mathrm{dep}}\right\}^{2}}{\left[\left(r_{\mathrm{c} 0}+\xi_{\mathrm{dep}}\right)^{2}+B_{\mathrm{i}}\left(t-t_{0}\right)\right]^{1 / 2}}$,

where

$B_{\mathrm{i}}=2 c_{\mathrm{i} 3} s_{\mathrm{i}, \mathrm{cr}}$.

To evaluate the integral in $I_{\mathrm{dep}}$ in Eq. (43a), we present $r_{\mathrm{c}, \mathrm{ef}}(t$, $t_{0}$ ) in Eq. (57) in the integrand of Eq. (43a) as a sum of three terms

$r_{\mathrm{c}, \mathrm{ef}}\left(t, t_{0}\right)=\frac{r^{2}\left(t, t_{0}\right)}{r\left(t, t_{0}\right)+\xi_{\mathrm{dep}}}=r_{\mathrm{c}, \mathrm{ef}}^{(1)}+r_{\mathrm{c}, \mathrm{ef}}^{(2)}+r_{\mathrm{c}, \mathrm{ef}}^{(3)}$, where

$r_{\mathrm{c}, \mathrm{ef}}^{(1)}\left(t, t_{0}\right)=\left[\left(r_{0}+\xi_{\mathrm{dep}}\right)^{2}+B_{\mathrm{i}}\left(t-t_{0}\right)\right]^{1 / 2}$,

$r_{\mathrm{c}, \mathrm{ef}}^{(2)}\left(t, t_{0}\right)=-2 \xi_{\mathrm{dep}}$

$r_{\mathrm{c}, \mathrm{ef}}^{(3)}\left(t, t_{0}\right)=\xi_{\mathrm{dep}}^{2}\left[\left(r_{0}+\xi_{\mathrm{dep}}\right)^{2}+B_{\mathrm{i}}\left(t-t_{0}\right)\right]^{-1 / 2}$,

Substitution of Eq. (59) with Eqs. (60a)-(60c) into Eq. (43a) for $I_{\mathrm{dep}}$ yields

$I_{\mathrm{dep}}(t)=y_{\mathrm{i}}^{\prime} \frac{4 \pi D_{\mathrm{v}} \rho_{\mathrm{is}}}{\Gamma_{2}} N_{\mathrm{a}} \bar{v}_{\mathrm{a}} J_{\mathrm{f}, \mathrm{hom}}^{(0)} \exp \left(u_{\mathrm{s}} s_{\mathrm{w}, \mathrm{cr}}\right) J_{0 \mathrm{i}}(t)$,

where $J_{0 \mathrm{i}}(t)$ introduced in Eq. (43c) is presented as a sum of the three terms

$J_{0 \mathrm{i}}(t)=\sum_{k=1}^{3} J_{0 \mathrm{i}}^{(k)}=\sum_{k=1}^{3} \int_{0}^{t} r_{\mathrm{c}, \mathrm{ef}}^{(k)}\left(t, t_{0}\right) \exp \left(\beta t_{0}\right) \mathrm{d} t_{0}$.

Substitution of Eqs. (60a)-(60c) into Eq. (62) and evaluation of the integrals $J_{0 \mathrm{i}}(t)$ given in Appendix A yields

$J_{0 \mathrm{i}}(t)=\exp (\beta t) \Psi$

where $\Psi$ is defined by the equations

$\Psi=\Psi_{1}+\Psi_{2}+\Psi_{3}$,

$\Psi_{1}=e^{\lambda} B_{\mathrm{i}}^{1 / 2} \beta^{-3 / 2}\left[\Gamma\left(\frac{3}{2}, \lambda\right)-\Gamma\left(\frac{3}{2}, \lambda+\beta t\right)\right]$,

$\Psi_{2}=2 \xi_{\mathrm{dep}} \beta^{-1}\left(e^{-\beta t}-1\right)$

$\Psi_{3}=e^{\lambda} \xi_{\mathrm{dep}}^{2}\left(\beta B_{\mathrm{i}}\right)^{-1 / 2}\left[\Gamma\left(\frac{1}{2}, \lambda\right)-\Gamma\left(\frac{1}{2}, \lambda+\beta t\right)\right]$

$\lambda=\frac{\beta\left(r_{0}+\xi_{\mathrm{dep}}\right)^{2}}{B_{\mathrm{i}}}=\frac{\left(u_{\mathrm{s}} c_{1 \mathrm{w}} w\right)\left(r_{0}+\xi_{\mathrm{dep}}\right)^{2}}{2 c_{\mathrm{i} 3} s_{\mathrm{i}, \mathrm{cr}}}$.

Here $\Gamma(\alpha, x)$ is the incomplete Euler's gamma function, its properties and asymptotics are defined in Appendix A. Using Eq. (63) for $J_{0 \mathrm{i}}(t)$, and the relation $u_{\mathrm{S}} s_{\mathrm{W}, \mathrm{cr}}+\beta t=s_{\mathrm{W}}(t)$, the deposition term $I_{\text {dep }}$ in Eq. (61) can be written as

$I_{\mathrm{dep}}(t)=y_{\mathrm{i}}^{\prime} \frac{4 \pi D_{\mathrm{v}} \rho_{\mathrm{is}}}{\Gamma_{2}}\left(N_{\mathrm{a}} \bar{v}_{\mathrm{a}} J_{\mathrm{f}, \text { hom }}^{(0)}\right) \exp \left[u_{\mathrm{s}} s_{\mathrm{W}}(t)\right] \Psi$.

Note that the water supersaturation $s_{\mathrm{W}}(t)$ at a time $t$ is present in the exponent. 
The function $\Psi$ defined by Eqs. (64)-(67) can be transformed and reduced to the functions more convenient for calculations. Using the recurrent relation for $\Gamma(3 / 2, x)$ (Gradshteyn and Ryzhik, 1994, see Appendix A)

$\Gamma(\alpha+1, \lambda)=\alpha \Gamma(\alpha, \lambda)+\lambda^{\alpha} e^{-\lambda}$,

and the relation between gamma function and error function $\operatorname{erf}(x)$,

$\Gamma(1 / 2, \lambda)=\sqrt{\pi}[1-\operatorname{erf}(\sqrt{\lambda})]$,

we can transform the gamma function in $\Psi_{1}$ as

$\Gamma\left(\frac{3}{2}, \lambda\right)=\frac{1}{2} \Gamma\left(\frac{1}{2}, \lambda\right)+\lambda^{1 / 2} e^{-\lambda}=\frac{\sqrt{\pi}}{2}[1-\operatorname{erf}(\sqrt{\lambda})]+\lambda^{1 / 2} e^{-\lambda}$.

Substituting this relation into Eqs. (65), (67) we can rewrite $\Psi_{1}$ and $\Psi_{3}$ with use of only $\operatorname{erf}(x)=\Phi(x)$ and without gamma function, which is more convenient for applications

$$
\begin{aligned}
\Psi_{1}= & e^{\lambda} B_{\mathrm{i}}^{1 / 2} \beta^{-3 / 2}\{(\sqrt{\pi} / 2)[\Phi(\sqrt{\lambda+\beta t})-\Phi(\sqrt{\lambda})] \\
& \left.+e^{-\lambda}\left[\lambda^{1 / 2}-(\lambda+\beta t)^{1 / 2} e^{-\beta t}\right]\right\}
\end{aligned}
$$$$
\Psi_{3}=e^{\lambda} \xi_{\text {dep }}^{2}\left(\beta B_{\mathrm{i}}\right)^{-1 / 2} \sqrt{\pi}[\Phi(\sqrt{\lambda+\beta t})-\Phi(\sqrt{\lambda})] .
$$

Then the function $\Psi$ is expressed with use of only $\Phi(x)=$ $\operatorname{erf}(x)$ :

$$
\begin{aligned}
\Psi(t) & =e^{\lambda} \beta^{-1 / 2} \sqrt{\pi}[\Phi(\sqrt{\lambda+\beta t})-\Phi(\sqrt{\lambda})]\left[(1 / 2) B_{\mathrm{i}}^{1 / 2} \beta^{-1}\right. \\
& \left.+\xi_{\mathrm{dep}}^{2} B_{\mathrm{i}}^{-1 / 2}\right]+B_{\mathrm{i}}^{1 / 2} \beta^{-3 / 2}\left[\lambda^{1 / 2}-(\lambda+\beta t)^{1 / 2} e^{-\beta t}\right] \\
& +2 \xi_{\mathrm{dep}} \beta^{-1}\left(e^{-\beta t}-1\right) .
\end{aligned}
$$

This expression can be further simplified by expressing the transcendent function erf $(x)$ via the elementary function tanh following Ghan et al. (1993)

$\operatorname{erf}(x) \approx \tanh [(2 / \sqrt{\pi}) x]$.

Then $\Psi$ becomes:

$$
\begin{aligned}
& \Psi(t)=e^{\lambda} \beta^{-1 / 2} \sqrt{\pi}[\tanh (2 \sqrt{(\lambda+\beta t) / \pi}) \\
& \quad-\tanh (2 \sqrt{\lambda / \pi})]\left[(1 / 2) B_{\mathrm{i}}^{1 / 2} \beta^{-1}+\xi_{\mathrm{dep}}^{2} B_{\mathrm{i}}^{-1 / 2}\right] \\
& +B_{\mathrm{i}}^{1 / 2} \beta^{-3 / 2}\left[\lambda^{1 / 2}-(\lambda+\beta t)^{1 / 2} e^{-\beta t}\right] \\
& +2 \xi_{\mathrm{dep}} \beta^{-1}\left(e^{-\beta t}-1\right) .
\end{aligned}
$$

Now, the deposition integral $I_{\text {dep }}$ in Eq. (69) is expressed only via the elementary functions. Another transition to the elementary functions can be done using equations for $\operatorname{erf}(x)$ given in Ren and MacKenzie (2005, 2007). In the next sections, the solutions of equations for supersaturation and crystal concentration will be expressed via $\Psi$. Although these expressions may look complicated, the analytical representation Eqs. (74), (76) reduce unavoidable errors caused by finite difference representations and numerical calculations and enables the derivation of simple asymptotic limits of $I_{\mathrm{dep}}$ and $N_{\mathrm{c}}$ for the diffusion and kinetic regimes of crystal growth as shown below.

\subsection{Solution of equations for supersaturation and crystal concentration}

Substituting Eq. (69) for $I_{\text {dep }}$ into the integral supersaturation equation Eq. (21), multiplying it by $\left(1+y_{\mathrm{i}}^{\prime}\right)$ and using the relation $\rho_{\mathrm{v}}=\rho_{\mathrm{is}}\left(1+y_{\mathrm{i}}^{\prime}\right)$, yields

$$
\begin{aligned}
\frac{d y_{\mathrm{i}}^{\prime}}{\mathrm{d} t} & =c_{1 \mathrm{i}} w\left(1+y_{\mathrm{i}}^{\prime}\right)-\frac{\Gamma_{2}}{\rho_{\mathrm{is}}} I_{\mathrm{dep}},=c_{1 \mathrm{i}} w\left(1+y_{\mathrm{i}}^{\prime}\right) \\
& -\left(4 \pi D_{\mathrm{v}}\right) y_{\mathrm{i}}^{\prime}\left(N_{\mathrm{a}} \bar{v}_{\mathrm{a}} J_{\mathrm{f}, \text { hom }}^{(0)}\right) \exp \left[u_{\mathrm{s}} s_{\mathrm{W}}(t)\right] \Psi .
\end{aligned}
$$

At $t=t_{\max }$ with maximum supersaturations $s_{\mathrm{i}, \max }$ and $s_{\mathrm{w}, \text { max }}$, the condition $\mathrm{d} s_{\mathrm{i}} / \mathrm{d} t=\mathrm{d} y_{\mathrm{i}}^{\prime} / \mathrm{d} t=0$ is satisfied, thus, the LHS of Eq. (77) is zero, which yields

$\exp \left[u_{\mathrm{s}} s_{\mathrm{W}, \max }\left(t_{\max }\right)\right]$

$=c_{1 \mathrm{i}} w\left(1+s_{\mathrm{i}, \max }\right) s_{\mathrm{i}, \text { max }}^{-1}\left(4 \pi D_{\mathrm{v}}\right)^{-1}\left(N_{\mathrm{a}} \bar{v}_{\mathrm{a}} J_{\mathrm{f}, \text { hom }}^{(0)}\right)^{-1} \Psi^{-1}$.

Now we can rewrite Eq. (33) for $R_{\mathrm{f}, \text { hom }}(t)$ with account for $J_{\text {f,hom }}$ from Eq. (41a) as

$$
\begin{aligned}
& R_{\mathrm{f}, \text { hom }}\left(t_{0}\right) \approx N_{\mathrm{a}} \bar{v}_{\mathrm{a}} J_{\mathrm{f}, \text { hom }}\left(t_{0}\right)=N_{\mathrm{a}} \bar{v}_{\mathrm{a}} J_{\mathrm{f}, \text { hom }}^{(0)} \exp \left[u_{\mathrm{s}} s_{\mathrm{W}}\left(t_{0}\right)\right] \\
& =N_{\mathrm{a}} \bar{v}_{\mathrm{a}} J_{\mathrm{f}, \mathrm{hom}}^{(0)} \exp \left[u_{\mathrm{s}} s_{\mathrm{w}, \mathrm{cr}}+\beta t_{0}\right] .
\end{aligned}
$$

The crystal concentration at the time $t$ is obtained by integrating over $t_{0}$

$$
\begin{aligned}
& N_{\mathrm{cm}}\left(t_{\mathrm{m}}\right)=\int_{t_{\mathrm{cr}, 1}}^{t_{\max }} R_{\mathrm{f}, \text { hom }}\left(t_{0}\right) \mathrm{d} t_{0} \\
& \approx N_{\mathrm{a}} \bar{v}_{\mathrm{a}} J_{f, \text { hom }}^{(0)}(T) \beta^{-1} \exp \left[u_{\mathrm{s}} s_{\mathrm{w}, \max }\left(t_{\mathrm{max}}\right)\right] \\
& \quad \times\left\{1-\exp \left[-\beta\left(t_{\max }-t_{\mathrm{cr}, 1}\right)\right]\right\} \\
& \approx N_{\mathrm{a}} \bar{v}_{\mathrm{a}} J_{f, \text { hom }}^{(0)}(T) \beta^{-1} \exp \left[u_{\mathrm{s}} s_{\mathrm{w}, \text { max }}\left(t_{\max }\right)\right] .
\end{aligned}
$$

The last equation accounts for the fact that $\left(t_{\max }-t_{\mathrm{cr}, 1}\right) \gg$ $\beta^{-1}$ or $\beta\left(t_{\max }-t_{\mathrm{cr}, 1}\right) \gg 1$ according to Eq. (54). Substituting $\exp \left[u_{\mathrm{s}} s_{\mathrm{W}, \max }\left(t_{\max }\right)\right]$ from Eq. (78) and using the approximate equality $s_{\mathrm{i} \text {,max }} \approx s_{\mathrm{i} \text {,cr }}$ due to small variations of $s_{\mathrm{i}}$ during nucleation as discussed above, we obtain finally an analytical parameterization of the concentration of the crystals in homogeneous freezing nucleation:

$$
\begin{aligned}
& N_{\mathrm{c}}\left(t_{\max }\right)=K_{\mathrm{gen}}\left(1+s_{\mathrm{i}, \mathrm{cr}}\right) s_{\mathrm{i}, \mathrm{cr}}^{-1} \Psi^{-1}, \\
& K_{\mathrm{gen}}=\left(4 \pi D_{\mathrm{v}}\right)^{-1} u_{\mathrm{s}}^{-1}\left(c_{1 \mathrm{i}} / c_{1 \mathrm{w}}\right) .
\end{aligned}
$$

Equation (81) gives $N_{\mathrm{c}}$ at time $t_{\max }$ with maximum supersaturation, i.e., at the end of the 1 st stage with growing $s_{\mathrm{i}}$. Some previous parameterizations assumed that $N_{\mathrm{c}}\left(t_{\max }\right)$ at the time $t_{\max }$ of maximum supersaturations is the final crystal concentration. However, as we have seen in Figs. 2, 4, 6, 7 , during the descending branch at $t_{\max }<t<t_{\mathrm{cr}, 2}, s_{\mathrm{w}}(t)$ decreases but still exceeds $s_{\mathrm{w}, \mathrm{cr}}$, therefore nucleation continues after $t_{\max }$ until $t_{\mathrm{cr}, 2}$, and $N_{\mathrm{c}}\left(t_{\max }\right)$ is approximately half the 
total $N_{\mathrm{c}, \text { tot }}\left(t_{\mathrm{cr}, 2}\right)$ after the cease of nucleation at $t>t_{\mathrm{cr}, 2}$. Evaluation of the 2nd stage at $t>t_{\max }$ with decreasing supersaturation in principle can be done in a similar way as for $t<t_{\max }$, although it is somewhat more complicated. To simplify the solution, we can use the solutions for $t=t_{\max }$ and slightly tune them using the results of the parcel model runs. Their detailed analysis shows that the total $N_{\mathrm{c}, \text { tot }}\left(t_{\mathrm{cr}, 2}\right)$ at $t>t_{\mathrm{cr}, 2}$, when nucleation has ceased, is proportional to $N_{\mathrm{c}}\left(t_{\max }\right)$; that is, $N_{\mathrm{c}, \text { tot }}$ can be obtained as

$N_{\mathrm{c}, \text { tot }} \approx K_{\mathrm{cor}} N_{\mathrm{c}}\left(t_{\max }\right)$.

Numerical experiments with the parcel model show that $K_{\text {cor }} \sim 1.8$ to 2.2 (Fig. 7). A more precise fit shows that this coefficient can be chosen as a function of the vertical velocity $w$ as

$K_{\mathrm{cor}}(w)=1.85+(2-1.85)\left(w / w_{\mathrm{sc}}\right)$ at $w<2 \mathrm{~m} \mathrm{~s}^{-1}$,

$K_{\text {cor }}(w)=2.0$, at $w \geq 2 \mathrm{~m} \mathrm{~s}^{-1}$,

and $w_{\mathrm{sc}}=2 \mathrm{~m} \mathrm{~s}^{-1}$. Even a simpler choice of the average is $K_{\text {cor }} \sim 2$, which accounts for about half of the crystals nucleating at decreasing supersaturation at $t_{\max }<t<t_{\mathrm{cr}, 2}$, still gives satisfactory results.

\subsection{Limiting cases}

The important asymptotics can be obtained by analysis of the characteristic parameters of the solution Eqs. (81), (82) with $\Psi$ from Eq. (74). The parameter $\lambda$ in Eq. (68) can be rewritten in the form

$$
\begin{aligned}
& \lambda=\frac{\beta\left(r_{0}+\xi_{\mathrm{dep}}\right)^{2}}{B_{\mathrm{i}}}=\left(\frac{r_{0}+\xi_{\mathrm{dep}}}{\Lambda}\right)^{2}, \\
& \Lambda=\left(\frac{B_{\mathrm{i}}}{\beta}\right)^{1 / 2}=\left(\frac{2 c_{\mathrm{i} 3} s_{\mathrm{i}, \mathrm{cr}}}{u_{\mathrm{s}} c_{1 \mathrm{w}} w}\right)^{1 / 2} .
\end{aligned}
$$

Here $\Lambda$ is a scaling length that characterizes the ratio of the crystal growth rate Eq. (12) to the supersaturation generation rate (the first term on the RHS of Eq. 77). Now we present asymptotics of the solution Eq. (81) at $\lambda \ll 1$ and $\lambda \gg 1$. The values of $\lambda$ and $\Lambda$ and the physical meaning of the asymptotic limits are analyzed below.

\subsubsection{Diffusion growth limit}

The values $\lambda \ll 1$ in Eq. (86) imply small $\xi_{\text {dep }}$ and $r_{0}$, and are typical of the diffusion regime of crystal growth with the deposition coefficient $\alpha_{\mathrm{d}} \sim 1$ or $\alpha_{\mathrm{d}}>0.1$ with not very large $w$ and not very low $T$. In this case, we can neglect in Eq. (74) for $\Psi$ all terms with $\xi_{\text {dep }}$ and $r_{0}$. Note that $\operatorname{erf}\left(\lambda^{1 / 2}\right) \rightarrow 0$ at $\lambda \ll 1 \rightarrow 0$ according to (A29). Using the estimates above, we can assume that $\beta t_{\max } \gg 1$, use the expansion (A27) for $\operatorname{erf}\left[\left(\lambda+\beta t_{\max }\right)^{1 / 2}\right)$ and neglect the terms with $\exp \left(-\beta t_{\max }\right)$. Then $\Psi$ is simplified in this diffusion regime as

$$
\begin{aligned}
\Psi_{\mathrm{dif}} & \approx(\sqrt{\pi} / 2) e^{\lambda} B_{\mathrm{i}}^{1 / 2} \beta^{-3 / 2} \\
& \approx(\pi / 2)^{1 / 2}\left(c_{3 \mathrm{i}} s_{\mathrm{i}, \mathrm{cr}}\right)^{1 / 2} u_{\mathrm{s}}^{-3 / 2}\left(c_{1 \mathrm{w}} w\right)^{-3 / 2} .
\end{aligned}
$$

Substitution of this expression into Eqs. (81), (82) yields

$$
\begin{aligned}
& N_{\mathrm{cm}, \mathrm{dif}}=K_{\mathrm{i}, \mathrm{dif}}\left(1+s_{\mathrm{i}, \mathrm{cr}}\right) s_{\mathrm{i}, \mathrm{cr}}^{-3 / 2}\left(c_{1 \mathrm{i}} w\right)^{3 / 2} \\
& K_{\mathrm{i}, \mathrm{dif}}=\left(2 \pi D_{\mathrm{v}}\right)^{-3 / 2}\left(\frac{\rho_{\mathrm{i}} \Gamma_{2}}{\rho_{\mathrm{is}}}\right)^{1 / 2} u_{\mathrm{s}}^{1 / 2}\left(\frac{c_{1 \mathrm{w}}}{c_{1 \mathrm{i}}}\right)^{1 / 2} \\
& =\frac{1}{\left(2 \pi D_{\mathrm{v}}\right)^{3 / 2}}\left(\frac{\rho_{\mathrm{i}} \Gamma_{2}}{\rho_{\mathrm{is}}}\right)^{1 / 2}\left[\frac{2 R}{k M_{\mathrm{w}} L_{\mathrm{m}}^{\mathrm{ef}}} \frac{\Delta F_{\mathrm{cr}, 0}(T)}{\ln \left(T_{0} / T\right)}\right]^{1 / 2}\left(\frac{c_{1 \mathrm{w}}}{c_{1 \mathrm{i}}}\right)^{1 / 2} .
\end{aligned}
$$

The properties of this solution are discussed below and compared with the other limits.

\subsubsection{Kinetic growth, small and large particles limits}

The limit $\lambda \gg 1$ is seen from Eq. (86) to be associated with the kinetic regime with large $\xi_{\text {dep }}$ (small $\alpha_{\mathrm{d}}$ ) or with large initial particle radius $r_{0}$ of freezing particles. It can be studied using the asymptotic property of $\operatorname{erf}(x)$ at $x \gg 1$ (Appendix A, Eq. A27)

$\operatorname{erf}(\sqrt{\lambda})=1-\frac{1}{\sqrt{\pi}} \lambda^{-1 / 2} e^{-\lambda}\left(1-\frac{1}{2 \lambda}\right)$.

Expanding in Eq. (74) for $\Psi$ the functions $\operatorname{erf}(\sqrt{\lambda})$ and $\operatorname{erf}\left(\sqrt{\lambda+\beta t_{\max }}\right)$ with Eq. (90), neglecting again the terms with $\exp \left(-\beta t_{\max }\right)$ and the terms $\lambda^{-3 / 2}$ compared to $\lambda^{-1 / 2}$, and collecting the terms of the same order, $\Psi$ can be written as

$$
\begin{aligned}
& \Psi_{\text {kin }}=\beta^{-1 / 2} \lambda^{-1 / 2}\left[(1 / 2) B_{\mathrm{i}}^{1 / 2} \beta^{-1}+\xi_{\text {dep }}^{2} B_{\mathrm{i}}^{-1 / 2}\right] \\
& +B_{\mathrm{i}}^{1 / 2} \beta^{-3 / 2} \lambda^{1 / 2}-2 \xi_{\text {dep }} \beta^{-1}=\left(r_{0}+\xi_{\text {dep }}\right)^{-1}\left[(1 / 2) B_{\mathrm{i}} \beta^{-2}\right. \\
& \left.+\xi_{\text {dep }}^{2} \beta^{-1}\right]+\left(r_{0}-\xi_{\text {dep }}\right) \beta^{-1} .
\end{aligned}
$$

This case is divided into 2 subcases: (a) when $\xi_{\text {dep }}$ is large (small deposition coefficient $\alpha_{\mathrm{d}}$ ) but $r_{0}$ is small (small particles limit), that is, $\xi_{\text {dep }} \gg r_{0}$; and (b) when $r_{0}$ is large (large particles limit); that is, $\xi_{\text {dep }} \ll r_{0}$, which may correspond to both diffusion or kinetic regimes. These limits are considered below.

\section{(a) $\lambda \gg 1, \xi_{\text {dep }} \gg r_{0}$, kinetic regime, small particles limit}

With these conditions, $r_{0}$ can be neglected compared to $\xi_{\text {dep }}$, and Eq. (91) for $\Psi$ is simplified

$\Psi_{\text {kin }, \mathrm{s}}=(1 / 2) B_{\mathrm{i}} \beta^{-2} \xi_{\text {dep }}^{-1}=c_{\mathrm{i} 3} S_{\mathrm{i}, \mathrm{cr}} u_{\mathrm{s}}^{-2}\left(c_{1 \mathrm{w}} w\right)^{-2}\left(\alpha_{\mathrm{d}} V_{\mathrm{w}} / 4 D_{\mathrm{v}}\right)$.

Substitution into the general Eq. (81) yields $N_{\mathrm{cm}}=N_{\mathrm{c}}$ at maximum $s_{\mathrm{wm}}$

$$
\begin{aligned}
& N_{\mathrm{cm}, \mathrm{kin}, \mathrm{s}}=K_{\mathrm{i}, \mathrm{kin}, \mathrm{s}}\left(1+s_{\mathrm{i}, \mathrm{cr}}\right) s_{\mathrm{i}, \mathrm{cr}}^{-2}\left(c_{1 \mathrm{w}} w\right)^{2}, \\
& K_{\mathrm{i}, \mathrm{kin}, \mathrm{s}}=\frac{1}{\left(\pi D_{\mathrm{v}}\right)} \frac{u_{\mathrm{s}}}{\alpha_{\mathrm{d}} V_{\mathrm{w}}}\left(\frac{\rho_{\mathrm{i}} \Gamma_{2}}{\rho_{\mathrm{is}}}\right) \frac{c_{1 \mathrm{i}}}{c_{1 \mathrm{w}}} .
\end{aligned}
$$

Thus, in this limit $N_{\mathrm{cm}} \sim w^{2}$, in agreement with Ren and MacKenzie (2005), but all coefficients are expressed now 
without empirical constants and $N_{\mathrm{cm}} \sim \rho_{\text {is }}^{-1}(T)$. Note also that the crystal concentration is inversely proportional to the deposition coefficient, $N_{\mathrm{cm}} \sim \alpha_{\mathrm{d}}^{-1}$; that is, the smaller $\alpha_{\mathrm{d}}$ or the more polluted clouds, the greater nucleated crystal concentration. Gierens et al. (2003) discussed possible reasons for $\alpha_{\mathrm{d}}$ as small as $10^{-3}$; in these cases, the dependence $1 / \alpha_{\mathrm{d}}$ can be significant. This is in agreement with the data from the INCA field experiment (Ovarlez et al., 2002; Ström et al., 2003; Haag et al., 2003; Gayet et al., 2004; Monier et al., 2006) that found greater ice crystal concentrations in cirrus in the more polluted Northern Hemisphere than in the cleaner Southern Hemisphere. This could be caused not only by the heterogeneous ice nucleation mode, but also by a small deposition coefficient in homogeneous nucleation in polluted areas.

\section{(b) Initial $r_{0}$ is large and $r_{0} \gg \xi_{\text {dep }}$, large particles limit}

Neglecting $\xi_{\text {dep }}$ compared to $r_{0}$, Eq. (91) can be further transformed

$$
\begin{aligned}
\Psi_{\text {kin }, 1} & =\frac{1}{2 r_{0}} B_{\mathrm{i}} \beta^{-2}+r_{0} \beta^{-1}=r_{0} \beta^{-1}\left(\frac{B_{\mathrm{i}}}{2 \beta r_{0}^{2}}+1\right) \\
& =r_{0} \beta^{-1}\left[(2 \lambda)^{-1}+1\right] \approx r_{0} \beta^{-1} .
\end{aligned}
$$

The last equality takes into account that $\lambda \gg 1$, so the first term in the parentheses is much smaller than the second and can be neglected. Substituting this $\Psi_{\text {kin,1 }}$ into the general solution Eq. (81), we obtain

$N_{\mathrm{cm}, 1}=\left(4 \pi D_{\mathrm{v}}\right)^{-1}\left(1+s_{\mathrm{i}, \mathrm{cr}}\right) s_{\mathrm{i}, \mathrm{cr}}^{-1} r_{0}^{-1}\left(c_{1 \mathrm{i}} w\right)$.

That is, the dependence on $w$ is linear, $N_{\mathrm{cm}} \sim w$. This linear $w$-dependence is in agreement with predictions in Kärcher and Lohmann (2002a, b) and in Ren and MacKenzie (2005). The term $\rho_{\text {is }}(T)$ is absent; thus the temperature dependence is much weaker than in the previous cases, and is caused by the $T$-dependence of $D_{\mathrm{v}}, c_{1 \mathrm{i}}$, and $s_{\mathrm{i}, \mathrm{cr}}$.

\subsection{Physical interpretation}

Two examples of calculations using this new parameterization are shown in Fig. 9 and Fig. 10. The crystal concentrations $N_{\mathrm{c}}(w)$ calculated in the diffusion approximation with the new Eqs. (87)-(89) and $\alpha_{\mathrm{d}}=1$ (denoted KC2012) for an air parcel ascending with a vertical velocity $w$ is shown in Fig. 9. The applicability of the diffusion approximation is justified by the small $\lambda \sim 10^{-3}$ to 0.03 with $\alpha_{\mathrm{d}}=1$ for all $w$. It is compared with the parameterizations by Sassen and Benson (2000; SB2000, to $w=1 \mathrm{~m} \mathrm{~s}^{-1}$ ), Liu and Penner (2005; LP2005), Kärcher and Lohmann (2002; KL2002). Also shown here are the results of several parcel model simulations from Lin et al. (2002) according to the protocols of CPMCP for the three values of $w=4,20$ and $100 \mathrm{~cm} \mathrm{~s}^{-1}$. Simulations were performed by Cotton, DeMott, Jensen, Kärcher, Lin, Sassen, and Liu as indicated in Fig. 9 (the models are described in Spice et al., 1999; DeMott et al., 1994; Jensen et al., 1994; Kärcher and Lohmann, 2002a, b; Lin, 1997; Sassen and Dodd, 1988, and Khvorostyanov and Sassen, 1998a; Liu and Penner, 2005); the results of parcel simulations from Khvorostyanov and Curry (2005) are added (KC2005). This figure shows that the new parameterization KC2012 lies within the spread of the parcel models results, being closer to the lower limit, and to the parcel simulations by Jensen who used a model with spectral microphysics and explicit supersaturation (Jensen et al., 1994). KC2012 is in qualitative agreement with Sassen and Benson (2000) at small $w$ and is especially close to the parameterization by Kärcher and Lohmann (2002a, b), although it was based on a substantially different approach. This supports the validity of the new parameterization based on an extension of the classical nucleation theory and shows that semi-empirical approaches lead to results that can be derived from the extended classical nucleation theory.

Figure 10 shows a comparison of the full solution Eqs. (81)-(85) with the diffusion limit Eqs. (87)-(89) at $\alpha_{\mathrm{d}}=$ 1 and the kinetic limit Eqs. (92)-(94) at $\alpha_{\mathrm{d}}=0.04,0.01$ and 0.001 . The diffusion approximation (solid circles) is valid at $\lambda \ll 1$, and limited at $w \leq 170 \mathrm{~cm} \mathrm{~s}^{-1}$; the kinetic limit is valid at $\lambda \gg 1$ and with $\alpha_{\mathrm{d}}=0.04$ is limited at $w>30 \mathrm{~cm} \mathrm{~s}^{-1}$. This figure illustrates good accuracy of the two approximations for corresponding values $\lambda$ and underscores the important role of the deposition coefficient. With small $\alpha_{\mathrm{d}}$, such as in polluted clouds, the crystal concentrations are substantially higher than with $\alpha_{\mathrm{d}}=1$ for clean clouds. So, polluted crystalline clouds should have a substantially greater albedo effect and this parameterization provides a quantitative tool for its estimation.

\section{Conclusions}

A new analytical parameterization of the homogeneous freezing suitable for cloud and climate models is derived from the extended classical nucleation theory and analytical solutions to the supersaturation equation. This parameterization includes the time dependence and can be used both for calculations of the crystal concentrations in cloud models with small time steps (e.g., Jensen et al., 1994; Khvorostyanov and Sassen, 1998b, 2002; Spice et al., 1999; Lin et al. 2002; Sassen et al., 2002; Khvorostyanov et al., 2001, 2003, 2006; Randall et al., 2003; Khairoutdinov and Randall, 2003; Fridlind et al., 2004; Krakovskaia and Pirnach, 2004; Khain et al., 2004; Morrison et al., 2005; Seifert and Beheng, 2006; Monier et al., 2006; Grabowski and Morrison, 2008; Klein et al., 2009; Xue et al., 2010; Fan et al., 2011; Curry and Khvorostyanov, 2012; Tao et al., 2012) and for substep parameterizations in the mesoscale models (e.g., Zhang et al., 2011; Veltishchev et al., 2011) and in the largescale climate models and GCMs with time steps that can be greater than the nucleation time $\tau_{\text {nuc }}$ (e.g., Lohmann and 

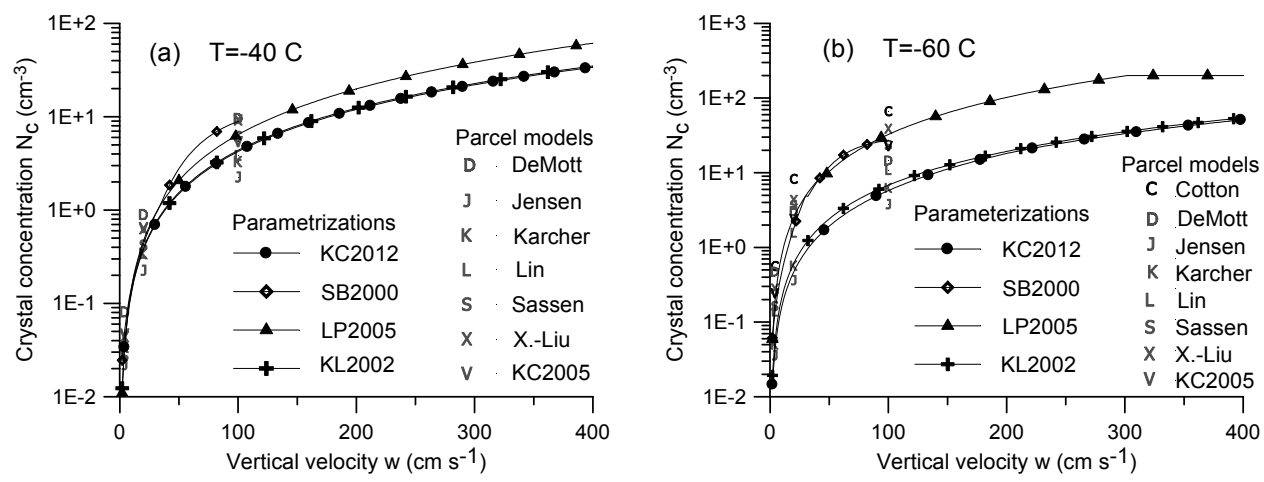

Fig. 9. Comparison of the new parameterization (87), (89) of the crystal concentration $N_{\mathrm{c}}(w)$ as a function of $w$ (KC2012) with the parameterizations by Sassen and Benson (2000, SB2000, limited to $w=100 \mathrm{~cm} \mathrm{~s}^{-1}$ ), Liu and Penner (2005, LP2005), Kärcher and Lohmann (2002, KL02), and with parcel model simulations from Lin et al. (2002) (Cotton, DeMott, Jensen, Kärcher, Lin, Sassen, Liu, as indicated in the legend) and from Khvorostyanov and Curry, 2005 (KC2005) for the three values of $w=4,20$ and $100 \mathrm{~cm} \mathrm{~s}^{-1}$.

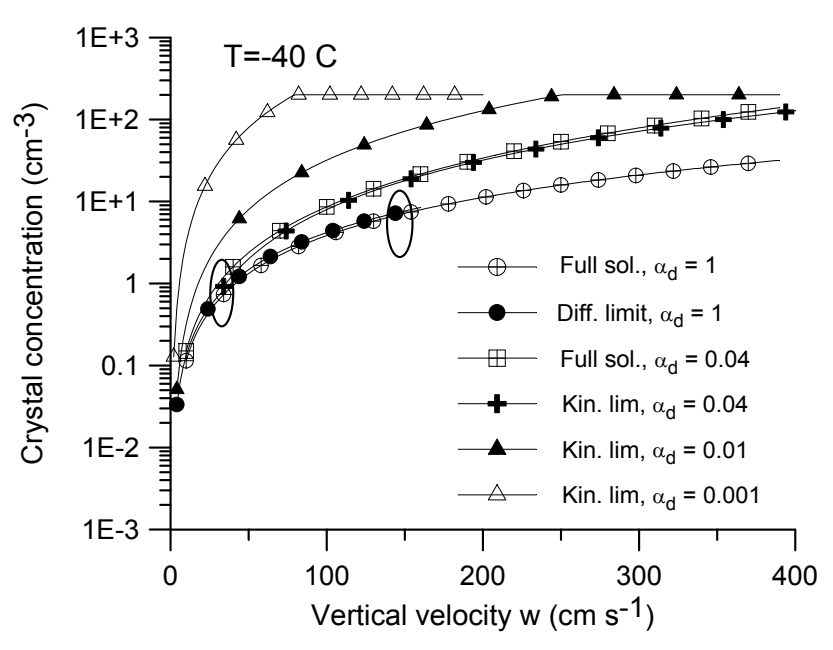

Fig. 10. Comparison of the full solution (81), (82) with $\Psi$ defined in (74) at two values of $\alpha_{\mathrm{d}}=1$ and 0.04 (Full sol.) with diffusion limit (87)-(89) and kinetic limit (92)-(94). The diffusion approximation (solid circles) is valid at $\lambda \ll 1$, and limited here at $w \leq 170 \mathrm{~cm} \mathrm{~s}^{-1}$; the kinetic limit is valid at $\lambda \gg 1$ and with $\alpha_{\mathrm{d}}=0.04$ is limited here at $w>30 \mathrm{~cm} \mathrm{~s}^{-1}$; both limits are denoted with ellipses.

Kärcher, 2002; Morrison and Gettelman, 2008; Gettelman et al., 2008; Sud et al., 2009).

We identify three different regimes of crystal homogeneous nucleation in cold clouds, depending on the cooling time of an air parcel. At small times, $t \ll \tau_{\text {nuc }}(\sim 40 \mathrm{~s})$, the crystal concentrations increase linearly with time and proportional to the concentration of the freezing haze particles $N_{\mathrm{a}}$. At larger times, $t \gg \tau_{\text {nuc }}$, but smaller than the time $t_{\max }$ of maximum supersaturation in the parcel, $N_{\mathrm{c}}$ increases exponentially with time. Crystal concentrations in these two regimes are proportional to the homogeneous nucleation rate and concentration of the aerosol particles. If uplift of an isolated parcel continues so that $t>t_{\max }$ and $t>t_{\mathrm{cr} 2}$, the super- saturation reaches and passes a maximum and falls below the threshold value, then a third regime occurs that can be called limiting regime. The dependence on the nucleation rate and haze concentration vanishes in this regime, although concentration of nucleated crystals is much smaller than the concentration of haze particles.

Expressions for the crystal concentration $N_{\mathrm{c}}$ in the third limiting regime are very simple, and somewhat surprising. They do not include most of the basic factors present in the original supersaturation equation: neither nucleation rate $J_{\text {hom }}\left(T, s_{\mathrm{w}}\right)$ nor concentration $N_{\mathrm{a}}$ of the haze particle, nor any characteristics of volume or size spectra or chemical composition. The reason why $N_{\mathrm{c}}$ does not depend on $N_{\mathrm{a}}$ can be explained by the fact that $N_{\mathrm{c}}$ is usually on the order of a few or a few tens per liter (rarely, a few hundred), while $N_{\mathrm{a}}$ is typically on the order of a few hundred per cubic centimeter. That is, only very small fraction of haze particles freezes, and the dependence of $N_{\mathrm{c}}$ on $N_{\mathrm{a}}$ vanishes at values of $N_{\mathrm{a}}$ much smaller than those available in the upper troposphere studied here. However, if $N_{\mathrm{a}}$ is small, $N_{\mathrm{c}}$ is limited by $N_{\mathrm{a}}$.

The major factors that govern homogeneous ice nucleation in the third limiting regime are the vertical velocity, $w$, the temperature, $T$, and the critical (threshold) saturation ratio $s_{\mathrm{i}, \mathrm{cr}}$. The equations for $N_{\mathrm{c}}$ derived here show that to first approximation in the diffusion limit, $N_{\mathrm{c}} \sim w^{3 / 2}$, and $N_{\mathrm{c}} \sim$ $\rho_{s i}^{-1 / 2}(T)$, both dependencies are the same as in Kärcher and Lohmann (2002a, b) and in Ren and MacKenzie (2005) in the diffusion growth limit. However, the actual dependence of $N_{\mathrm{c}}$ on $w$ and $T$ is more complicated and somewhat different since $s_{\mathrm{i}, \mathrm{cr}}^{-3 / 2}$ also includes dependence on $w$ and $T$, and the critical supersaturation $s_{\mathrm{i}, \mathrm{cr}}$ also depends on $T$ and substantially grows toward low $T$; the coefficient $K_{\mathrm{i} \text {,dif }}$ depends on $T$ also via factors $D_{\mathrm{v}}, c_{1 \mathrm{w}}, c_{1 \mathrm{i}}, u_{\mathrm{s}}$. In the kinetic growth or large particle limits, $N_{\mathrm{c}}$ can be proportional to $w^{2}$ or to $w$, depending on the initial particle radius, in agreement with the previous semi-empirical parameterizations. 
The nucleation rate derived here varies exponentially with time, and this dependence is characterized by some scaling nucleation time $\tau_{\text {nuc }}$ as in Ford (1998a, b), Kärcher and Lohmann (2002a, b), and Ren and MacKenzie (2005). The time $\tau_{\text {nuc }}$ is expressed here directly via the parameters of CNT and fundamental physical constants.

The accuracy of the parameterization equations for $N_{\mathrm{c}}$ was estimated by comparison with data on $N_{\mathrm{c}}$ from the International Cirrus Parcel Model Comparison Project (CPMCP) (Lin et al., 2002) and parcel simulation results. The average error of this parameterization relative to the parcel runs described here is about $\pm 5-15 \%$. This is a satisfactory accuracy, considering that the difference in $N_{\mathrm{c}}$ among various models in CPMCP was much greater.

\section{Appendix A}

\section{Evaluation of the integrals}

$J_{0 \mathrm{i}}^{(k)}=\int_{0}^{t} r_{\mathrm{c}, \mathrm{ef}}^{(k)}\left(t, t_{0}\right) \exp \left(\beta t_{0}\right) \mathrm{d} t_{0}$

These integrals are defined in Eq. (62) with $\beta$ in Eq. (51), $B_{\mathrm{i}}$ in Eq. (58) and $r_{\mathrm{c}, \mathrm{ef}}^{(k)}\left(t, t_{0}\right)$ defined in Eqs. $(60 \mathrm{a}, \mathrm{b}, \mathrm{c})$

$\beta=u_{\mathrm{s}} c_{1 \mathrm{w}} w, B_{\mathrm{i}}=2 c_{\mathrm{i} 3} s_{\mathrm{i}, \mathrm{cr}}$,

$r_{\mathrm{c}, \mathrm{ef}}^{(1)}\left(t, t_{0}\right)=\left[\left(r_{0}+\xi_{\text {dep }}\right)^{2}+B_{\mathrm{i}}\left(t-t_{0}\right)\right]^{1 / 2}$,

$r_{\mathrm{c}, \mathrm{ef}}^{(2)}\left(t, t_{0}\right)=-2 \xi_{\mathrm{dep}}$,

$r_{\mathrm{c}, \mathrm{ef}}^{(3)}\left(t, t_{0}\right)=\xi_{\mathrm{dep}}^{2}\left[\left(r_{0}+\xi_{\mathrm{dep}}\right)^{2}+B_{\mathrm{i}}\left(t-t_{0}\right)\right]^{-1 / 2}$.

The first of these integrals is

$$
\begin{aligned}
J_{0 \mathrm{i}}^{(1)} & =\int_{0}^{t} r_{\mathrm{c}, \mathrm{ef}}^{(1)}\left(t, t_{0}\right) \exp \left(\beta t_{0}\right) \mathrm{d} t_{0} \\
& =\int_{0}^{t}\left[\left(r_{0}+\xi_{\mathrm{dep}}\right)^{2}+B_{\mathrm{i}}\left(t-t_{0}\right)\right]^{1 / 2} \exp \left(\beta t_{0}\right) \mathrm{d} t_{0},
\end{aligned}
$$

Introducing a new variable $x=t_{0} / t$, it is transformed

$J_{0 \mathrm{i}}^{(1)}=B_{\mathrm{i}}^{1 / 2} t^{3 / 2} \int_{0}^{1}(1-x+a)^{1 / 2} \exp (\beta t x) \mathrm{d} x$,

$a=\frac{\left(\xi_{\mathrm{dep}}+r_{0}\right)^{2}}{B_{\mathrm{i}} t}$.

Introducing now a new variable, $z=1-x$, this integral transforms into

$J_{0 \mathrm{i}}^{(1)}=B_{\mathrm{i}}^{1 / 2} t^{3 / 2} e^{\beta t} J_{1 \mathrm{i}}^{(1)}, \quad J_{1 \mathrm{i}}^{(1)}=\int_{0}^{1}(z+a)^{1 / 2} \exp (-\beta t z) \mathrm{d} z .(A 7)$
The next change of the variable, $z^{\prime}=z+a$, yields

$J_{1 \mathrm{i}}^{(1)}=e^{\lambda} \int_{a}^{1+a} z^{\prime 1 / 2} \exp \left[-\beta t z^{\prime}\right] \mathrm{d} z^{\prime}$,

and $\lambda$ does not depend on $t$

$\lambda=a \beta t=\frac{\left(\xi_{\mathrm{dep}}+r_{0}\right)^{2} \beta}{B_{\mathrm{i}}}=\frac{\left(u_{\mathrm{s}} c_{1 \mathrm{w}} w\right)\left(\xi_{\mathrm{dep}}+r_{0}\right)^{2}}{2 c_{\mathrm{i} 3} s_{\mathrm{i}, \mathrm{cr}}}$.

We introduce a new variable $x^{\prime}=\beta t z^{\prime}$. The limits $z^{\prime}=a$ and $z^{\prime}=(1+a)$ transform into $x^{\prime}=a \beta t=\lambda$ and $x^{\prime}=\beta t(1+$ $a)=\lambda+\beta t$. Then we have

$J_{1 \mathrm{i}}^{(1)}$

$$
\begin{aligned}
& =\frac{\exp (\lambda)}{(\beta t)^{3 / 2}}\left[\int_{\lambda}^{\infty} x^{\prime 1 / 2} \exp \left(-x^{\prime}\right) \mathrm{d} x^{\prime}+\int_{\infty}^{\lambda+\beta t} x^{\prime 1 / 2} \exp \left(-x^{\prime}\right) \mathrm{d} x^{\prime}\right], \\
& =\frac{\exp (\lambda)}{(\beta t)^{3 / 2}}\left[\Gamma\left(\frac{3}{2}, \lambda\right)-\Gamma\left(\frac{3}{2}, \lambda+\beta t\right)\right]
\end{aligned}
$$

Here $\Gamma(\mu, \lambda)$ is the incomplete Euler's gamma function (Gradshteyn and Ryzhik, 1994)

$\Gamma(\mu, \lambda)=\int_{\lambda}^{\infty} x^{\mu-1} \exp (-x) \mathrm{d} x$.

Substitution of Eqs. (A10a) into (A7) yields

$J_{0 \mathrm{i}}^{(1)}=e^{\beta t} B_{\mathrm{i}}^{1 / 2} \beta^{-3 / 2} e^{\lambda}\left[\Gamma\left(\frac{3}{2}, \lambda\right)-\Gamma\left(\frac{3}{2}, \lambda+\beta t\right)\right]$.

Calculation of the second integral $J_{0 \mathrm{i}}^{(2)}$ is much easier:

$$
\begin{aligned}
J_{0 \mathrm{i}}^{(2)} & =\int_{0}^{t} r_{\mathrm{c}, \text { ef }}^{(2)}\left(t, t_{0}\right) \exp \left(\beta t_{0}\right) \mathrm{d} t_{0}=-2 \xi_{\mathrm{dep}} \int_{0}^{t} \exp \left(\beta t_{0}\right) \mathrm{d} t_{0} \\
& =-2 \xi_{\mathrm{dep}} \beta^{-1}\left[e^{\beta t}-1\right]=e^{\beta t} 2 \xi_{\mathrm{dep}} \beta^{-1}\left[e^{-\beta t}-1\right] .
\end{aligned}
$$

The third integral is

$$
\begin{aligned}
J_{0 \mathrm{i}}^{(3)} & =\int_{0}^{t} r_{\mathrm{c}, \mathrm{ef}}^{(3)}\left(t, t_{0}\right) \exp \left(\beta t_{0}\right) \mathrm{d} t_{0} \\
& =\xi_{\text {dep }}^{2} \int_{0}^{t} \frac{\exp \left(\beta t_{0}\right)}{\left[B_{\mathrm{i}}\left(t-t_{0}\right)+\left(r_{0}+\xi_{\mathrm{dep}}\right)^{2}\right]^{1 / 2}} \mathrm{~d} t_{0} .
\end{aligned}
$$

Similar to evaluation of the first integral, introducing a new variable $x=t_{0} / t$, and then $z=1-x$, this integral is reduced to

$$
J_{0 \mathrm{i}}^{(3)}=\frac{\xi_{\mathrm{dep}}^{2} t^{1 / 2} e^{\beta t}}{B_{\mathrm{i}}^{1 / 2}} J_{1 \mathrm{i}}^{(3)}, \quad J_{1 \mathrm{i}}^{(3)}=\int_{0}^{1} \frac{\exp (-\beta t z)}{(z+a)^{1 / 2}} d \mathrm{z},
$$


where $a$ is the same as in Eq. (A6b). Introducing now a new variable $z^{\prime}=\beta t z$, we obtain

$J_{1 \mathrm{i}}^{(3)}=(\beta t)^{-1 / 2} J_{2 \mathrm{i}}^{(3)}, \quad J_{2 \mathrm{i}}^{(3)}=\int_{0}^{\beta t} \frac{\exp \left(-z^{\prime}\right)}{\left(z^{\prime}+\lambda\right)^{1 / 2}} \mathrm{~d} z^{\prime}$

The integral $J_{2 \mathrm{i}}^{(3)}$ here is similar to Eq. (A7). Substituting here $x=z^{\prime}+\lambda$, and accounting for the change of the limits $(0, \beta t)$ to $(\lambda, \lambda+\beta t)$ yields

$$
\begin{aligned}
J_{2 \mathrm{i}}^{(3)} & =e^{\lambda} \int_{\lambda}^{\lambda+\beta t} x^{-1 / 2} e^{-x} \mathrm{~d} x \\
& =e^{\lambda}\left[\int_{\lambda}^{\infty} x^{-1 / 2} e^{-x} \mathrm{~d} x+\int_{\infty}^{\lambda+\beta t} x^{-1 / 2} e^{-x} \mathrm{~d} x\right] \\
& =e^{\lambda}\left[\Gamma\left(\frac{1}{2}, \lambda\right)-\Gamma\left(\frac{1}{2}, \lambda+\beta t\right)\right],
\end{aligned}
$$

where $\Gamma(\alpha, x)$ is again the incomplete gamma function. Substituting Eq. (A16) into Eq. (A15) and into Eq. (A14), we obtain

$J_{0 \mathrm{i}}^{(3)}=e^{\beta t} \xi_{\mathrm{dep}}^{2}\left(\beta B_{\mathrm{i}}\right)^{-1 / 2} e^{\lambda}\left[\Gamma\left(\frac{1}{2}, \lambda\right)-\Gamma\left(\frac{1}{2}, \lambda+\beta t\right)\right]$.

It is more convenient in many cases to use the error function $\Phi(x)=\operatorname{erf}(x)$ defined as

$\operatorname{erf}(x) \equiv \Phi(x)=\frac{2}{\sqrt{\pi}} \int_{0}^{x} e^{-x^{\prime 2}} \mathrm{~d} x^{\prime}$

instead of incomplete gamma functions, for which coding and finding asymptotics can be easier. This can be done using the relations (Gradshteyn and Ryzhik, 1994, Chapter 8, Eqs. 8.359 and 8.356)

$\Gamma(1 / 2, \lambda)=\sqrt{\pi}[1-\operatorname{erf}(\sqrt{\lambda})]$,

$\Gamma(\alpha+1, \lambda)=\alpha \Gamma(\alpha, \lambda)+\lambda^{\alpha} e^{-\lambda}$.

Using these two relations, the $\Gamma(3 / 2, \lambda)$ can be transformed as

$$
\begin{aligned}
\Gamma\left(\frac{3}{2}, \lambda\right) & =\frac{1}{2} \Gamma\left(\frac{1}{2}, \lambda\right)+\lambda^{1 / 2} e^{-\lambda} \\
& =\frac{\sqrt{\pi}}{2}[1-\operatorname{erf}(\sqrt{\lambda})]+\lambda^{1 / 2} e^{-\lambda} .
\end{aligned}
$$

Collecting all three integrals $J_{0 \mathrm{i}}^{(k)}$ yields

$J_{0 \mathrm{i}}=\sum_{k}^{3} J_{0 \mathrm{i}}^{(k)}=e^{\beta t} \Psi, \quad \Psi=\Psi_{1}+\Psi_{2}+\Psi_{3}$,

$$
\begin{aligned}
\Psi_{1} & =e^{\lambda} B_{\mathrm{i}}^{1 / 2} \beta^{-3 / 2}\left[\Gamma\left(\frac{3}{2}, \lambda\right)-\Gamma\left(\frac{3}{2}, \lambda+\beta t\right)\right] \\
& =e^{\lambda} B_{\mathrm{i}}^{1 / 2} \beta^{-3 / 2}\{(\sqrt{\pi} / 2)[\Phi(\sqrt{\lambda+\beta t})-\Phi(\sqrt{\lambda})]
\end{aligned}
$$

$\left.+e^{-\lambda}\left[\lambda^{1 / 2}-(\lambda+\beta t)^{1 / 2} e^{-\beta t)}\right]\right\}$.

$\Psi_{2}=2 \xi_{\mathrm{dep}} \beta^{-1}\left(e^{-\beta t}-1\right)$

$\Psi_{3}=e^{\lambda} \xi_{\mathrm{dep}}^{2}\left(\beta B_{\mathrm{i}}\right)^{-1 / 2}\left[\Gamma\left(\frac{1}{2}, \lambda\right)-\Gamma\left(\frac{1}{2}, \lambda+\beta t\right)\right]$

$=e^{\lambda} \xi_{\text {dep }}^{2}\left(\beta B_{\mathrm{i}}\right)^{-1 / 2} \sqrt{\pi}[\Phi(\sqrt{\lambda+\beta t})-\Phi(\sqrt{\lambda})]$.

These expressions are used in Sect. 3 for evaluation of the deposition integral $J_{\text {dep }}$ in the parameterization of homogeneous nucleation.

The asymptotic expansion of $\Phi(\sqrt{\lambda})$ at large $\lambda \gg 1$ with account for the first three terms is (Gradshteyn and Ryzhik, 1994, Eq. 8.254)

$\Phi(\sqrt{\lambda})=\operatorname{erf}(\sqrt{\lambda})=1-\frac{1}{\sqrt{\pi}} \lambda^{-1 / 2} e^{-\lambda}\left(1-\frac{1}{2 \lambda}+\frac{3}{4 \lambda^{2}}\right)$.

It follows from this equation and Eq. (A.17a) that

$\lim _{x \rightarrow \infty} \Phi(x)=1, \quad \int_{0}^{\infty} e^{-x^{\prime 2}} \mathrm{~d} x^{\prime}=\frac{\sqrt{\pi}}{2}$.

The other limit at small argument $x \ll 1$ with account for only the first term is (Gradshteyn and Ryzhik, 1994, Eq. 8.253)

$\lim _{x \rightarrow 0} \Phi(x)=\frac{2}{\sqrt{\pi}} x \exp \left(-x^{2}\right)$.

The incomplete gamma function is related to the gamma function as

$\Gamma(\mu, \infty)=\Gamma(\mu)$.

The last function has the property

$\Gamma(1 / 2)=\sqrt{\pi}$.

These asymptotic properties of $\Phi(x)$ and $\Gamma(\mu)$ are used in Sect. 3 for evaluation of the asymptotic behavior of the solutions to the supersaturation equations and parameterizations of homogeneous ice nucleation processes. 
Acknowledgements. This work was partially supported at the early stage by the Department of Energy Atmospheric Radiation Measurement Program and NASA Modeling and Parameterization Program. The authors are grateful to Olaf Hellmuth for careful reviewing the manuscript, his huge work with verification of the equations and corrections of misprints, and for useful discussions of the nucleation problems and remarks that allowed to improve the paper. Ben Murray and Thomas Koop are thanked for the useful remarks that allowed to clarify the discussion. The authors are grateful to Svenja Lange and Anja Krzykowski for careful typesetting and correction of the manuscript.

Edited by: M. Krämer

\section{References}

Barahona, D. and Nenes, A.: Parameterization of cirrus cloud formation in large-scale models: Homogeneous nucleation, J. Geophys. Res., 113, D11211, doi:10.1029/2007JD009355, 2008.

Bertram, A. K., Koop, T., Molina, L. T., and Molina, M. J.: Ice formation in $\left(\mathrm{NH}_{4}\right)_{2} \mathrm{SO}_{4}-\mathrm{H}_{2} \mathrm{O}$ particles, J. Phys. Chem. A, 104, 584-588, 2000.

Chen Y., DeMott, P. J., Kreidenweis, S. M., Rogers, D. C., and Sherman, E.: Ice formation by sulfate and sulfur acid aerosols under upper-tropospheric conditions, J. Atmos. Sci., 57, 3752-3766, 2000.

Clegg, S. I., Brimblecombe, P., and Wexler, A. S.: A thermodynamic model of the system $\mathrm{H}^{+}-\mathrm{NH}_{4}^{+}-\mathrm{SO}_{4}^{2-}-\mathrm{NO}^{3-}-\mathrm{H}_{2} \mathrm{O}$ at tropospheric temperatures, J. Phys. Chem., 102, 2137-2154, 1998.

Curry, J. A. and Khvorostyanov, V. I.: Assessment of some parameterizations of heterogeneous ice nucleation in cloud and climate models, Atmos. Chem. Phys., 12, 1151-1172, doi:10.5194/acp12-1151-2012, 2012.

Defay, R., Prigogine, I., and Bellemans, A.: Surface Tension and Absorption, 432 pp., Wiley, New York, 1966.

DeMott, P. J.: Laboratory studies of cirrus cloud processes, in: “Cirrus", edited by: Lynch, D., Sassen, K., Starr, D. O'C., and Stephens, G., Oxford University Press, New York, 102-135, 2002.

DeMott, P. J., Meyers, M. P., and Cotton, W. R.: Parameterization and impact of ice initiation processes relevant to numerical model simulation of cirrus clouds, J. Atmos. Sci., 51, 77-90, 1994.

Dufour, L. and Defay, R.: Thermodynamics of Clouds, 255 pp., Academic Press, New York, 1963.

Eadie, W. J.: A molecular theory of the homogeneous nucleation of ice from supercooled water, PhD Dissertation, University of Chicago, Cloud Physics Lab, Tech. Note 40, 117 pp., 1971.

Fan, J., Ghan, S., Ovchinnikov, M., Liu, X., Rasch, P. J., and Korolev, A.: Representation of Arctic mixed-phase clouds and the Wegener-Bergeron-Findeisen process in climate models: Perspectives from a cloud-resolving study, J. Geophys. Res., 116, D00T07, doi:10.1029/2010JD015375, 2011.

Feistel, R.: TEOS-10: A new international oceanographic standard for seawater, ice, fluid water and humid air, International Journal of Thermophysics, doi:10.1007/s10765-010-0901-y, 2012.

Feistel, R. and Wagner, W.: A new equation of state for $\mathrm{H}_{2} \mathrm{O}$ ice Ih, J. Phys. Chem. Ref. Data, 35, 1021-1047, doi:10.1063/1.2183324, 2006.
Ford, I. J: How aircraft nucleate ice particles: A simple model, J. Aerosol Sci., 29, S1117, doi:10.1016/S0021-8502(98)90741-8, 1998a.

Ford, I. J.: Ice nucleation in jet aircraft exhaust plumes, in: Air Pollution Research Report 68: Pollution from aircraft emissions in the North Atlantic flight corridor (POLINAT2), edited by: Schumann, U., Report EUR 18877, European Commission, 1998, 269-287, 1998b.

Frenkel, Ya. I.: Kinetic Theory of Liquids, Oxford University Press, 592 pp., 1946.

Fridlind, A., Ackerman, A. S., Jensen, E. J., Heymsfield, A. J., Poellot, M. R., Stevens, D. E., Wang, D., Miloshevich, L. M., Baumgardner, D., Lawson, R. P., Wilson, J. C., Flagan, R. C., Seinfeld, J. H., Jonsson, H. H., VanReken, T. M., Varutbangkul, V., and Rissman, T. A.: Evidence for the predominance of midtropospheric aerosols as subtropical anvil cloud nuclei, Science, 304, 718-722, 2004.

Fuchs, N. A.: Evaporation and Droplet Growth in Gaseous Media, Pergamon Press, 242 pp., 1959.

Gayet, J.-F., Ovarlez, J., Shcherbakov, V., Ström, J., Schumann, U., Minikin, A., Auriol, F., Petzold, A., and Monier, M.: Cirrus cloud microphysical and optical properties at southern and northern midlatitudes during the INCA experiment, J. Geophys. Res., 109, D20206, doi:10.1029/2004JD004803, 2004.

Gettelman, A., Liu, X., Ghan, S. J., Morrison, H., Park, S., and Conley, A. J.: Global simulations of ice nucleation and ice supersaturation with an improved cloud scheme in the Community Atmosphere Model, J. Geophys. Res., 115, D18216, doi:10.1029/2009JD013797, 2010.

Ghan, S., Chuang, C., and Penner, J.: A parameterization of cloud droplet nucleation. Part 1, Single aerosol species, Atmos. Res., 30, 197-222, 1993.

Ghan, S. J., Abdul-Razzak, H., Nenes, A., Ming, Y., Liu, X., Ovchinnikov, M., Shipway, B., Meskhidze, N., Xu, J., and Shi, $\mathrm{X}$.: Droplet nucleation: Physically-based parameterizations and comparative evaluation, J. Adv. Model. Earth Syst., 3, M10001, doi:10.1029/2011MS000074, 2011.

Gierens, K. M., Monier, M., and Gayet, J.-F.: The deposition coefficient and its role for cirrus clouds, J. Geophys. Res., 108, 4069, doi:10.1029/2001JD001558, 2003.

Grabowski, W. W. and Morrison, H.: Toward the mitigation of spurious cloud-edge supersaturation in cloud models, Mon. Weather Rev., 136, 1224-1234, doi:10.1175/2007MWR2283.1, 2008.

Gradshteyn, I. S. and Ryzhik, I. M.: Table of Integrals, Series, and Products, Fifth Ed., Academic, San Diego, Calif., 1204 pp., 1994.

Haag, W., Kärcher, B., Ström, J., Minikin, A., Lohmann, U., Ovarlez, J., and Stohl, A.: Freezing thresholds and cirrus cloud formation mechanisms inferred from in situ measurements of relative humidity, Atmos. Chem. Phys., 3, 1791-1806, doi:10.5194/acp3-1791-2003, 2003.

Hellmuth, O., Khvorostyanov, V. I., Curry, J. A., Shchekin, A. K., Schmelzer, J. W. P., and. Baidakov, V. G: Review on the Phenomenology and Mechanism of Atmospheric Ice Formation: Selected Questions of Interest, in: Nucleation Theory and Applications, edited by: Schmelzer, J. W. P., Röpke, G., and Priezzhev, V. B., Joint Institute for Nuclear Research, Bogoliubov Laboratory of Theoretical Physics, Dubna, ISBN 978-5-9530-0301-8, 2012a. 
Hellmuth, O., Khvorostyanov, V. I., Curry, J. A., Shchekin, A. K., Schmelzer, J. W. P., Feistel, R., Djikaev, Y. S., and Baidakov, V. G.: Theoretical Aspects of Atmospheric Ice Formation, in: Nucleation Theory and Applications, edited by: Schmelzer, J. W. P., Special Issues. Review Series on Selected Topics of Atmospheric Sol Formation, Vol. 5, Joint Institute for Nuclear Research, Bogoliubov Laboratory of Theoretical Physics, Dubna, 548 pp., 2012 b.

Heymsfield, A. J. and Miloshevich, L. M.: Homogeneous ice nucleation and supercooled liquid water in orographic wave clouds, J. Atmos. Sci., 50, 2335-2353, 1993.

Heymsfield, A. J. and Miloshevich, L. M.: Relative humidity and temperature influences on cirrus formation and evolution: Observations from wave clouds and FIRE II, J. Atmos. Sci., 52, 43024326, 1995.

Holten, V., Bertrand, C. E., Anisimov, M. A., and Sengers, J. V.: Thermodynamic modeling of supercooled water. Technical report for the International Association for the Properties of Water and Steam (IAPWS) (September 2011), Tech. rep., Institute for Physical Science and Technology and Department of Chemical and Biomolecular Engineering, University of Maryland, College Park, Maryland 20742, USA, 2011.

Holten, V., Bertrand, C. E., Anisimov, M. A., and Sengers, J. V.: Thermodynamics of supercooled water, J. Chem. Phys., 136, 094507, doi:10.1063/1.3690497, 2012.

IAPWS: Guideline on a Low-Temperature Extension of the IAPWS-95 Formulation for Water Vapor, Tech. rep., The International Association for the Properties of Water and Steam, Boulder, Colorado, USA, September/October 2012, 2012.

Ice Physics and the Natural Environment, Proc. NATO Advanced Research Workshop, v. 56, edited by: Wettlaufer, J. S., Dash, J. G., and Untersteiner, N., Springer, Berlin, 356 pp., 1999.

IOC, SCOR and IAPSO: The International Thermodynamic Equation of Seawater - 2010: Calculation and Use of Thermodynamic Properties, written by: McDougall,T. J., Feistel, R., Wright, D. G., Pawlowicz, R., Millero, F. J., Jackett, D. R., King, B. A., Marion, G. M., Seitz, S., Spitzer, P., and Chen, C. T. A., Tech. rep., Intergovernmental Oceanographic Commission, Manuals and Guides No. 56, UNESCO (English), 196 pp., Paris 2010, http://www.teos-10.org, 2010.

Jeffery, C. A. and Austin, P. H.: Homogeneous nucleation of supercooled water: results from a new equation of state, J. Ceophys. Res., 102, 25269-25279, 1997.

Jensen, E. J., Toon, O. B., Westphal, D. L., Kinne, S., and Heymsfield, A. J.: Microphysical modeling of cirrus, 1. Comparison with 1986 FIRE IFO measurements, J. Geophys. Res., 99, 10421-10442, 1994.

Kanno, H. and Angell, C. A.: Homogeneous nucleation and glass formation in aqueous alkali halide solutions at high pressures, J. Phys. Chem., 81, 2639-2643, 1977.

Kärcher, B. and Lohmann, U.: A parameterization of cirrus cloud formation: Homogeneous freezing of supercooled aerosols, J. Geophys. Res., 107, 4010, doi:10.1029/2001JD000470, 2002a.

Kärcher, B. and Lohmann, U.: A Parameterization of cirrus cloud formation: Homogeneous freezing including effects of aerosol size, J. Geophys. Res., 107, 4698, doi:10.1029/2001JD001429, 2002b.

Kashchiev, D.: Nucleation: Basic Theory with Applications, Batterworth-Heineman, Oxford, 512 pp., 2000.
Khain, A. P., Pokrovsky, A., Pinsky, M., Seifert, A., and Phillips, V.: Simulation of effects of atmospheric aerosols on deep turbulent convective clouds using a spectral microphysics mixed-phase cumulus cloud model. Part I: Model description and possible applications, J. Atmos. Sci., 61, 2963-2982, 2004.

Khairoutdinov, M. F. and Randall, D.: Cloud resolving modeling of the ARM summer 1997 IOP: Model formulation, results, uncertainties, and sensitivities, J. Atmos. Sci., 60, 607-625, 2003.

Khvorostyanov, V. I. and Curry, J. A.: A new theory of heterogeneous ice nucleation for application in cloud and climate models, Geophys. Res. Lett., 27, 4081-4084, 2000.

Khvorostyanov, V. I. and Curry, J. A.: Thermodynamic theory of freezing and melting of water and aqueous solutions, J. Phys. Chem. A, 108, 11073-11085, 2004a.

Khvorostyanov, V. I. and Curry, J. A.: The theory of ice nucleation by heterogeneous freezing of deliquescent mixed CCN. Part 1: Critical radius, energy and nucleation rate, J. Atmos. Sci., 61, 2676-2691, 2004b.

Khvorostyanov, V. I. and Curry, J. A.: The theory of ice nucleation by heterogeneous freezing of deliquescent mixed CCN. Part 2: Parcel model simulation, J. Atmos. Sci., 62, 261-285 2005.

Khvorostyanov, V. I. and Curry, J. A.: Kinetics of cloud drop formation and its parameterization for cloud and climate models, J. Atmos. Sci., 65, 2784-2802, 2008.

Khvorostyanov, V. I. and Curry, J. A.: Critical humidities of homogeneous and heterogeneous ice nucleation: inferences from extended classical nucleation theory, J. Geophys. Res., 114, D04207, doi:10.1029/2008JD011197, 2009a.

Khvorostyanov, V. I. and Curry, J. A.: Parameterization of cloud drop activation based on analytical asymptotic solutions to the supersaturation equation, J. Atmos. Sci., 66, 1905-1925, $2009 \mathrm{~b}$.

Khvorostyanov, V. I. and Sassen, K.: Towards the theory of homogeneous nucleation and its parameterization for cloud models, Geophys. Res. Lett., 25, 3155-3158, 1998a.

Khvorostyanov, V. I. and Sassen, K.: Cirrus cloud simulation using explicit microphysics and radiation. Part I, Model description, J. Atmos. Sci., 55, 1808-1821, 1998b.

Khvorostyanov, V. I. and Sassen, K.: Microphysical processes in cirrus and their impact on radiation: A mesoscale modeling perspective, in: Cirrus, edited by: Lynch, D., Sassen, K., Starr, D. O'C., and Stephens, G., Oxford University Press, New York, 397-432, 2002.

Khvorostyanov, V. I., Curry, J. A., Pinto, J. O., Shupe, M., Baker, B., and Sassen, K.: Modeling with explicit spectral water and ice microphysics of a two-layer cloud system of altostratus and cirrus observed during the FIRE Arctic Clouds Experiment, J. Geophys. Res., 106, 15099-15112, 2001.

Khvorostyanov, V. I., Curry, J. A., Gultepe, I., and Strawbridge, K.: A springtime mixed-phase cloud over the Beaufort Sea polynya: Three-dimensional simulation with explicit spectral microphysics and comparison with observations, J. Geophys. Res., 108, 4296, doi:10.1029/2001JD001489, 2003.

Khvorostyanov, V. I., Morrison, H., Curry, J. A., Baumgardner, D., and Lawson, P.: High supersaturation and modes of ice nucleation in thin tropopause cirrus: Simulation of the 13 July 2002 Cirrus Regional Study of Tropical Anvils and Cirrus Layers case, J. Geophys. Res., 111, D02201, doi:10.1029/2004JD005235, 2006. 
Klein, S. A.,. McCoy, R. B, Morrison, H., Ackerman, A. S., Avramov, A., de Boer, G., Chen, M., Cole, J. N. S., Del Genio, A. D., Falk, M., Foster, M. J., Fridlind, A., Golaz, J.-C., Hashino, T., Harrington, J. Y., Hoose, C., Khairoutdinov, M. F., Larson, V. E., Liu, X, Luo, Y., McFarquhar, G. M., Menon, S., Neggers, R. A. J., Park, S., Poellot, M. R., Schmidt, J. M., Sednev, I., Shipway, B. J., Shupe, M. D., Spangenberg, D. A., Sud, Y. C., Turner, D. D., Veron, D. E., von Salzen, K., Walker, G. K., Wang, Z., Wolf, A. B., Xie, S., Xu, K.-M., Yang, F., and Zhango G.: Intercomparison of model simulations of mixed-phase clouds observed during the ARM Mixed-Phase Arctic Cloud Experiment. I. Single-layer cloud, Q. J. Roy. Meteor. Soc., 135, 979-1002, 2009.

Köhler, H.: The nucleus in and the growth of hygroscopic droplets, Trans. Farad. Soc., 32, 1152-1161, 1936.

Koop, T. and Zobrist, B.: Parameterizations for ice nucleation in biological and atmospheric systems, Phys. Chem. Chem. Phys., 11, 10839-10850, 2009.

Koop, T., Ng, H. P., Molina, L. T., and Molina, M. J.: A new optical technique to study aerosol phase transitions: The nucleation of ice from $\mathrm{H}_{2} \mathrm{SO}_{4}$ aerosols, J. Phys. Chem. A, 102, 8924-8931, 1998.

Koop, T., Luo, B. P., Tsias, A., and Peter, T.: Water activity as the determinant for homogeneous ice nucleation in aqueous solutions, Nature, 406, 611-614, 2000.

Krakovskaia, S. V. and Pirnach, A. M.: A theoretical study of the microphysical structure of mixed stratiform frontal clouds and their precipitation, Atmos. Res., 47-48, 491-503, 2004.

Laaksonen, A., Talanquer, V., and Oxtoby, D. W.: Nucleation: Measurements, theory and atmospheric applications, Ann. Rev. Phys. Chem., 46, 489-524, 1995.

Lin, R.-F.: A numerical study of the evolution of nocturnal cirrus by a two-dimensional model with explicit microphysics. $\mathrm{PhD}$ thesis, The Pennsylvania State University, 199 pp., 1997.

Lin, R.-F., Starr, D. O'C., DeMott, P. J., Cotton, R., Sassen, K., Jensen, E., Kärcher, B., and Liu, X.: Cirrus parcel model comparison project. Phase 1: The critical components to simulate cirrus initiation explicitly, J. Atmos. Sci., 59, 2305-2329, 2002.

Liu, X. H. and Penner, J. E.: Ice nucleation parameterization for global models, Meteorol. Z., 14, 499-514, 2005.

Lohmann, U. and Kärcher, B.: First interactive simulations of cirrus clouds formed by homogeneous freezing in the ECHAM general circulation model, J. Geophys. Res., 107, 4105, doi:10.1029/2001JD000767, 2002.

Malkin, T. L., Murray, B. J., Brukhno, A. V., Anwar, J., and Salzmann, C. G.: Structure of ice crystallized from supercooled water, P. Natl. Acad. Sci., 109, 1041-1045, doi:10.1073/pnas.1113059109, 2012.

Martin, S. T.: Phase transitions of aqueous atmospheric particles, Chem. Rev., 100, 3403-3453, 2000.

McDougall, T. J., Feistel, R., Millero, F. J., Jackett, D. R., Wright, D. G., King, B. A., Marion, G. M., Chen, C., Spitzer, P., and Seitz, S.: The International Thermodynamic Equation Of Seawater 2010 (TEOS-10): Calculation and Use of Thermodynamic Properties, UNESCO 2009, IOC Manuals and Guides, 150 pp., www.teos10.org, 2010.

Meyers, M. P., DeMott, P. J., and Cotton, W. R.: New primary icenucleation parameterizations in an explicit cloud model, J. Appl. Meteor., 31, 708-721, 1992.
Mishima, O. and Stanley, H. E.: The relationship between liquid, supercooled and glassy water, Nature, 396, 329-335, 1998.

Monier, M., Wobrock, W., Gayet, J.-F., and Flossmann, A.: Development of a detailed microphysics cirrus model tracking aerosol particle's histories for interpretation of the recent INCA campaign, J. Atmos. Sci., 63, 504-525, 2006.

Morrison, H. and Gettelman, A.: A new two-moment bulk stratiform cloud microphysics scheme in the community atmosphere model, version 3(CAM3). Part I: Description and numerical tests, J. Clim., 21, 3642-3659, doi:10.1175/2008JCLI2105.1, 2008.

Morrison, H., Curry, J. A., and Khvorostyanov, V. I.: A new doublemoment microphysics parameterization for application in cloud and climate models, Part 1: Description, J. Atmos. Sci., 62, 3683-3704, 2005.

Murray, B. J. and Bertram, A. K.: Formation and stability of cubic ice in water droplets, Phys. Chem. Chem. Phys., 8, 186-192, 2006.

Murray, B. J., Knopf, D. A., and Bertram, A. K.: The formation of cubic ice under conditions relevant to Earth's atmosphere, Nature, 434, 202-205, 2005.

Murray, B. J., Broadley S. L., Wilson, T. W., Bull, S. J., Wills, R. H., Christenson, H. K., and Murray E. J.: Kinetics of the homogeneous freezing of water, Phys. Chem. Chem. Phys., 12, 1038010387,2010

Ovarlez, J., Gayet, J.-F., Gierens, K., Ström, J., Ovarlez, H., Auriol, F., Busen, R., and Schumann, U.: Water vapour measurements inside cirrus clouds in Northern and Southern hemispheres during INCA, Geophys. Res. Lett., 29, 1813, doi:10.1029/2001GL014440, 2002.

Pruppacher, H. R. and Klett, J. D.: Microphysics of Clouds and Precipitation, 2nd ed., Kluwer Academic Publishers: Boston, MA, 954 pp., 1997.

Randall, D., Krueger, S., Bretherton, C., Curry, J., Duynkerke, P., Moncrieff, M., Ryan, B., Starr, D., Miller, M., Rossow, W., Tselioudis, G., and Wielicki, B.: Confronting models with data. The GEWEX Cloud Systems Study, B. Am. Meteorol. Soc., 84, 455469, 2003.

Rasmussen, D. H.: Thermodynamic and nucleation phenomena: A set of experimental observations, J. Cryst. Growth, 56, 56-66, 1982.

Ren, C. and MacKenzie, A. R.: Cirrus parameterisation and the role of ice nuclei, Q. J. Roy. Meteorol. Soc., 131, 1585-1605, 2005.

Ren, C. and MacKenzie, A. R.: Closed-form approximations to the error and complementary error functions and their applications in atmospheric science, Atmos. Sci. Lett., 8, 70-73, doi:10.1002/asl.154, 2007.

Sassen, K. and Benson, S.: Ice nucleation in cirrus clouds: A model study of the homogeneous and heterogeneous nucleation modes, Geophys. Res. Lett., 27, 521-524, 2000.

Sassen, K. and Dodd, G. C.: Homogeneous nucleation rate for highly supercooled cirrus cloud droplets, J. Atmos. Sci., 45, 1357-1369, 1988.

Sassen, K. and Dodd, G. C.: Haze particle nucleation simulation in cirrus clouds, and application for numerical and lidar studies, J. Atmos. Sci., 46, 3005-3014, 1989.

Sassen, K., Wang, Z., Khvorostyanov, V. I., Stephens, G. L., and Bennedetti, A.: Cirrus cloud ice water content radar algorithm evaluation using an explicit cloud microphysical model, J. Appl. Meteorol., 41, 620-628, 2002. 
Sedunov, Y. S.: Physics of Drop Formation in the Atmosphere, Wiley, New York, 234 pp., 1974.

Seifert, A. and Beheng, K. D.: A two-moment cloud microphysics parameterization for mixed-phase clouds. Part 1: Model description, Meteorol. Atmos. Phys., 92, 45-66, doi:10.1007/s00703005-0112-4, 2006.

Seinfeld, J. H. and Pandis, S. N.: Atmospheric Chemistry and Physics, Wiley, New York, 1326 pp., 1998.

Slezov, V. V. and Schmelzer, J. W. P.: Kinetics of nucleation-growth processes: the first stages, in: Nucleation Theory and Applications, edited by: Schmelzer, J. W. P., Röpke, G., and Priezzhev, V. B., 6-81, JINR, Joint Institute for Nuclear Research, Bogoliubov Laboratory of Theoretical Physics, Dubna, ISBN 5-85165-539-9, http://theor.jinr.ru/meetings/2012/nta/, 1999.

Spice, A., Johnson, D. W., Brown, P. R. A., Darlison, A. G., and Saunders, C. P. R.: Primary ice nucleation in orographic cirrus cloud: A numerical simulation of the microphysics, Q. J. Roy. Meteorol. Soc., 125, 1637-1667, 1999.

Ström, J., Seifert, M., Kärcher, B., Ovarlez, J., Minikin, A., Gayet, J.-F., Krejci, R., Petzold, A., Auriol, F., Haag, W., Busen, R., Schumann, U., and Hansson, H. C.: Cirrus cloud occurrence as function of ambient relative humidity: a comparison of observations obtained during the INCA experiment, Atmos. Chem. Phys., 3, 1807-1816, doi:10.5194/acp-3-1807-2003, 2003.
Sud, Y. C., Wilcox, E., Lau, W. K.-M., Walker, G. K., Liu, X.H., Nenes, A., Lee, D., Kim, K.-M., Zhou, Y., and Bhattacharjee, P. S.: Sensitivity of boreal-summer circulation and precipitation to atmospheric aerosols in selected regions - Part 1: Africa and India, Ann. Geophys., 27, 3989-4007, doi:10.5194/angeo27-3989-2009, 2009.

Tao, W.-K., Chen, J.-P., Li, Z., Wang, C., and Zhang, C.: Impact of aerosols on convective clouds and precipitation, Rev. Geophys., 50, RG2001, doi:10.1029/2011RG000369, 2012.

Twomey, S.: The nuclei of natural cloud formation. Part II: The supersaturation in natural clouds and the variation of cloud droplet concentration, Pure Appl. Geophys., 43, 243-249, 1959.

Veltishchev, N. F., Zhupanov, V. D., and Pavlyukov, Yu. B.: Shortrange forecast of heavy precipitation and strong wind using the convection-allowing WRF models, Russian Meteorol. Hydrol., 36, 47-58, 2011.

Xue, L., Teller, A., Rasmussen, R., Geresdi, I., Pan, Z.: Effects of aerosol solubility and regeneration on warm-phase orographic clouds and precipitation simulated by a detailed bin microphysical scheme, J. Atmos. Sci., 67, 3336-3354, 2010.

Zhang, H., Sokolik, I. N., and Curry, J. A.: Impact of dust aerosols on Hurricane Helene's early development through the deliquescent heterogeneous freezing mode, Atmos. Chem. Phys. Discuss., 11, 14339-14381, doi:10.5194/acpd-11-14339-2011, 2011. 